\title{
jeen
}

AUTARQUIA ASSOCIADA À UNIVERSIDADE DE SÃO PAULO

\section{AVALIAÇÃO DA HIGROSCOPICIDADE DE AEROSSÓIS URBANOS PELA TÉCNICA LIDAR RAMAN}

\author{
Patricia Ferrini Rodrigues
}

\begin{abstract}
Tese apresentada como parte dos requisitos para obtenção do Grau de Doutor em Ciências na Área de Tecnologia Nuclear - Materiais
\end{abstract}

Orientador:

Prof. Dr. Eduardo Landulfo 
INSTITUTO DE PESQUISAS ENERGÉTICAS E NUCLEARES

Autarquia associada à Universidade de São Paulo

\title{
AVALIAÇÃO DA HIGROSCOPICIDADE DE AEROSSOIS URBANOS PELA TÉCNICA LIDAR RAMAN
}

\author{
Patricia Ferrini Rodrigues
}
Tese apresentada como parte dos requisitos para obtenção do Grau de Doutor em Ciências na Área de Tecnologia Nuclear - Materiais
Orientador:
Prof. Dr. Eduardo Landulfo

Versão Corrigida

Versão Original disponível no IPEN

São Paulo

2014 
Dedico este trabalho a Edézio Salviano Rodrigues e a Marisa Ferrini Rodrigues, por terem sido os seres mais perfeitos que a natureza poderia ter me designado como pai e mãe. Minha eterna gratidão. 


\section{AGRADECIMENTOS}

Quando eu comecei este doutorado direto, há cinco anos, tinha algumas motivações que são completamente diferentes das que tenho hoje. Em cinco anos, muita coisa mudou... E eu acredito que além do conhecimento técnico/teórico alcançado por alguém que não tinha a menor experiência na área e nenhuma espécie de treinamento para ela, o que eu aprendi de mais grandioso é que existe um cenário grave e urgente de consequências de toda a nossa atividade no planeta, e além daquilo que já fazemos no cotidiano, é impensável que não estreitemos nossa relação com aqueles que são responsáveis pelo estabelecimento de políticas públicas e com a área educacional e divulgação de ciência.

Isto posto, gostaria de agradecer ao meu orientador, Eduardo Landulfo, por todas as conversas (incluindo as brigas), por todos os conselhos que eu teimosamente não segui (e que as vezes resultaram em erros e outras em acertos), e por todas as vezes que ele confiou mais de mim do que eu em mim mesma.

Agradeço também aos meus colegas de trabalho, especialmente Fábio Juliano da Silva Lopes, que, dentro de todas as pessoas que passaram por este grupo de pesquisa, sempre foi para mim um exemplo de determinação, disciplina, esforço e integridade ética. Não tenho a menor dúvida de que, uma vez de posse de seu próprio grupo de pesquisa, será um dos grandes expoentes na área ambiental no Brasil e no mundo. Agradeço à Renata Facundes da Costa, minha amiga e colega de trabalho, que me deu suporte em momentos muito delicados. Walter Nakaema e Eliane Larossa, pela ótima convivência, e Paulo Almeida, pela parceria tanto no laboratório como nas empreitadas literárias.

Aos bons amigos que eu fiz em todas as viagens e campanhas fora do Brasil: Monique Walker e David Whiteman (NASA Goddard Space Flight Center), Martin Cardirola, Elena Montilla e Antonieta Riquelme (Centro de Óptica e fotônica de Concepción), Daniel Nisperuza e Andrés Esteban (Universidad de Medellín), Boris Barja (Centro de Óptica Atmosférica de Camaguey), Maria Jose Granados-Muños e Juan Luis Guerrero-Rascado (Universidad de Granada), entre muitos, muitos outros.

À todos os funcionários de Centro de Laser e Aplicações do IPEN, principalmente Sr. Luís, Sueli e Antônia, pela simpatia e ética no trabalho. 
À Denise Trombani e Vernon Maraschin, meus mestres de Swásthya Yôga, que além de me ensinarem os princípios desta filosofia milenar, também me serviram de guia no caminho do autoconhecimento.

À Lara Alvares, minha pequena irmã na vida.

Ao meu mais que amigo Leonardo Ulian Dall'Evedove, que não só esteve presente neste momento da minha vida, como em muitos outros no passado, e em todos os que virão no futuro.

À minha família postiça, Bruno Bacellar, Camila Comin e meu afilhado Francisco, pelo compartilhamento da visão de mundo. E à Monica Ferrini, minha tia mais que querida.

À Olívia Costa, pelo amor, companheirismo, apoio, incentivo, ajuda e café na reta final desta jornada.

Ao meu pai, Edézio Salviano Rodrigues e minha mãe, Marisa Ferrini Rodrigues: nada que eu diga nestas poucas linhas vai ser capaz de traduzir todo o sentimento que eu tenho de gratidão por vocês dois terem proporcionado a mim e ao meu irmão, Ricardo Ferrini Rodrigues, todas as condições necessárias para que nos tornássemos os seres humanos íntegros que somos.

A todos os que de alguma maneira contribuíram para este trabalho, e que eu não pude citar, por um motivo ou por outro.

A mim mesma, por me permitir errar e continuar tentando.

Ao apoio financeiro da Fundação de Amparo à Pesquisa do Estado de São Paulo (FAPESP) a este doutorado direto, por meio do processo número 2009/14758-7. 
"Eu sou a chuva que lança a areia do Saara sobre os automóveis de Roma / Eu sou a sereia que dança, a destemida Iara, água e folha da Amazônia"

Reconvexo - Composição de Caetano Veloso e Interpretação de Maria Bethânia 


\title{
AVALIAÇÃO DA HIGROSCOPICIDADE DE AEROSSÓIS URBANOS PELA TÉCNICA LIDAR RAMAN
}

\author{
Patricia Ferrini Rodrigues
}

\begin{abstract}
Resumo
A cobertura de nuvens e os aerossóis são os dois principais fatores que modulam a energia solar que atinge a superfície e é absorvida pela atmosfera. Esses dois fatores, portanto, têm um papel essencial no clima do planeta. Há atualmente um interesse nos efeitos radiativos dos aerossóis, particularmente por causa da atividade antrópica, que aumenta sua concentração na atmosfera, e por sua íntima relação com a formação de nuvens.

Partículas que podem ser ativadas e ganhar água para se tornarem nevoeiro ou gotas de nuvens, na presença de supersaturação de vapor de água, são chamadas de Núcleo de Condensação de Nuvens. O estudo das partículas que aumentam de tamanho com o ganho de água conforme aumenta a umidade relativa (higroscopicidade) torna-se então de fundamental importância no entendimento da contribuição dos aerossóis na regulação do clima do planeta.

O LIDAR é um instrumento promissor no estudo da higroscopicidade dos aerossóis atmosféricos, porque pode operar em ambiente não perturbado e em condições muito próximas da saturação. O LIDAR Raman apresenta a vantagem de poder obter o perfil de vapor de água e retroespalhamento de aerossóis no mesmo volume atmosférico e sem nenhuma suposição a priori a respeito da razão LIDAR

Este trabalho objetiva avaliar o crescimento higroscópico do material particulado urbano em São Paulo, Brasil, e em Washington, D.C, Estados Unidos - durante a campanha NASA-Discover-AQ - com o uso da técnica LIDAR Raman, obtendo o fator de crescimento por higroscopicidade. Apesar da metodologia - que se baseia na determinação de uma atmosfera bem misturada com o uso de radiossondagem - já ter sido utilizada na literatura, este trabalho acrescenta importantes informações, já que não se tem notícias de outros estudos extensos com múltiplos casos feitos com o LIDAR Raman para avaliação de higroscopicidade nos Estados Unidos, bem como é a primeira vez que este estudo é feito em São Paulo, como resultado de três anos de aquisição de dados.

Os resultados mostram que é possível identificar o crescimento higroscópico dos aerossóis em ambas os ambientes de estudo, cuja detecção depende de condições atmosféricas que estão raramente presentes, tornando o estudo da higroscopicidade com o LIDAR um desafio que exige uma extensa coleta de dados. Mostram ainda que a determinação da origem e o estudo conjugado das propriedades químicas da população de aerossóis são informações que auxiliariam no entendimento do comportamento higroscópico, aprofundamentos estes que podem ser derivados deste trabalho.
\end{abstract}

Palavras-chave: LIDAR Raman, higroscopicidade, aerossol 


\title{
EVALUATION OF HYGROSCOPIC GROWTH OF URBAN AEROSSOLS USING RAMAN LIDAR TECHNIQUE
}

\author{
Patricia Ferrini Rodrigues
}

\begin{abstract}
Absctract
The cloud cover and aerosols are two main factors that modulate the solar energy that reaches the surface and is absorbed by the atmosphere. These two factors therefore have a key role in global climate. There is currently an interest in the radiative effects of aerosols, particularly because of human activity, increasing its concentration in the atmosphere, and its close relationship with cloud formation

Particles that can be activated and gain water to form fog or cloud droplets in the presence of water vapor supersaturation, are called Cloud Condensation Nucleus. The study of particles that increase in size because of the uptake of water under increasing relative humidity conditions (hygroscopicity) then becomes of fundamental importance in understanding the contribution of aerosols in regulating the global climate.

The LIDAR is a promising tool in the study of hygroscopic properties of atmospheric aerosols, because it can operate in undisturbed environment and much close to saturation conditions. The Raman LIDAR has the advantage of being able to obtain the profile of water vapor and aerosol backscatter at the same atmospheric volume and no a priori assumption of the LIDAR ratio.

This study aims to evaluate the hygroscopic growth of urban particulate matter in Sao Paulo, Brazil, and Washington, DC, United States - during the NASA-Discover-AQ campaign - using the technique Raman LIDAR, getting the growth factor by hygroscopicity . Although the methodology - which is based on determination of a well-mixed atmosphere using radiosonde - have already been described in the literature, this work adds important information, since they do not have other news with multiple cases extensive studies made with the LIDAR Raman hygroscopicity for evaluation in the United States, and is the first time that this study is done in São Paulo, as a result of three years of data acquisition.

The results show that it is possible to identify the hygroscopic growth of aerosol in both environments, whose detection depends on atmospheric conditions that are rarely present, making the study of hygroscopic properties with LIDAR a challenge that requires extensive data collection. Also, show that the determination of origin and the combined study of chemical properties of the population of aerosols would assist in the understanding of hygroscopic behavior.
\end{abstract}

Key words: Raman LIDAR, hygroscopicity, aerosol 


\section{Sumário}

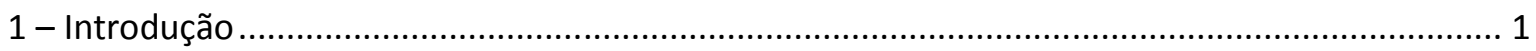

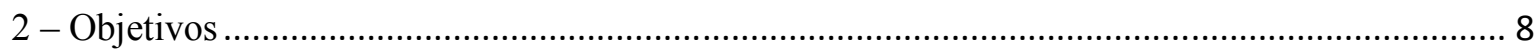

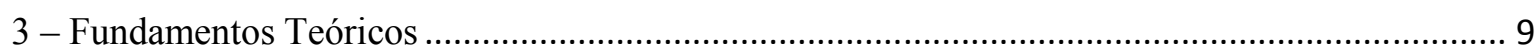

3.1 - Extinção e Espalhamento de luz por material particulado .................................................. 9

3.1 .1 - Extinção e transmissão da luz ................................................................................ 9

3.1.2 - Espalhamento elástico e Função de fase de espalhamento.......................................... 11

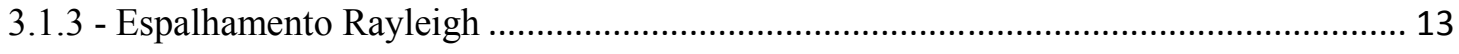

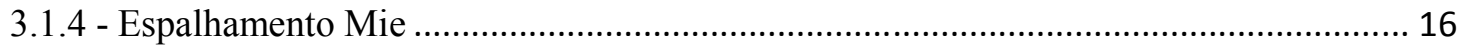

3.1.5 - Espalhamento Raman .......................................................................................... 20

3.2 - Técnica de Sensoriamento Remoto com LIDAR ……........................................................ 22

3.2.1 - O LIDAR Elástico ............................................................................................. 25

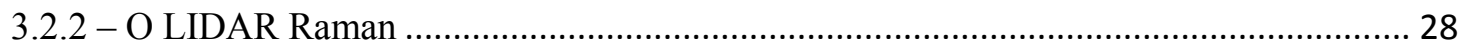

3.2.3 - Medidas da Razão de Mistura de Vapor de água ........................................................ 30

3.2.4 - Incerteza na medida da razão de mistura de vapor de água ........................................ 32

3.2.5 - A calibração das medidas de vapor de água ................................................................. 33

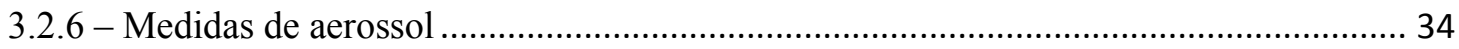

3.3 - Higroscopicidade de aerossóis atmosféricos ........................................................................ 36

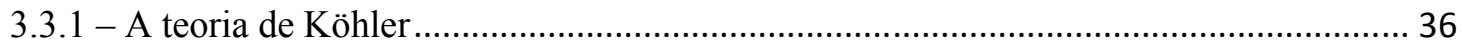

3.3.2 - O fator de crescimento por higroscopicidade e sua determinação com o LIDAR ....... 39

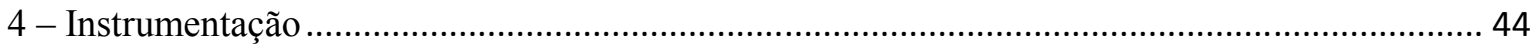

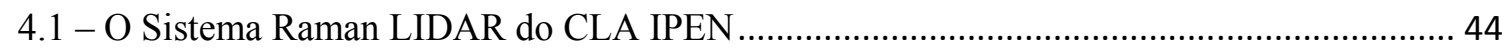

4.2 - Modificações no antigo sistema LIDAR para medidas de vapor de água............................ 46

4.2.1 - O novo sistema de deteç̧ão .................................................................................. 47

4.3 - O sistema LIDAR Raman da Howard University (HURL) ............................................. 48

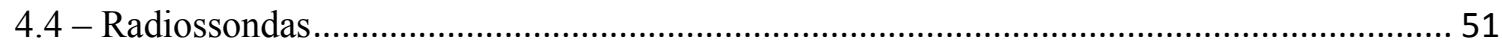

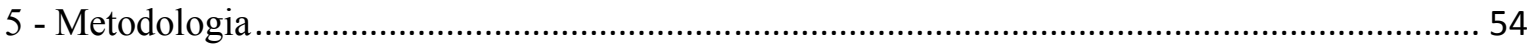

5.1- Campanhas de aquisição de dados ..................................................................................... 54

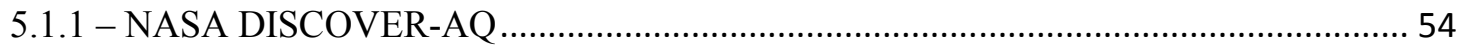

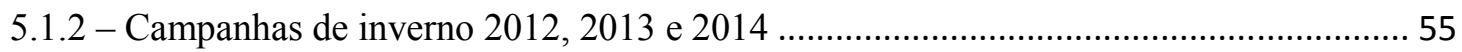




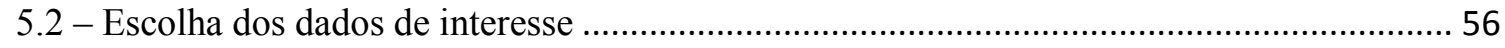

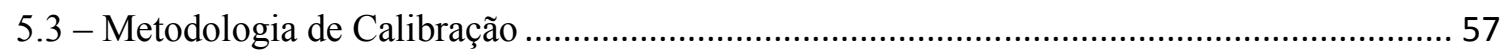

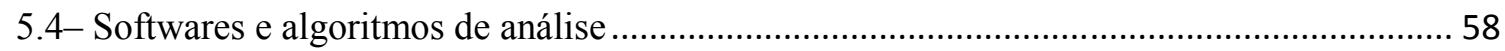

5.4.1 - Obtenção da razão de mistura de vapor de água e a RL do MSP-LIDAR I ................. 59

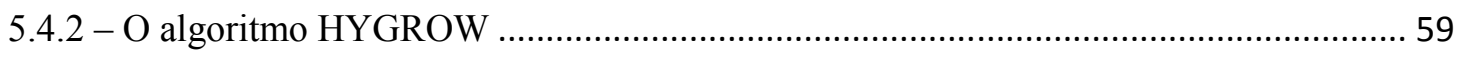

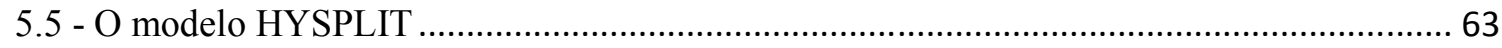

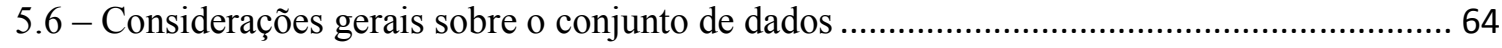

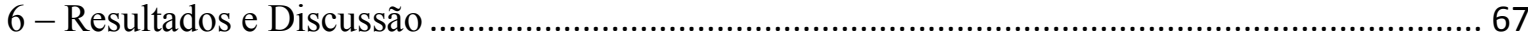

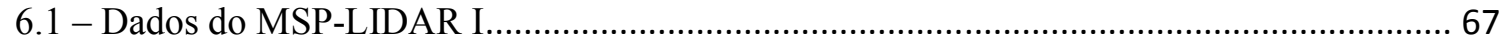

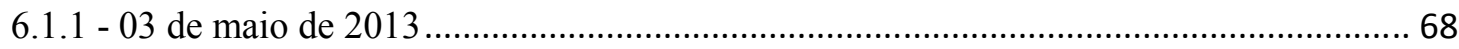

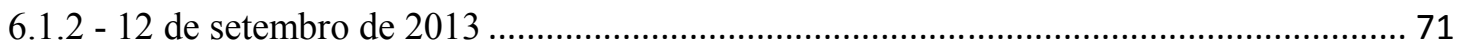

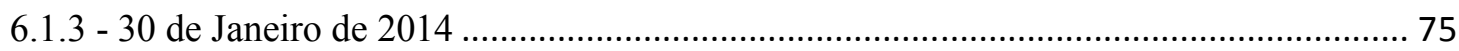

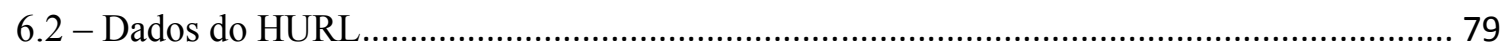

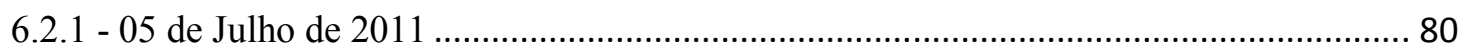

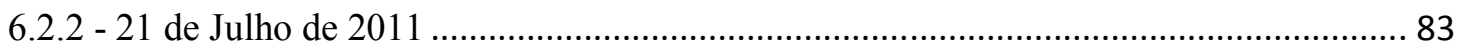

6.3 - Discussões gerais e comparação com outros trabalhos encontrados na literatura................. 87

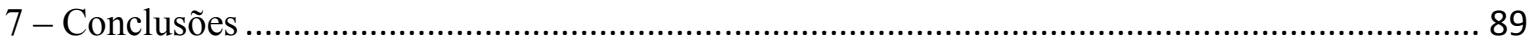

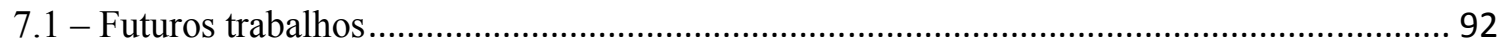

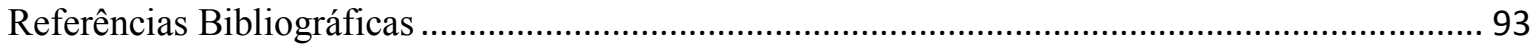




\section{1 - Introdução}

Com a publicação do novo relatório do Painel Intergovernamental de Mudanças Climáticas (Stocker, 2013) notou-se que ainda há uma necessidade de se compreender melhor os efeitos provocados pela interação entre os aerossóis e as nuvens. Forçante Radiativa é um termo definido como a mudança na radiação líquida na tropopausa causada por uma perturbação aplicada em uma variável atmosférica quando se mantém todas as outras fixas, e se permite à temperatura alcançar o equilíbrio (Houghton, 2001). Até 2000, como o próprio IPCC apresentava, o nível de compreensão das forçantes, no que se refere à contribuição de aerossóis, era muito baixo, e apesar de haver a compreensão de que a forçante devida aos aerossóis é negativa, a barra de incerteza era muito alta e não havia quantificação disponível. A partir de 2005, conforme o mostrado na figura 1.1, ganhou-se uma melhor percepção sobre estes efeitos, apesar das incertezas ainda serem bastante elevadas e ainda haver uma quantificação dúbia entre efeitos de aerossóis e nuvens. A partir do relatório do IPCC de 2013 (figura 1.2), houve um melhor entendimento das forçantes positivas causadas por aerossóis absorvedores, como black carbon e das forçantes negativas provocadas por aerossóis espalhadores, além da contribuição por meio da interação com nuvens.

O vapor de água na região do infra-vermelho, a cobertura de nuvens e os aerossóis são os três principais fatores que modulam a energia solar que atinge a superfície e é absorvida pela atmosfera. Esses dois fatores, portanto, têm um papel essencial no clima do planeta. Compreender esse papel é um trabalho bastante desafiador, pois é preciso conhecer a distribuição espacial, a evolução temporal, e os processos que controlam suas mudanças e interação com outros componentes do sistema climático terrestre.

Há atualmente um interesse nos efeitos radiativos dos aerossóis, particularmente por causa da atividade antrópica que aumenta sua concentração na atmosfera. Esses aerossóis antrópicos influenciam o balanço radiativo do sistema Terra-Atmosfera de duas maneiras diferentes: o primeiro é o efeito direto, que se refere às propriedades que têm os aerossóis de espalhar e absorver radiação no espectro solar e terrestre, alterando o albedo terrestre. $\mathrm{O}$ segundo é o efeito indireto, que se refere às modificações provocadas nas propriedades microfísicas (portanto radiativas e temporais) das nuvens. 
Componentes das Forçantes Radiativas

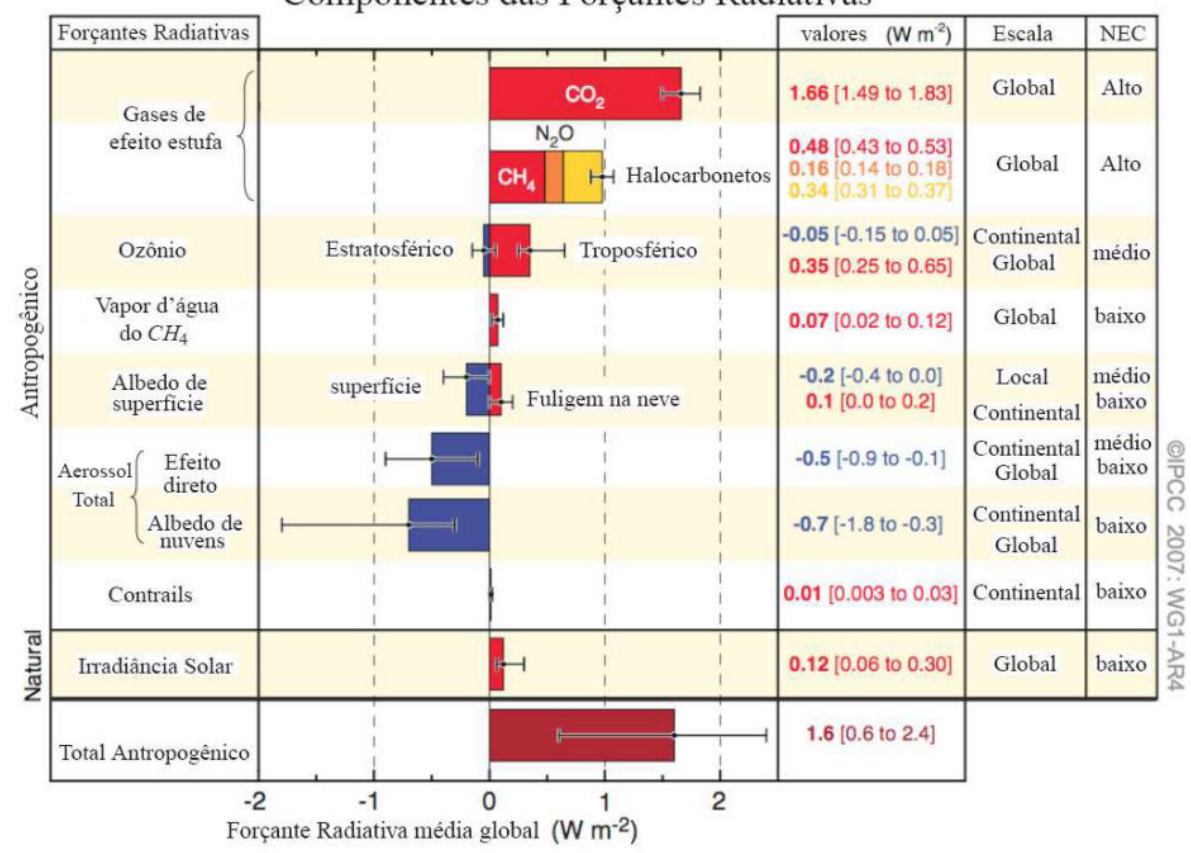

Figura 1.1 - Forçantes naturais e antrópicas para do clima em 2005, segundo o Painel Intergovernamental de Mudanças Climáticas. Fonte: Adaptado de (Solomon, 2007).

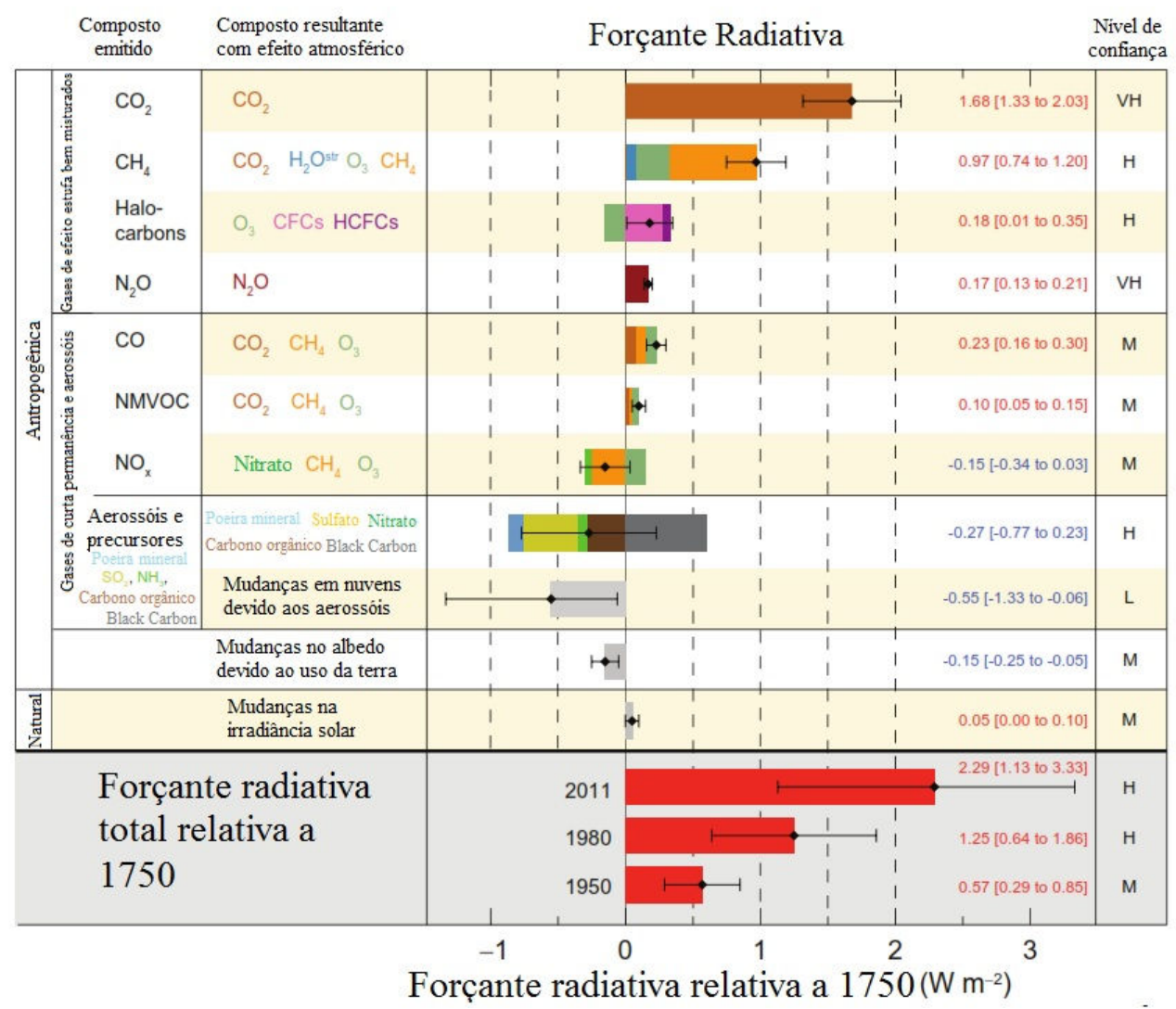

Figura 1.2 - Forçantes naturais e antrópicas para do clima em 2013, segundo o Painel Intergovernamental de Mudanças Climáticas. Fonte: Adaptado de (Stoker, 2013). 
Como mostrado na figura 1.3, os efeitos indiretos de aerossóis são normalmente divididos em dois: o primeiro efeito indireto, que se refere ao aumento da população de gotas e à diminuição do tamanho médio das gotas, para um conteúdo fixo de água líquida (efeito Twomey), e o segundo efeito indireto, que se refere à interferência na eficiência de precipitação devido à diminuição do tamanho das gotas, tendendo a aumentar o conteúdo de água líquida nas nuvens, bem como seu tempo médio de vida e profundidade óptica.

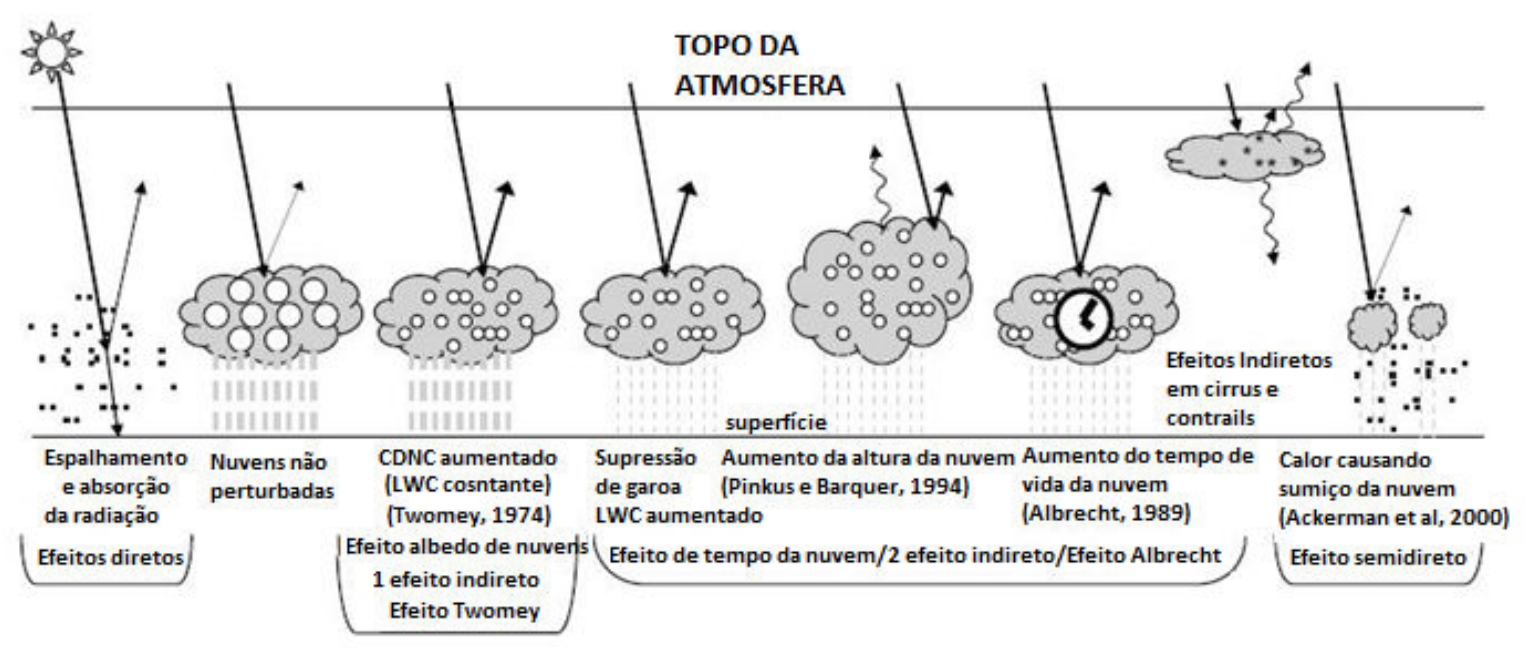

Figura 1.3 - Representação esquemática dos efeitos diretos e indiretos dos aerossóis. CDNC significa Cloud Drop Number Concentration (ou concentração de gotas nas nuvens) e LWC significa Liquid Water Content (ou conteúdo de água líquida). Adaptado de: (Solomon, 2007)

Há alguns aerossóis atmosféricos de interesse quando queremos considerar efeitos diretos, sendo eles os sulfatos, a poeira mineral, o black carbon e o carbono orgânico (Menon, 2004). Enquanto a forçante radiativa devido a gases de efeito estufa pode ser determinada com um grau satisfatório de acurácia, o grau de incerteza devido aos efeitos diretos de aerossóis ainda é muito alto, e as estimativas dependem de modelos que ainda são imprecisos e difíceis de verificar. Três grandes áreas de incerteza existem: na quantidade atmosférica, nos parâmetros ópticos e na implementação da quantidade atmosférica e dos parâmetros ópticos nos modelos para cálculo da forçante radiativa.

A carga atmosférica de uma espécie de aerossol antrópico é determinada por fatores como combustão, emissão, idade, transporte convectivo e processo de remoção, cada um com uma incerteza associada. Os parâmetros ópticos carregam incertezas na distribuição de tamanho, composição química, tipo de mistura, modo de mistura e esfericidade. Incertezas nos cálculos da forçante se devem à parametrização dos efeitos da umidade relativa, da 
distribuição horizontal e vertical de aerossóis, entre outros parâmetros. (Haywood e Boucher, 2000)

Os efeitos indiretos são geralmente classificados em duas categorias: o efeito no albedo e o efeito na duração.

O efeito no albedo (também chamado de primeiro efeito indireto) é resultado do seguinte fenômeno: as gotas de nuvens se formam na baixa atmosfera pela condensação de água nas partículas de aerossol existentes. Consequentemente, a concentração, tamanho e propriedades higroscópicas da partícula de aerossol têm influência na concentração e tamanho dessas gotas. Essa influência, por sua vez, afeta as propriedades radiativas das nuvens para ondas curtas, mesmo sem a mudança nas propriedades termodinâmicas macroscópicas da nuvem. Especificamente, o aumento na concentração de CCN resulta no aumento da concentração de gotas. Os sulfatos e o material particulado emitido por queima de biomassa parecem ser os principais aerossóis antrópicos que contribuem para esse efeito (Solomon, 2007).

Já o segundo efeito indireto, ou efeito na duração, ocorre com a diminuição do tamanho médio das gotas associado com um aumento da concentração de gotas de nuvem, causando uma diminuição da precipitação e portanto pelo aumento na duração da nuvem. Esse aumento na duração, e consequentemente na fração de cobertura de nuvens, aumentaria tanto as propriedades radiativas para ondas curtas quanto para ondas longas.

A inibição da precipitação pode alterar a distribuição vertical de umidade na atmosfera e modificar o ciclo hidrológico. Embora esses efeitos não possam ser quantificados ainda, eles parecem exercer uma influência geral no clima planetário tão importante quanto os dos gases de efeito estufa. Muitos estudos são feitos no sentido de quantificar esse efeito, com desafios bastante grandes e com a inclusão de simplificações, exigindo ajustes nos modelos de previsão que hoje ainda não se mostram totalmente eficientes.

Os efeitos semidiretos referem-se à absorção da radiação solar por aerossóis, levando a uma mudança na cobertura e no conteúdo de água líquida de nuvens. (Koch, 2010). Os aerossóis da queima de biomassa, por exemplo, possuem altas concentrações de black carbon e, por isso, possuem propriedades absorvedoras significativas quando comparadas à 
atmosfera limpa. A absorção de radiação na atmosfera pode alterar sua umidade relativa e seu perfil vertical de temperatura, afetando a estabilidade atmosférica e, por conseguinte, reduzindo a formação de nuvens, fenômeno recentemente denominado como efeito semidireto dos aerossóis (Solomon, 2007). Pouco ainda é conhecido sobre esse efeito. O mesmo pode ocorrer para aerossóis de outras fontes, como poeira mineral.

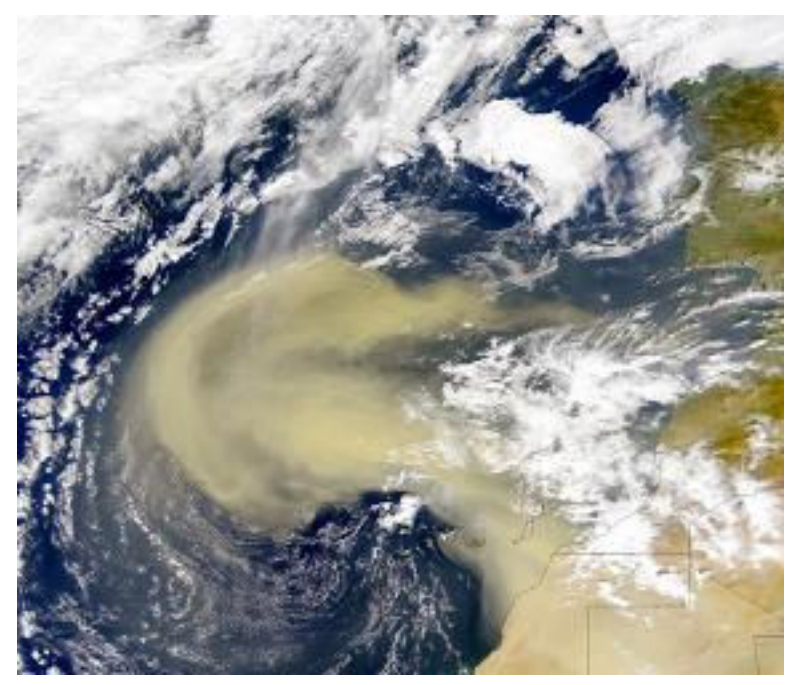

Figura 1.4 - Imagem de satélite de uma tempestade de areia originada no deserto do Saara. E possível perceber a inibição da formação de nuvens no caminho da tempestade de areia. Fonte: http://news.bbc.co.uk/2/hi/science/nature/661091.stm (acesso em 01/12/2014)

Percebe-se que então existe uma grande importância em conhecer a maneira como os aerossóis se relacionam com a formação de nuvens. Partículas que podem ser ativadas e ganhar água para se tornarem nevoeiro ou gotas de nuvens, na presença de supersaturação de vapor de água são chamadas de Núcleo de Condensação de Nuvens (CCN - Cloud Condensation Nuclei). Para uma dada massa de material solúvel em particular, existe um valor crítico de supersaturação de vapor de água, abaixo do qual a partícula existe em um estado estável, e acima do qual a partícula espontaneamente cresce até se tornar uma gota de $10 \mu \mathrm{m}$ ou mais de diâmetro. O número de partículas de uma determinada população de aerossóis que pode se comportar como CCN é, portanto, uma função da supersaturação. Para stratus marinhos, a supersaturação é da ordem de 0,1 a $0,5 \%$, e o diâmetro mínimo das partículas é da ordem de $0,05 \mu \mathrm{m}$ a $0,14 \mu \mathrm{m}$. A concentração de CCN varia de $100 / \mathrm{cm}^{3} \mathrm{em}$ regiões marinhas remotas a milhares por $\mathrm{cm}^{3}$ em áreas urbanas poluídas. (Seinfeld e Pandis, 2006) 
Uma parcela de ar passa, em média, algumas horas em uma nuvem e dias fora dela. A vida média de um CCN é de cerca de uma semana. Desta maneira, um mesmo CCN passa por 5 a 10 ciclos de ativação-evaporação antes de ser removido na forma de precipitação.

Detalhes sobre os aerossóis que se comportam como CCN serão abordados ao longo deste trabalho. Os objetivos de estudo que aqui se apresentam estão relacionados exatamente ao melhor entendimento das propriedades dos aerossóis de se comportarem como CCN, ou melhor, da capacidade desses aerossóis de ganharem água e se tornarem gotas de nuvens, o que é conhecido como crescimento higroscópico.

O crescimento higroscópico depende de propriedades físico-químicas das partículas (Whiteman, 2003; Feingold e Morley 2003; Feingold e Grund, 1994; Tardif, 2002) e quando tratamos de atmosferas urbanas, essa composição química, e certas propriedades como distribuição de tamanho, estado de mistura, etc, não são simples de serem determinadas e nem sempre estudos estão disponíveis.

O sensoriamento remoto com LIDAR (Light Detection and Ranging) tem se mostrado muito útil no estudo do crescimento higroscópico de aerossóis, por permitir o estudo das propriedades ópticas dos aerossóis em seu próprio ambiente e em condições muito próximas da saturação (Feingold e Morley 2003), (Feingold e Grund, 1994). Para isso, vários tipos de LIDAR são utilizados, sendo mais frequente o uso dos LIDAR elástico e Raman.

Apesar dessas vomtagens apresentadas pelo LIDAR no estudo da higroscopicidade de aerossóis, poucos estudos estão disponíveis utilizando este instrumento, (GranadosMuñoz, 2014; Veselovski e Whiteman, 2009; Tardif, 2002), sendo mais abundante na literatura os trabalhos que estudam essa propriedade dos aerossóis com o uso de câmaras controladas. Assim, os trabalhos que buscam desenvolver a técnica LIDAR para estudo da higroscopicidade e consequentemente o comportamento destas partículas como núcleo de condensação de nuvens são de fundamental importância.

Esse trabalho se propõe a contribuir para o entendimento do crescimento higroscópico de aerossóis em atmosferas urbanas, principalmente continental poluída, como é o caso de São Paulo. Para isso, como é a primeria vez que este estudo está sendo conduzido no Brasil, foi preciso desenhar uma metodologia e aprimorar o sistema MSP-LIDAR I (Município de São Paulo LIDAR 1), que se encontra no Centro de Laser e Aplicações do 
Instituto de Pesquisas Energéticas e Nucleares. Após aprimorado o sistema, a metodologia foi aplicada à análise de 63 dias de medida de dados em São Paulo e 80 casos de medidas obtidas durante a campanha NASA DISCOVER-AQ (Deriving Information on Surface conditions from Column and Vertically Resolved Observations Relevant to Air Quality). Procura-se obter um parâmetro empírico representativo da tendência higroscópica de aerossóis. Foi possível encontrar três casos em São Paulo e dois casos em Washington-DC. Esses resultados foram então comparados com outros dados encontrados na literatura. 


\section{2 - Objetivos}

O objetivo deste trabalho é utilizar a técnica LIDAR Raman no estudo das propriedades higroscópicas de aerossóis em atmosferas urbanas, na cidade de São Paulo e em Washington-DC, determinando o fator de crescimento por higroscopicidade e implantando pela primeira vez no Brasil uma metodologia para obtenção destas propriedades com o uso do LIDAR Raman.

Como parte dos objetivos, este trabalho busca desenvolver rotinas locais de análise de dados do LIDAR Raman, para determinação do fator de crescimento por higroscopicidade a partir do retroespalhamento e do vapor de água obtidos pelo LIDAR calibrado com o uso de radiossondagens. 


\section{3 - Fundamentos Teóricos}

\section{1 - Extinção e Espalhamento de luz por material particulado}

\subsection{1 - Extinção e transmissão da luz}

Quando um feixe de luz incide em um meio contendo material espalhador, ocorre um desvio desse feixe em todas as direções, variando em intensidade que depende do ângulo de incidência da luz e das características físicas dos espalhadores presentes no meio. A atmosfera é um meio que contém grande quantidade de espalhadores, sejam eles moléculas, partículas de aerossol ou nuvens contendo gotas e cristais de gelo.

$\mathrm{Na}$ atmosfera, o espalhamento é geralmente acompanhado por absorção, sendo que os absorvedores predominantes são materiais como carvão e black carbon. Tanto o espalhamento quanto a absorção removem energia de um feixe de radiação que atravessa um meio, causando sua atenuação. A atenuação total é denominada extinção.

$\mathrm{Na}$ quantificação dos processos de espalhamento e absorção, utilizam-se leis empíricas derivadas do seguinte raciocínio: tomemos como referência um feixe de luz propagando-se segundo uma orientação $\Omega$ e espectralmente bem definido, com radiância

espectral $L_{o}(\lambda, \Omega)\left(\frac{W}{\mathrm{~m}^{2} \mathrm{sr} \mu \mathrm{m}}\right)$, viajando por um meio de espessura s, como na Figura 3.1. Esse feixe sofrerá atenuação em sua intensidade devido aos processos de espalhamento e absorção ao longo do seu caminho óptico e passará a ter uma intensidade $L_{1}(\lambda, \Omega)$, menor que a inicial.

Suponhamos que esse meio seja dividido em pequenas partes com espessura diferencial $d s$. A intensidade de radiação na direção de propagação após atravessar uma camada $d s, L(\lambda, \Omega)+d L(\lambda, \Omega)$, pode ser escrita como:

$$
d L(\lambda, \Omega, s)=-L(\lambda, \Omega, s) \alpha(\lambda, s) d s
$$

onde $\alpha(\lambda, s)$ é o coeficiente linear de extinção e é função da densidade do meio e da seção de extinção por unidade de massa (Liou, 2002). A expressão 3.1.1 é conhecida como Lei de Beer-Bouguer-Lambert, e descreve o decréscimo da radiância espectral ao atravessar um meio homogêneo (Seinfeld e Pandis, 2006), (Liou, 2002) 


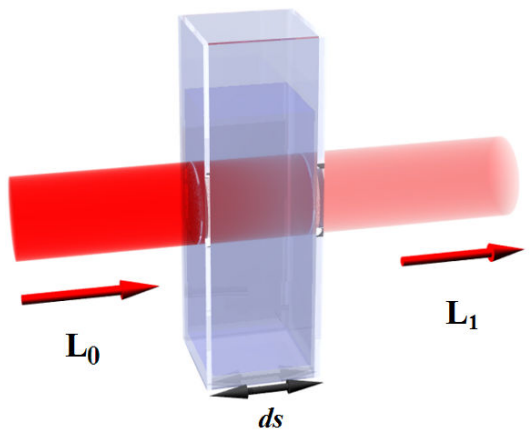

Figura 3.1 - representação esquemática da transmissão de feixe de luz paralelo incidente sobre um meio de espessura ds.

Integrando a equação 3.1.1 em todo o caminho óptico, ou seja, nos limites de integração de 0 até s, obtém-se a intensidade do feixe ao emergir do meio dada pela seguinte equação:

$$
L_{1}(\lambda, \Omega, s)=L_{0}(\lambda, \Omega, s) \exp \left\{-\int_{0}^{s} \alpha(\lambda, s) d s\right\}
$$

A partir dessa expressão define-se a transmitância ou transmissividade do meio, que é a capacidade do meio de transmitir radiação, dada por:

$$
T=\frac{\mathrm{L}_{1}(\lambda, \Omega)}{\mathrm{L}_{0}(\lambda, \Omega)}
$$

Os valores de transmitância variam de 0 a 1 . Para meios em que nenhuma radiação emergente é detectada a transmitância é igual a zero, quando a radiação emergente é igual aquela que entrou no meio a transmitância é igual a 1.

Da equação 3.1.1 define-se ainda uma outra grandeza, a profundidade óptica do meio s, entre as posições $s_{1}$ e $s_{2}$ do caminho óptico, dada por:

$$
\tau(\lambda)=\int_{\mathrm{s} 1}^{\mathrm{s} 2} \alpha(\lambda) \mathrm{ds}
$$

O termo $\alpha(\lambda)$ na integral é conhecido como coeficiente linear de extinção, que representa a medida da atenuação do feixe de radiação ao atravessar um meio material, ou a redução da intensidade do feixe por unidade de caminho óptico. 


\subsection{2 - Espalhamento elástico e Função de fase de espalhamento}

Quando uma onda eletromagnética com comprimento de onda $\lambda$ incide sobre uma partícula cujo índice de refração difere daquele do meio no qual a onda se propaga, ocorre absorção de energia da onda incidente e a reemissão de uma fração dessa energia, num ângulo sólido total cujo centro é a própria partícula, o que se denomina espalhamento. Quando o comprimento da onda reemitido pela partícula é igual ao comprimento da onda incidente, o espalhamento se denomina elástico. Trataremos de dois casos de espalhamento inelástico nas seções seguintes, a saber, o espalhamento Raman e o espalhamento Mie. Quando há diferença nos comprimentos de onda incidente e reemitido, o espalhamento é chamado inelástico, caso que será estudado na discussão do espalhamento Raman.

A distribuição da radiação espalhada em diferentes orientações é dependente de características das partículas espalhadoras. Uma dessas características é a proporção entre o tamanho da partícula e o comprimento de onda da radiação incidente, conhecida como parâmetro de tamanho, sendo que $D_{a}$ é o diâmetro da partícula.

$$
a=\frac{D_{a} \pi}{\lambda}
$$

Uma partícula de pequeno diâmetro espalha radiação nas direções frontal e traseira com a mesma proporção. Quando há um aumento dessa relação entre o tamanho da partícula e o comprimento de onda da radiação incidente, a radiação espalhada concentra-se nas regiões frontais, apresentando padrões de maior complexidade, como é possível ver nas Figuras 3.2 a 3.4
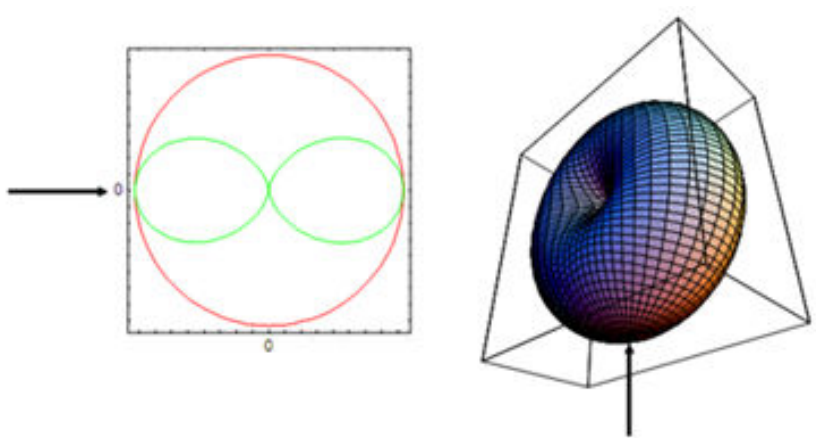

Figura 3.2 - Padrão de espalhamento para a $=0.1$ (correspondente a uma partícula de raio $\cong 15 \mathrm{~nm}(150 \AA)$ para um comprimento de onda incidente de $1 \mu \mathrm{m}$. A partícula está localizada na origem. Esse é um regime de espalhamento simétrico (Whiteman, 2006). 

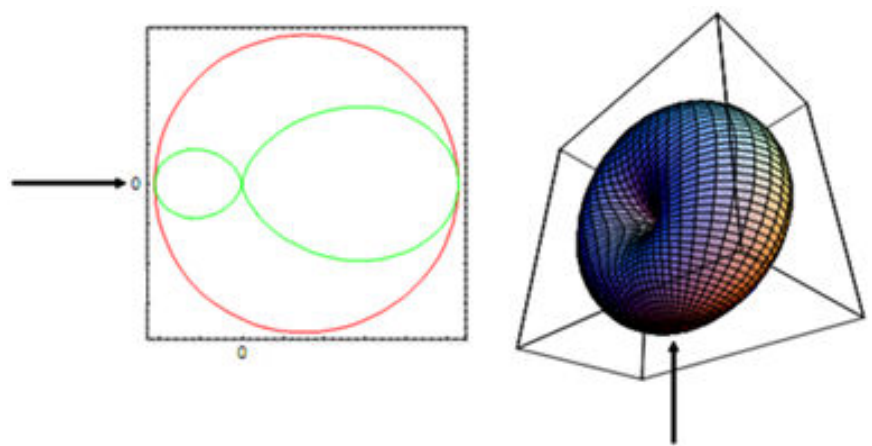

Figura 3.3 - Padrão de espalhamento para a = 1 (correspondente a uma partícula de raio $\cong 150 \mathrm{~nm}(1500 \AA)$ para um comprimento de onda incidente de $1 \mu \mathrm{m}$. A partícula está localizada na origem. Esse é um regime de espalhamento que conserva ainda alguma simetria, enquanto pode-se perceber algum espalhamento preferencial frontal. (Whiteman, 2006).
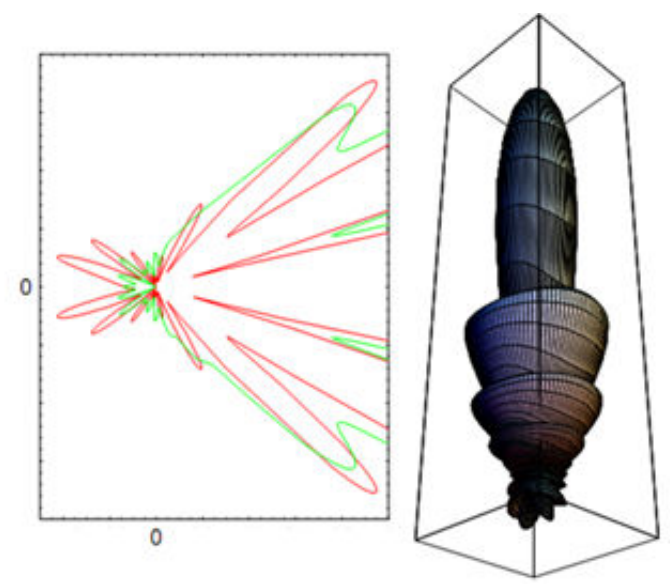

Figura 3.4 - Padrão de espalhamento para $\mathrm{a}=10$ (correspondente a uma partícula de raio $\cong 1,5 \mu \mathrm{m}$ ) para um comprimento de onda incidente de $1 \mu \mathrm{m}$. A partícula está localizada na origem. Esse é um regime de espalhamento com extrema predominância frontal. (Whiteman, 2006).

A função matemática que trata o padrão angular de espalhamento é denominada função de fase, aqui representada pela letra P. É um termo adimensional que depende da direção de incidência e do ângulo de espalhamento, $\Theta$, que é o ângulo entre as direções de incidência e de espalhamento, como mostra a figura 3.5.

Outro parâmetro importante na quantificação do espalhamento é o índice de refração da partícula $\left(m_{t}\right)$, que é uma grandeza complexa, e pode ser escrito da seguinte forma:

$$
m_{t}=m_{r}+i m_{i}
$$


onde a parte real, $m_{r}$, é responsável pelo espalhamento e a parte imaginária, $m_{i}$, é responsável pelos processos de absorção da radiação eletromagnética (Seinfeld e Pandis, 2006).

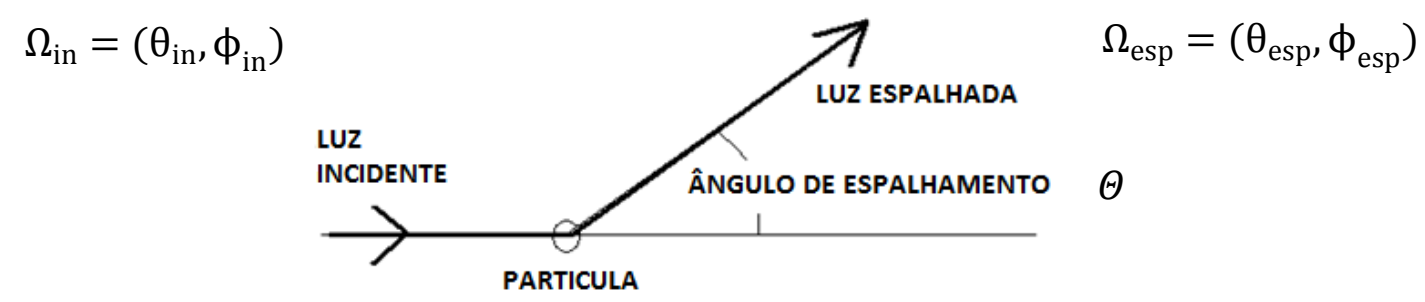

Figura 3.5 - Definição do ângulo de espalhamento no plano. $\Omega_{\mathrm{in}}=\left(\theta_{\mathrm{in}}, \phi_{\mathrm{in}}\right)$ representa as coordenadas da orientação de incidência, $\Omega_{\text {esp }}=\left(\theta_{\text {esp }}, \phi_{\text {esp }}\right)$ representa as coordenadas da orientação de espalhamento ou emergente após o espalhamento e $\Theta$ é o ângulo de espalhamento (ângulo entre a direção incidente e a direção espalhada). Adaptado de: http://www.soest.hawaii.edu/porter/Scattering_Angle.bmp (acesso em $01 / 12 / 2014)$

\subsection{3 - Espalhamento Rayleigh}

O espalhamento Rayleigh se aplica ao estudo do espalhamento de partículas muito menores que o comprimento de onda da radiação incidente (partículas com raio menor que $0,1 \mu \mathrm{m})$, considerando-a exposta à radiação eletromagnética como um dipolo oscilante. A função que o descreve é obtida fazendo a integração da probabilidade de espalhamento no ângulo sólido descrito pela esfera, obtendo-se a seguinte equação:

$$
\int_{0}^{2 \pi} \int_{0}^{\pi} \frac{P(\Theta)}{4 \pi} \operatorname{sen} \Theta d \Theta d \varphi=1
$$

para qual a solução é da forma:

$$
P(\Theta)=\frac{3}{4}\left(1+\cos ^{2} \Theta\right)
$$

O espalhamento Rayleigh apresenta forte dependência espectral, de forma que quanto menor o comprimento de onda da radiação eletromagnética incidente, maior é a quantidade de energia removida do feixe devido ao espalhamento molecular. Conforme o tamanho das partículas aumenta, menor é a dependência espectral de suas propriedades ópticas.

A intensidade do espalhamento Rayleigh é dada por: 


$$
I(r, \theta, \lambda)=\frac{I_{o}}{r^{2}} \eta^{2}\left(\frac{2 \pi}{\lambda}\right)^{4}\left[\frac{1+\cos ^{2} \Theta}{2}\right]
$$

onde $\eta$ representa a polarizabilidade do espalhador, $I_{o}$ é a intensidade da radiação incidente, $\Theta$ é o ângulo de espalhamento, $\lambda$ é o comprimento de onda e $r$ é a distância do volume espalhador.

Combinando as equações 3.1 .8 e 3.1.9, vem:

$$
I(r, \Theta, \lambda)=\frac{I_{o}}{r^{2}} \eta^{2} \frac{32 \pi^{4}}{3 \lambda^{4}} P(\Theta)
$$

Essa relação mostra que o espalhamento Rayleigh é dependente do inverso da quarta potência de $\lambda$, o que significa que para espalhadores pequenos, a radiação com os menores comprimentos de onda é espalhada com mais eficiência. Isso explica a coloração azul do céu, já que a radiação proveniente do sol com comprimento de onda na região do azul é preferencialmente espalhada pelas moléculas presentes na atmosfera, atingindo a Terra como radiação difusa.

Pode-se deduzir ainda a potência espalhada como sendo a integral da densidade de fluxo de energia $(I \Delta \Omega)$ sobre uma esfera de raio $\mathrm{R}$ e com um ângulo sólido $\Delta \Omega$ sob o qual a radiação foi espalhada.

$$
\operatorname{Pot}_{s}=\int_{\Omega}(I \Delta \Omega) R^{2} d \Omega=F_{o} \eta^{2} \frac{128 \pi^{5}}{3 \lambda^{4}}
$$

sendo $F_{o}$ a densidade de fluxo incidente $I \Delta \Omega$. Pode-se definir agora a seção de espalhamento como sendo:

$$
\sigma_{\mathrm{s}}=\frac{\text { Pot }_{\mathrm{s}}}{\mathrm{F}_{\mathrm{o}}}=\eta^{2} \frac{128 \pi^{5}}{3 \lambda^{4}}
$$

que representa a área efetiva da partícula ou espalhador com a qual a radiação interage. $\mathrm{O}$ termo de polarizabilidade, $\eta$, deriva do princípio de dispersão da onda eletromagnética (Liou, 2002), e é dado por:

$$
\eta=\frac{3}{4 \pi \mathrm{MD}_{\mathrm{s}}^{\prime}} \frac{\left(\mathrm{m}_{\mathrm{r}}^{2}-1\right)}{\left(\mathrm{m}_{\mathrm{r}}^{2}+2\right)}
$$

sendo $\mathrm{MD}^{\prime}$ a densidade molecular do espalhador em nível do mar, e $m_{r}$ a componente real do índice de refração. 
A parte real do índice de refração do ar pode ser calculada segundo a formulação de (Bodhaine, 1999):

$$
\begin{array}{cc}
\left(m_{r}-1\right) x 10^{8}=8060.51+\frac{2.480,990}{132,274-(1 / \lambda)}+\frac{17.455,7}{39,32957-(1 / \lambda)}, & \text { se } \lambda<0.23 \mu \mathrm{m} \\
\left(m_{r}-1\right) x 10^{8}=\frac{5.791,817}{238,0185-(1 / \lambda)^{2}}+\frac{167,909}{57,362-(1 / \lambda)}{ }^{2}, & \text { se } \lambda>0.23 \mu \mathrm{m}
\end{array}
$$

Usando 3.1.12 e 3.1.13, podemos escrever a seção de de espalhamento molecular da seguinte maneira:

$$
\sigma_{s}=\frac{24 \pi^{3}\left(m_{r}^{2}-1\right)^{2}}{\lambda^{4} M D_{s}^{\prime 2}\left(m_{r}^{2}+2\right)^{2}}\left(\frac{6+3 \rho}{6-7 \rho}\right)
$$

incluindo o termo de correção $\left(\frac{6+3 \rho}{6-7 \rho}\right)$, que conta para a anisotropia molecular (Liou, 2002; Whiteman, 2006). Esse termo é conhecido como fator de King (F) e leva em consideração a polarizabilidade $\rho$, devido ao fato das moléculas espalhadoras diatômicas no ar não serem esferas homogêneas.

O Fator de King pode ser calculado em função da concentração de $\mathrm{CO}_{2}$ também usando a formulação de Bates (1984), da seguinte forma:

$$
F\left(\text { air }, \mathrm{CO}_{2}\right)=\frac{78,084 \mathrm{~F}\left(\mathrm{~N}_{2}\right)+20,946 \mathrm{~F}\left(\mathrm{O}_{2}\right)+0,934 \mathrm{~F}(\mathrm{Ar})+\mathrm{F}\left(\mathrm{CO}_{2}\right)+C_{\mathrm{CO}_{2}}}{78,084+20,946+0,934+C_{\mathrm{CO}_{2}}}
$$

sendo $\quad F\left(N_{2}\right)=1,034+\frac{3,17 \times 10^{-4}}{\lambda^{2}}, \quad F\left(0_{2}\right)=1,096+\frac{1,385 \times 10^{-4}}{\lambda^{2}}+\frac{1,448 \times 10^{-4}}{\lambda^{4}}, \quad F(A r)=1$ (molécula monoatômica) e $F\left(\mathrm{CO}_{2}\right)=1.15$

Sabendo-se ser o coeficiente de retroespalhamento Rayleigh $\left(\beta_{\mathrm{s}}\right)$ a uma temperatura padrão dado pela formulação abaixo, onde $M D_{s}(r)$ é a densidade molecular em função da altitude,

$$
\beta_{\mathrm{s}}(\mathrm{r}, \lambda)=\mathrm{MD}_{\mathrm{s}}(\mathrm{r}) \sigma_{\mathrm{s}}
$$

temos finalmente, substituindo a equação 3.1.12 nas equações 3.1.16: 


$$
\beta_{s}(r, \lambda)=\operatorname{MD}_{s} \frac{24 \pi^{3}\left(m_{r}^{2}-1\right)^{2}}{\lambda^{4} M^{\prime 2}{ }_{s}^{2}\left(m_{r}^{2}+2\right)^{2}} F\left(\text { air, } C O_{2}\right)
$$

que é a formulação utilizada para cálculo do retroespalhamento Rayleigh.

\subsection{4 - Espalhamento Mie}

O espalhamento causado por uma partícula esférica cujo tamanho aumenta e se aproxima da ordem de grandeza do comprimento de onda foi descrito em 1908 por Mie, a partir das equações de Maxwell. No modelo Mie, existe uma mudança na fase do campo elétrico com a mudança no tamanho da partícula, ocorrendo efeitos que podem ser construtivos ou destrutivos. Ao contrário do espalhamento Rayleigh, que podia ser descrito por um modelo de dipolos, o espalhamento Mie necessita de um modelo de multipolos (Whiteman, 2006).

Considerando-se o índice de refração complexo da partícula, o parâmetro de tamanho e a forma (que ainda será considerada esférica), são definidos o coeficiente de espalhamento $\left(\alpha_{s}\right)$ e as seções de choque eficazes de espalhamento $\left(\sigma_{s}\right)$ e absorção $\left(\sigma_{a}\right)$ da seguinte maneira, considerando um material espalhador cujas partículas apresentam o mesmo tamanho:

$$
\begin{gathered}
\alpha_{s}(r, \lambda)=M D_{s}(z)\left[\sigma_{a}+\sigma_{s}\right] \\
\sigma_{s}(r, \lambda)=\pi z^{2} Q_{s}\left[\left(\frac{2 \pi r}{\lambda}\right), m_{t}(r, \lambda)\right] \\
\sigma_{a}(r, \lambda)=\pi z^{2} Q_{a}\left[\left(\frac{2 \pi r}{\lambda}\right), m_{t}(r, \lambda)\right]
\end{gathered}
$$

sendo $\alpha$ o coeficiente linear de extinção $\left(\mathrm{m}^{-1}\right), M D$ é a densidade de partículas, $\sigma_{s}$ e $\sigma_{a}$ as seções de espalhamento e absorção, respectivamente.

Se assumirmos partículas de diferentes composições e tamanhos, MD pode ser escrita:

$$
M D=\int_{r_{1}}^{r_{2}} N(r) d r
$$


onde $r_{1}$ e $r_{2}$ são os raios limite da população, ou seja, o maior e o menor raios, e N é o número de partículas com um determinado raio. Essa integral é chamada função distribuição de tamanho.

A teoria Mie é resolvida em função do ângulo de espalhamento, do parâmetro de tamanho da partícula definido em 3.1.5 e do índice de refração complexo definido em 3.1.6:

$$
\begin{aligned}
& S_{1}(\theta)=\sum_{i=1}^{\infty} \frac{2 i+1}{i(i+1)}\left[a_{i} \pi_{i} \cos (\theta)+b_{i} \tau_{i} \cos (\theta)\right] \\
& S_{2}(\theta)=\sum_{i=1}^{\infty} \frac{2 i+1}{i(i+1)}\left[a_{i} \pi_{i} \cos (\theta)+a_{i} \tau_{i} \cos (\theta)\right]
\end{aligned}
$$

sendo $\theta$ o ângulo de espalhamento e os termos $\pi_{i}$ e $\tau_{i}$ descritos por:

$$
\begin{gathered}
\pi_{i} \cos (\theta)=\frac{1}{\operatorname{sen}(\theta)} P_{i}^{1} \cos (\theta) \\
\tau_{i} \cos (\theta)=\frac{d}{d \theta} P_{i}^{1} \cos (\theta)
\end{gathered}
$$

nas quais $P_{i}^{1}$ é o Polinômio de Legendre associado (Liou, 2002) e (Whiteman, 2006) e $a_{i}$ e $b_{i}$ são os coeficientes de espalhamento Mie, definidos por:

$$
\begin{aligned}
& a_{i}=\frac{k \psi_{i}(k a) \psi_{i}^{\prime}(a)-\psi_{i}(a) \psi_{i}^{\prime}(k a)}{k \psi_{i}^{\prime}(k a) \xi_{i}^{\prime}(x a)-\xi_{i}(a) \psi_{i}^{\prime}(k a)} \\
& b_{i}=\frac{\psi_{i}(k a) \psi_{i}^{\prime}(a)-k \psi_{i}(a) \psi_{i}^{\prime}(k a)}{\psi_{i}^{\prime}(k a) \xi_{i}^{\prime}(a)-k \xi_{i}(a) \psi_{i}^{\prime}(k a)}
\end{aligned}
$$

onde o termo a representa o parâmetro de tamanho e o termo $\mathbf{k}$ a componente imaginária do índice de refração. Os termos $\psi_{i}(k a)$ e $\xi_{i}(a)$ são as funções de Ricatti-Bessel e escritas em termos da função esférica de Bessel (Whiteman, 2006)

Os coeficientes de extinção, espalhamento e retroespalhamento são definidos como: 


$$
\begin{gathered}
Q_{\text {ext }}(k, x)=\frac{2}{x^{2}} \sum_{i=1}^{\infty}(2 i+1) \operatorname{Re}\left[a_{i}(k, x)+b_{i}(k, x)\right] \\
Q_{s}(k, x)=\frac{2}{x^{2}} \sum_{i=1}^{\infty}(2 i+1)\left[\left|a_{i}(k, x)\right|^{2}+\left|b_{i}(k, x)\right|^{2}\right] \\
Q_{\text {backs }}(k, x)=\left|\frac{1}{x^{2}} \sum_{i=1}^{\infty}(2 i+1)(-1)^{i}\left[a_{i}(k, x)-b_{i}(k, x)\right]\right|^{2}
\end{gathered}
$$

Devido à evidente complexidade da função de fase na aproximação por polinomial de Legendre, é conveniente utilizar aproximações analíticas para a função de fase que simplifiquem seu grau de anisotropia ou assimetria. Isso é feito com a introdução de um fator de assimetria g utilizando a função de Henyey-Greenstein:

$$
P_{H G}(\cos \Theta, g)=\frac{1-\mathrm{g}^{2}}{\left(1+\mathrm{g}^{2}-2 \mathrm{~g} \cos \Theta\right)^{\frac{3}{2}}}
$$

onde g assume o valor zero quando o espalhamento é simétrico (e se obtém $P_{H G}(\cos \Theta, \mathrm{g})=$ 1 , a função de fase normalizada) e o valor 1 quando o espalhamento é completamente frontal.

Conforme os valores do parâmetro a aumentam, a eficiência de espalhamento tende a 2 devido a processos de difração da luz (Liou, 2002), conforme apresentado na figura 3.6. Pode-se perceber que para pequenos valores de parâmetro de tamanho, com r menor ou da mesma ordem do comprimento de onda, a dependência espectral é alta. Essa dependência diminui conforme o aumento do parâmetro de tamanho, aproximando-se do valor 2 .

O coeficiente linear de espalhamento pode ser escrito em função do fator de eficiência (Measures, 1984):

$$
\beta_{\text {scat }}=\frac{\lambda^{3}}{8 \pi} \int_{z_{1}}^{z_{2}} r^{2} Q_{s}(k, x) N(z) d r
$$

Partindo-se do coeficiente de extinção definido em 3.1.20, define-se a profundidade óptica de aerossóis (AOD):

$$
\tau(\lambda, z)=\int_{\infty}^{z} \alpha\left(\lambda, z^{\prime}\right) d z^{\prime}
$$




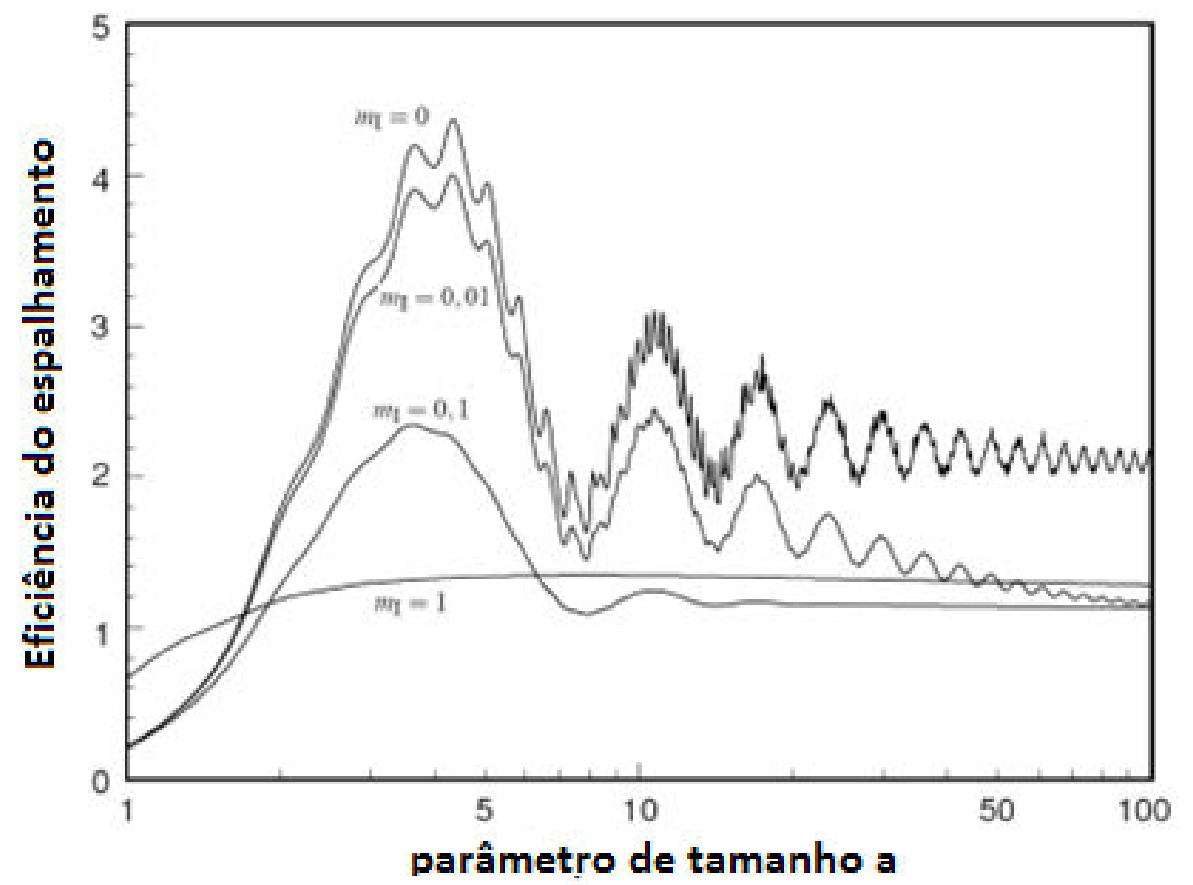

Figura 3.6 - Fator de eficiência de espalhamento em função do parâmetro de tamanho a para a parte real do índice de refração, $m_{r}=1,5$, e para quatro valores diferentes da parte imaginária $m_{i}$. Figura adaptada de Wallace e Hobbs (2006).

Sabendo que o espalhamento molecular apresenta forte dependência espectral, como discutido anteriormente, e que a dependência diminui com o aumento do parâmetro de tamanho, pode-se estimar o tamanho médio das partículas de aerossol existentes numa determinada região da atmosfera a partir do valor da profundidade óptica de aerossóis em diferentes comprimentos de onda. O coeficiente de Ångström é definido:

$$
\delta\left(\lambda_{1}, \lambda_{2}\right)=\frac{-\ln \left[\tau\left(\lambda_{1}\right) / \tau\left(\lambda_{2}\right)\right]}{\ln \left[\left(\lambda_{1}\right) /\left(\lambda_{2}\right)\right]}
$$

Quanto maior o valor de $\delta$, maior a dependência espectral, e portanto menor o parâmetro de tamanho. Para a maioria dos aerossóis atmosféricos, $\delta$ se encontra entre 1 e 2 .

E por último, como as partículas de aerossol podem remover energia do feixe eletromagnético por espalhamento ou por absorção, define-se ainda um parâmetro que quantifica a fração da extinção devida à absorção e a fração complementar devida ao espalhamento. Esse parâmetro é chamado de albedo simples e é definido como:

$$
\omega(\lambda, r)=\frac{\beta_{\text {scat }}(\lambda, r)}{\beta_{\text {scat }}(\lambda, r)+\beta_{\text {abs }}(\lambda, r)}=\frac{\beta_{\text {scat }}(\lambda, r)}{\beta_{\text {tot }}(\lambda, r)}
$$


Nos casos em que o albedo simples é igual a 1 há ausência de absorção e nos casos em que é igual a zero há ausência de espalhamento.

\subsection{5 - Espalhamento Raman}

Para compreender o efeito Raman é útil recordar as principais características dos espectros moleculares. Uma molécula pode absorver energia radiante no infravermelho longínquo ou em micro-ondas, convertendo-a em energia cinética de rotação. Pode também absorver fótons infravermelhos e utilizar essa energia para transitar para estados vibracionais; pode finalmente absorver energia no visível e no ultravioleta por meio de transições eletrônicas, tal como os átomos.

Note que este estado não é necessariamente um estado excitado. Quando esta molécula absorve um fóton de energia $h v$ e transita para um estado intermediário (ou virtual), a partir do qual emite ou difunde imediatamente um fóton de energia $h v_{s}<\mathrm{h} v_{\mathrm{i}}$, trata-se de uma transição de Stokes (red-shift). Como a energia se conserva, a diferença $h v_{i}-h v_{s}=h v_{n}$, sendo $h v_{i}$ a energia do fóton incidente e $h v_{s}$ a energia fóton espalhado,

faz passar a molécula para um estado vibracional de energia mais elevada. É igualmente possível criar um estado rotacional ou mesmo eletrônico. Nos casos em que o estado inicial é um estado excitado (o que se pode conseguir aquecendo a amostra, por exemplo), a molécula depois de absorver e emitir um fóton pode passar de um estado de energia inferior ao estado inicial, realizando uma transição anti-Stokes (blue-shift). Neste caso $h v_{s}>h v_{i}, \mathrm{o}$ que significa que parte da energia vibracional da molécula $\left(h v_{n}=h v_{s}-h v_{i}\right)$ deve ter sido convertido em energia radiante. Em ambos os casos, as diferenças entre $v_{s}$ e $v_{i}$ correspondem a diferenças entre níveis de energia específicas da substância em estudo e permitem induzir algumas características da sua estrutura molecular (Wheitkamp, 2005).

O laser é a fonte ideal para estudos de difusão espontânea de Raman; trata-se de uma fonte intensa, quase monocromática e disponível numa larga gama de frequências. Embora o espalhamento Raman associado a estados rotacionais tenha sido observado antes da invenção do laser, a sensibilidade dos instrumentos mais recentes é muito elevada o que torna a análise mais fácil e permite analisar efeitos decorrentes do movimento dos elétrons (Inaba e Kobayashi, 1972). 
Em geral, as moléculas possuem baixa secção de espalhamento para Raman e alta dependência espectral, o que torna preferível o uso de comprimentos de onda mais curtos para estudo das moléculas atmosféricas. Por causa da atenuação do feixe de laser por moléculas atmosféricas (principalmente ozônio) comprimentos de onda entre 320nm (UV) e 550nm (verde) são indicados. No espectro da luz visível, porém, a alta transmissão atmosférica (baixa extinção do sinal por espalhamento Raman) compensa parcialmente a baixa secção de espalhamento (Ansmann, Riebesell e Weitkamp, 1990).

A figura 3.7 representa o espectro das transições Raman Stokes e Raman AntiStokes, respeitadas as regras de seleção para as transições energéticas moleculares, que são: $v=0, \pm 1 e \mathrm{~J}=0, \pm 2$; transições com $\Delta v=0$ e $\Delta \mathrm{J}=0$ são espalhamento Rayleigh; $\Delta v=$ $+1 \rightarrow$ Stokes; $\Delta v=-1 \rightarrow$ Anti-Stokes; Se $\Delta \mathrm{J}=0$, as linhas Raman têm pouca mudança de freqüência entre si e são agrupadas no ramo chamado $Q ; \Delta \mathrm{J}=+2 \rightarrow \operatorname{Ramo} S$; $\Delta \mathrm{J}=-2 \rightarrow \operatorname{Ramo} O$; se $\Delta v=0$, o espectro resultante é chamado Stokes e Anti-Stokes puros (Weitkamp 2005). Em condições atmosféricas, o fenômeno do espalhamento Stokes ocorre com muito mais probabilidade que o espalhamento Anti-Stokes. (Ansmann, Riebesell, e Weitkamp, 1990).

A tabela 1 mostra os desvios do ramo Q do espectro vibracional-rotacional Raman para algumas moléculas de interesse no monitoramento da poluição atmosférica, envolvendo o sensoriamento remoto com um laser com um comprimento de onda de $337,1 \mathrm{~nm}$.

Tabela 1 - Comprimento de onda Raman para moléculas atmosféricas para o comprimento de onda de $337,1 \mathrm{~nm}$ da radiação incidente.

\begin{tabular}{cc}
\hline \hline Molécula & $\lambda$ Raman (nm) \\
\hline \hline $\mathrm{N}_{2}$ & 365,9 \\
$\mathrm{H}_{2}$ & 392,2 \\
$\mathrm{O}_{2}$ & 355,9 \\
$\mathrm{H}_{2} \mathrm{O}$ & 384,4 \\
$\mathrm{CO}_{2}$ & 353,7 \\
$\mathrm{SO}_{2}$ & 350,8 \\
\hline \hline
\end{tabular}

Fonte: adaptado de (Weitkamp, 2005). 

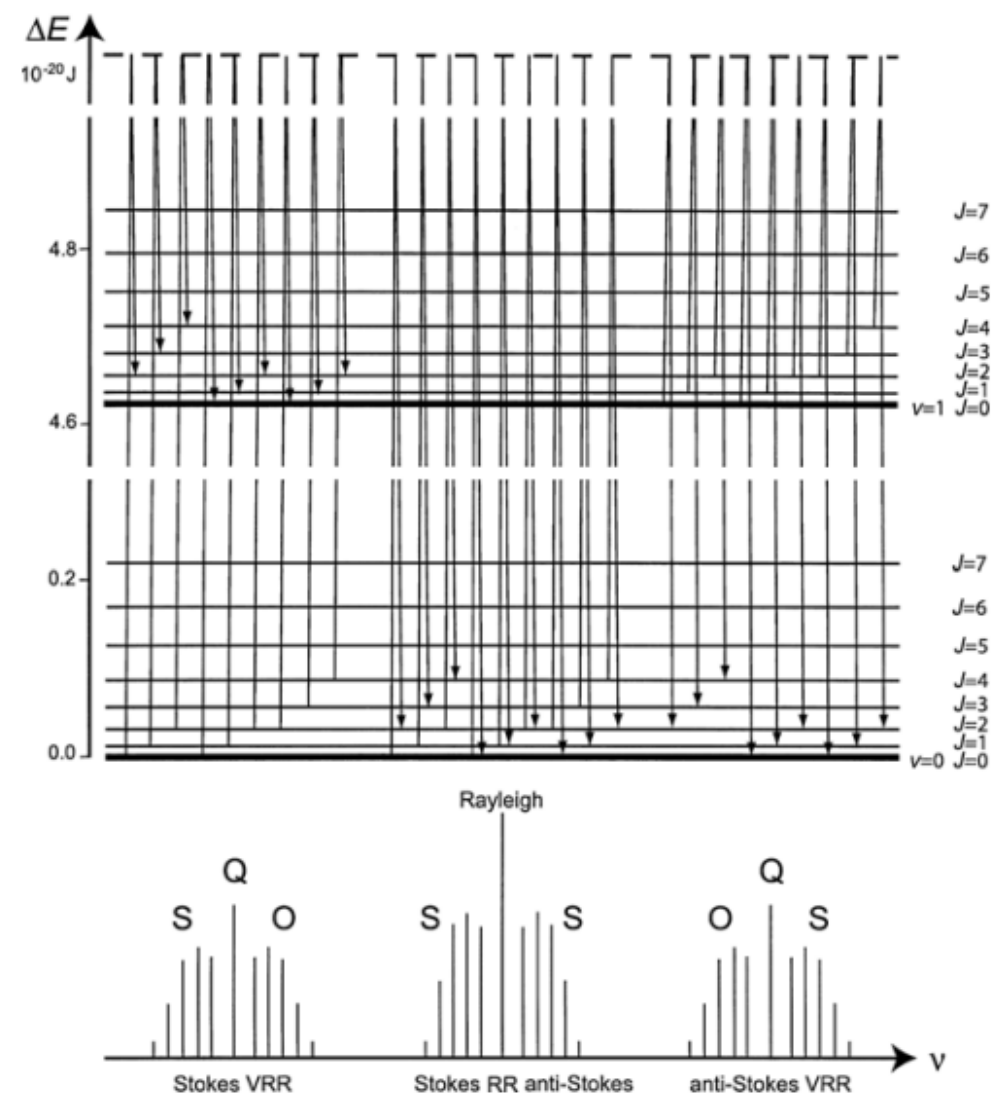

Figura 3.7 - Representação esquemática do espectro de transição Raman, mostrando a transição Stokes e Anti-Stokes nas bandas S, Q e O (Weitkamp, 2005).

\section{2 - Técnica de Sensoriamento Remoto com LIDAR.}

A técnica LIDAR é o sensoriamento remoto da atmosfera utilizando uma fonte de radiação laser. O nome vem do acrônimo de Light Detection And Ranging. São utilizados princípios físicos semelhantes à técnica de radar.

Apesar de existirem técnicas LIDAR diferenciadas de acordo com o tipo de interação da radiação com os constituintes atmosféricos (como por exemplo, LIDAR Elástico, LIDAR Raman, LIDAR Doppler, DIAL - LIDAR de Absorção Diferencial, LIDAR de Fluorescência, LIDAR de Ressonância, HSRL - LIDAR de Alta Resolução Espectral (Measures, 1984), (Weitkamp, 2005), (Whiteman, 2006), este trabalho trata apenas do LIDAR Elástico e do LIDAR Raman, que serão utilizados para o propósito de investigação do problema apresentado.

O princípio básico de funcionamento da técnica é: um pulso de laser é usado para emitir um feixe de radiação através da atmosfera. Esse pulso emitido com intensidade de 
propagação I através da atmosfera interage com os constituintes atmosféricos em seu percurso. Uma fração da luz laser emitida é espalhada por partículas e moléculas na atmosfera. O espalhamento do laser é emitido em todas as direções de incidência do laser. Somente uma pequena parte desse espalhamento do laser retorna para o sistema de recepção e coleta óptica do LIDAR, fenômeno esse chamado de retroespalhamento.

Quanto à posição relativa entre o transmissor e o receptor, os sistemas LIDAR podem adquirir a configuração monoestática ou biestática. Monoestática é a configuração onde o transmissor e o receptor encontram-se no mesmo lugar. Para essa configuração há duas possibilidades, a monoaxial, onde o feixe e o campo visual do telescópio são coaxiais, e a biaxial, onde o transmissor é adjacente ao receptor. Na configuração biestática, o transmissor e o receptor encontram-se em locais diferentes, às vezes separados por alguns quilômetros de distância (Whiteman, 2006).

O telescópio capta o sinal retroespalhado e direciona para o fotoreceptor, onde é convertido de luz para sinal elétrico. A atmosfera determina o sinal Lidar por meio de dois fatores: coeficiente de retroespalhamento $(\beta)$ e coeficiente de extinção $(\alpha)$ (Measures, 1984).

Apesar de haver muitos tipos de lasers utilizados na técnica LIDAR operando em comprimentos de onda que variam desde 250nm (UV) a $11 \mu \mathrm{m}$ (infravermelho), o laser $\mathrm{Nd}$ :YAG (neodymium-doped yttrium aluminium garnet; $\mathrm{Nd}: \mathrm{Y}_{3} \mathrm{Al}_{5} \mathrm{O}_{12}$ ), cujo comprimento de onda fundamental é $1064 \mathrm{~nm}$, que pode ser dobrada, duplicada e quadruplicada (532 nm, $355 \mathrm{~nm}, 266 \mathrm{~nm}$, respectivamente), apresenta vantagens em relação à diversidade de comprimentos de onda que oferece. Também há vantagem na escolha dos lasers pulsados, devido à estreita largura de banda e baixa divergência do feixe, e pulsos estreitos e curtos temporalmente.

A área do céu que pode ser vista pelo receptor (telescópio) é chamada campo visual (field of view, FOV). É conveniente que essa área seja pequena, para que o ruído de fundo (luz proveniente de outras fontes que não o espalhamento da luz transmitida pelo feixe, como a luz solar, das estrelas ou de iluminação urbana) seja diminuido. Existe uma função que mede a intersecção entre o feixe e o campo visual do telescópio, a função de overlap. Quando há completa sobreposição entre o feixe e o campo visual do telescópio, essa função é igual a 1. Para diminuir a divergência do feixe, pode se fazer uso de um sistema de lentes 
colimadoras ou ainda de um sistema que expande o diâmetro do feixe ao mesmo tempo que aumenta seu paralelismo. Esse sistema é chamado de expansor de feixe ou beam expander.

A monocromaticidade do laser é um característica bastante vantajosa, pois permite que a luz retroespalhada seja espectralmente filtrada com o uso de filtros de interferência colocados na frente dos tubos fotomultiplicadores (PMTs). Esses filtros de banda estreita transmitem uma fração do sinal restroespalhado e uma parte muito pequena do ruído.

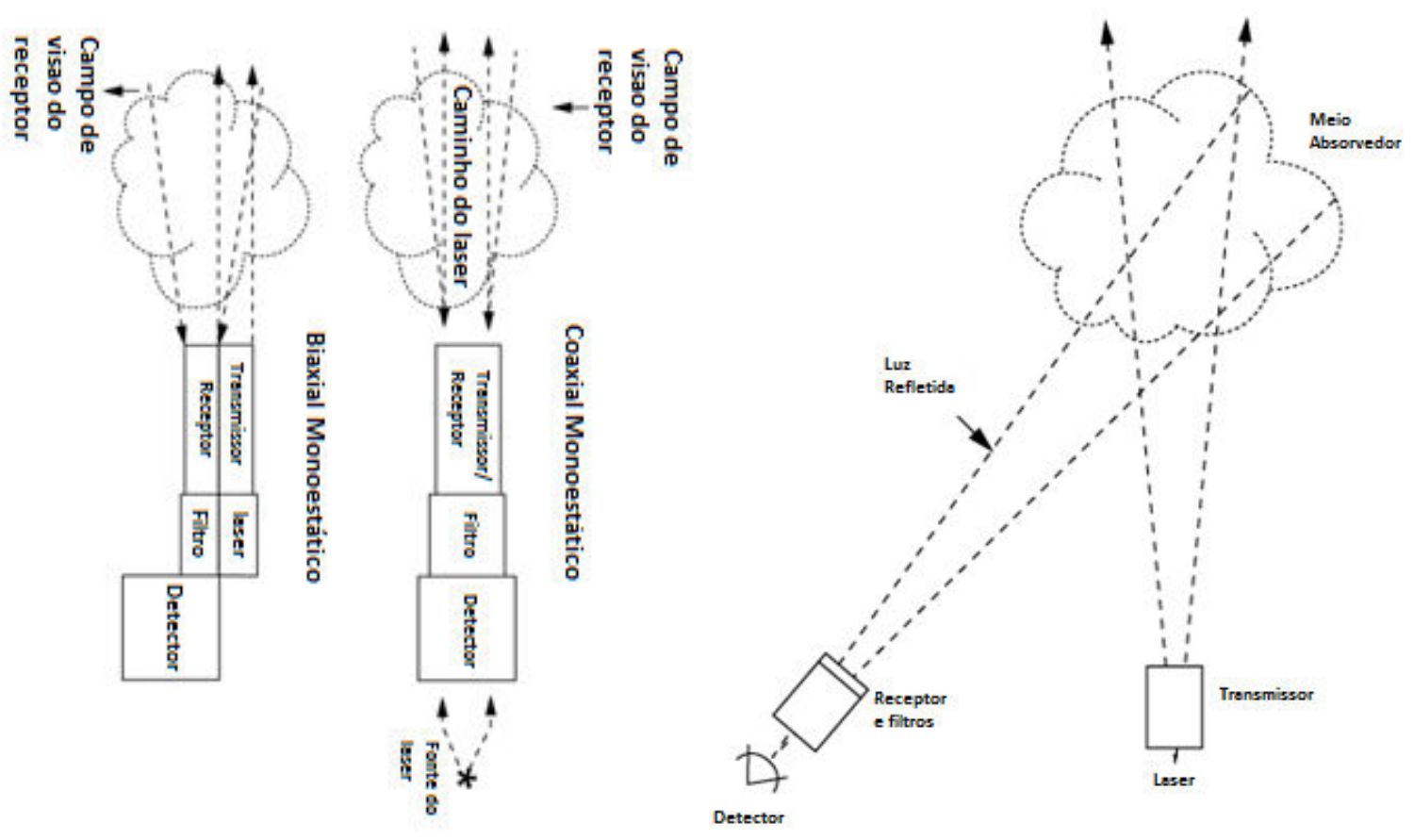

Configuração Monoestática Biaxial e Coaxial

Configuração Biestática

Figura 3.8 - Representação esquemática das configurações monoestáticas (coxial e biaxial) e biestáticas, mostrando a posição relativa do transmissor e do receptor.

Uma outra vantagem do laser pulsado é que ele permite a medida do tempo entre a transmissão e o espalhamento do pulso na atmosfera, sendo que a resolução espacial do sistema será dada pela largura temporal do pulso e pelo componente registro electrônica. A taxa de repetição precisa ser ajustada para que um pulso possa ser transmitido e retroespalhado, alcançando o receptor antes que o próximo pulso seja disparado. Isso faz com que a taxa de repetição fique próxima dos $20 \mathrm{~Hz}$ para sistemas que trabalham em baixas altitudes. (Argall e Siga, 2004). 
O sistema de recepção é formado por telescópio contendo um espelho primário, responsável pela captação do sinal restroespalhado, e um espelho secundário, que foca o sinal na caixa de detecção. O tamanho do espelho primário é um fator determinante na potência do sinal retroespalhado, portanto, é um dos parâmetros da equação do sistema LIDAR, como será discutido posteriormente. Os telescópios podem ter geometria Newtoniana ou Cassegraniana. Na caixa de detecção, o sinal retroespalhado é selecionado, filtrado e dirigido aos dispositivos fotomultiplicadores. Estes convertem os fótons incidentes em pulsos de corrente elétrica, que são detectados pelo registrador permanente de intensidade do pulso, que tem como saída essa intensidade corrigida em função da altitude.

Os sinais captados pelas fotomultiplicadoras podem ser registrados de duas maneiras: por meio de contagem de fótons, na qual os pulsos são individualmente contados e justamente por ser mais sensível é usada para medidas de sinais menos intensos, provenientes de grandes distâncias; ou por meio de detecção analógica, na qual uma corrente média devida aos fótons é medida e registrada, geralmente utilizada para distâncias próximas ao sistema, as quais possuem um forte sinal de retroespalhamento (Lopes, 2011).

Esses dois sinais podem ser utilizados de forma conjunta, fazendo o procedimento de “glueing”, que consiste na combinação dos sinais analógicos (AD) e contagem de fótons (PC) para as regiões onde cada um desses sinais é mais favorecido. O princípio é formar pares ordenados de dados $(\mathrm{AD}, \mathrm{PC})$ em uma região onde ambos são considerados razoavelmente lineares e realizar uma regressão. A regressão determina o coeficiente de "glueing" que é usado para converter a escala $\mathrm{AD}$ em uma escala de contagens de fótons "virtual". (Torres, 2008)

\subsection{1 - O LIDAR Elástico}

O Lidar elástico é uma forma bastante utilizada da técnica LIDAR. Em linhas gerais, o feixe de luz é emitido e espalhado de forma elástica por partículas e moléculas, conforme foi descrito nos espalhamentos Mie e Rayleigh. No processo de retroespalhamento, são obtidos dois fatores, o coeficiente de retroespalhamento $(\beta)$ e o coeficiente de extinção $(\alpha)$.(Eichinger, 2004)

O coeficiente de retroespalhamento obtido é a somatória da contribuição do retroespalhamento de moléculas e partículas. 


$$
\beta(\lambda, r)=\beta_{m}(\lambda, r)+\beta_{a e r}(\lambda, r)
$$

O coeficiente de extinção deriva da Lei de Beer-Lambert, e foi descrito na equação 3.1.1, e também é a somatória da extinção devida aos aerossóis e moléculas. Como a extinção é a somatória do espalhamento e da absorção, vem:

$$
\alpha(\lambda, \mathrm{z})=\alpha(\lambda, \mathrm{r})_{\mathrm{m}}^{\mathrm{abs}}+\alpha(\lambda, \mathrm{r})_{\mathrm{m}}^{\mathrm{scat}}+\alpha(\lambda, \mathrm{r})_{\mathrm{aer}}^{\mathrm{scat}}+\alpha(\lambda, \mathrm{r})_{\mathrm{aer}}^{\mathrm{abs}}
$$

onde $\alpha(\lambda, r)_{m}^{a b s}, \alpha(\lambda, r)_{a e r}^{a b s}$ são os coeficientes de extinção devido à absorção por moléculas e por aerossóis, respectivamente, e $\alpha(\lambda, r)_{m}^{\text {scat }}, \alpha(\lambda, r)_{a e r}^{\text {scat }}$ são os fatores de extinção devido ao espalhamento por moléculas e por aerossóis, respectivamente.

Os dois fatores, $\alpha(\lambda, r)$ e $\beta(\lambda, r)$ compõem a equação do LIDAR elástico, que também envolve parâmetros atmosféricos e parâmetros geométricos do sistema:

$$
P(r)=P_{0} \frac{c \tau}{2} Q_{e f} A \frac{\beta(\lambda, r)}{r^{2}} \exp \left[-2 \int_{0}^{r} \alpha\left(\lambda, r^{\prime}\right) d r^{\prime}\right]
$$

onde P(r) é o sinal (potência) retornado da distância r no tempo t (Watts), $r$ é a distância do volume investigado na atmosfera (metros), $\mathrm{P}_{0}$ é o sinal recebido no tempo $\mathrm{t}_{\mathrm{o}}$ (Watts), c é a velocidade da luz (m/s), $\tau$ é a duração do pulso do laser (ns), $Q_{e f}$ é o fator eficiência do sistema, A é a área da seção transversal do telescópio $\left(\mathrm{m}^{2}\right), \beta(\lambda, r)$ é o coeficiente de retroespalhamento a distância $\mathrm{r}\left(\mathrm{km}^{-1} \mathrm{sr}^{-1}\right), \alpha(\lambda, z)$ é o coeficiente de extinção na distância $\mathrm{r}$ $\left(\mathrm{km}^{-1}\right)$. A figura 3.9 é uma representação esquemática dos elementos geométricos relacionados à equação de LIDAR.

As medidas feitas com um lidar elástico fornecem informação sobre o coeficiente de espalhamento e de extinção, considerando que de alguma maneira essas duas informações possam ser separadas. O retroespalhamento e a extinção, devido às moléculas presentes na atmosfera, podem ser determinados com o uso de dados meteorológicos obtidos por radiossondagem ou por meio de modelos atmosféricos, que fornecem a densidade molecular em função da altitude. Dessa maneira, precisa-se obter a fração devida ao material particulado, dominada pelo espalhamento Mie. 


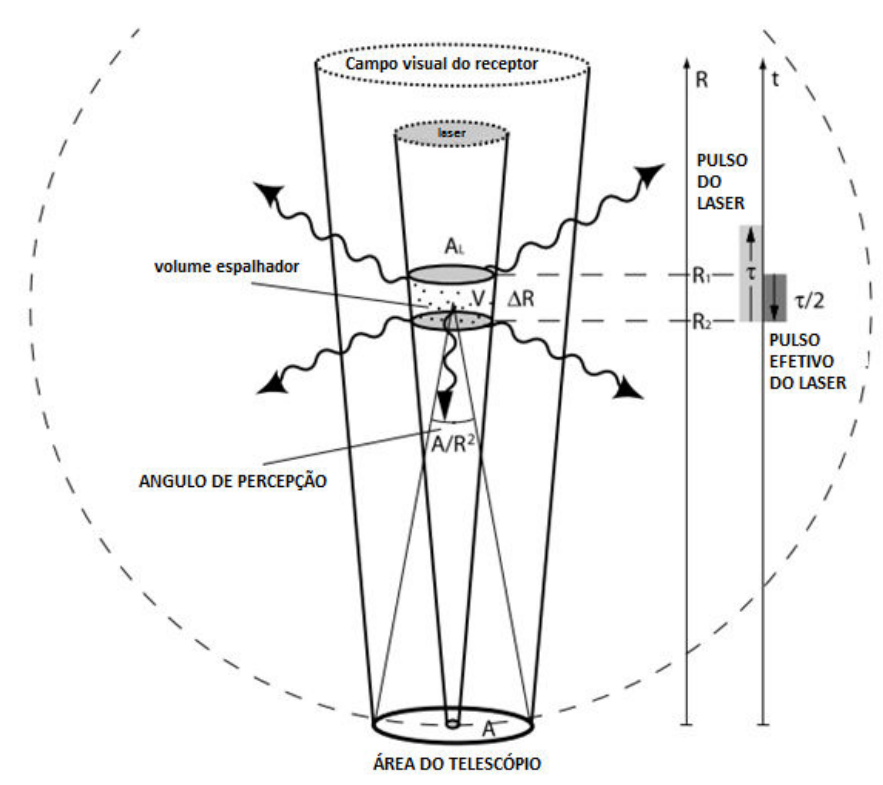

Figura 3.9 - Representação dos elementos geométricos presentes na equação de LIDAR, para um sistema Monoestático Coaxial. Adaptado de Weitkamp (2005)

O método de inversão de Klett $(1981,1983,1986)$ é um método analítico muito utilizado para extrair o coeficiente de extinção e de retroespalhamento em uma atmosfera não homogênea a partir do sinal de retorno em um único comprimento de onda. Segundo esse tratamento, o sinal mais adequado para análise é o logaritmo natural do sinal de retorno corrigido pelo quadrado da distância:

$$
S(r)=\ln \left[\operatorname{Pr}^{2}(r)\right]
$$

Tomando um valor de referência $S_{0}=S\left(r_{o}\right)$, no qual $r_{o}$ é uma distância de referência, temos:

$$
S(r)-S\left(r_{0}\right)=\ln \left[\operatorname{Pr}^{2}(r)\right]-\ln \left[\operatorname{Pr}_{o}^{2}\left(r_{o}\right)\right]=\ln \left[\frac{\operatorname{Pr}^{2}(r)}{P r_{o}^{2}\left(r_{o}\right)}\right]
$$

Utilizando a equação clássica de LIDAR 3.2.3 e substituindo a 3.2.5, vem:

$$
S(r)-S\left(r_{0}\right)=\ln \left[\frac{\beta(r)}{\beta\left(r_{o}\right)}\right]-2 \int_{z}^{z_{0}} \alpha\left(\lambda, r^{\prime}\right) d r^{\prime}
$$

Derivando (3.2.6) em função de r, vem:

$$
\frac{d S}{d r}=\frac{1}{\beta} \frac{d \beta}{d r}-2 \alpha
$$


Esse resultado mostra que a aproximação de Klett é dependente ainda do coeficiente de retroespalhamento e de extinção. Para solucionar esse problema, introduz-se a RL (Razão LIDAR), que é o quociente entre o coeficiente de extinção e o de retroespalhamento:

$$
R L=\frac{\alpha(r)}{\beta(r)}
$$

A RL depende de propriedades físicas, químicas e morfológicas das partículas, que dependem da umidade relativa e da altitude. Exatamente pela múltipla dependência, a determinação da razão de LIDAR é umas das principais dificuldades da técnica de uso do LIDAR elástico num único comprimento de onda. Nesse caso, é necessária a utilização de instrumentos complementares, como o fotômetro solar (Landulfo et al, 2003), que fornece dados da profundidade óptica (definida como a integral do coeficiente de extinção em todo o perfil atmosférico (Seinfeld e Pandis, 2006).

Utilizando então os valores fornecidos pelo fotômetro, pode-se aplicar a seguinte relação:

$$
\tau(\lambda)=\int_{\infty}^{z} \alpha(\lambda, r) d r=\int_{z}^{z_{o}} R L(\lambda, r) \beta(\lambda, r)
$$

Assim, de posse dos valores de retroespalhamento, pode-se inferir o valor da extinção.

\subsection{2 - O LIDAR Raman}

A técnica LIDAR Raman tem sido freqüentemente usada nas medidas atmosféricas e apresenta vantagens em relação ao LIDAR elástico. Uma delas reside exatamente que nenhuma suposição a priori dos valores da RL precisa ser feita. O sinal de retroespalhamento inelástico é afetado unicamente pelo termo de extinção do aerossol, mas não por seu retroespalhamento (Ansmann, Riebesell e Weitkamp, 1990). Assim, o termo de retroespalhamento devido às partículas não aparece na equação LIDAR Raman, que é dada por:

$$
P\left(\Delta \lambda_{R a}, r\right)=P_{0} \frac{c \tau}{2} A \frac{\beta\left(\lambda_{R a}, r\right)}{r^{2}} \exp \left\{-\int_{0}^{r}\left[\alpha\left(\lambda, r^{\prime}\right)+\alpha\left(\lambda_{R a}, r^{\prime}\right)\right] d r^{\prime}\right\}
$$


na qual $P\left(\Delta \lambda_{R a}, r\right)$ é a potência do sinal detectado a uma distância $r, P_{0}$ é a potência do sinal transmitido, c é a velocidade da luz, $\tau$ a duração do pulso emitido pelo laser, A a área efetiva do receptor (telescópio), $\beta\left(\lambda_{R a}, r\right)$ representa o espalhamento Raman de moléculas, $\alpha\left(\lambda, r^{\prime}\right)$ o coeficiente de extinção no caminho de ida do laser com comprimento de onda $\lambda$ e $\alpha\left(\lambda_{R a}, r^{\prime}\right)$ o coeficiente de extinção no caminho de volta do laser com o comprimento de onda Raman, $\lambda_{R a}$. A partir da equação 3.2.10 pode-se obter o coeficiente de extinção de aerossóis para o sistema LIDAR Raman.

O termo que representa o retroespalhamento molecular $\beta\left(\lambda_{R a}, r\right)$ pode ser calculado por meio da densidade molecular $M D_{R a}$, que para medidas Raman geralmente é obtida pela densidade molecular do $N_{2}$, e também utilizando a seção de espalhamento Raman para o comprimento de onda $\lambda_{R a}$ e num ângulo de espalhamento de $180^{\circ}$, tal que:

$$
\beta_{m o l}\left(\lambda_{R a}, r\right)=M D_{R a} \frac{d \sigma(\lambda, \pi)}{d \Omega}
$$

onde $\frac{d \sigma(\lambda, \pi)}{d \Omega}$ é a seção diferencial de espalhamento Raman e pode ser obtida a partir de dados de radiossondagem ou a partir de perfis atmosféricos padrão de temperatura e pressão. A densidade molecular pode ser obtida da mesma forma, conforme já descrito no espalhamento Rayleigh.

Inserindo a equação 3.2.11 na equação 3.2.10 e realizando algumas manipulações algébricas, é possível obter a equação para o coeficiente de extinção de aerossóis (Ansmann, Riebesell, e Weitkamp, 1990)

$$
\alpha_{a e r}(\lambda, r)=\frac{\frac{d}{d z}\left\{\ln \left[\frac{M D_{R a}(r)}{X\left(\lambda_{R a}, r\right)}\right]\right\}-\alpha_{m o l}(\lambda, r)-\alpha_{m o l}\left(\lambda_{R a}, r\right)}{1+\left(\frac{\lambda}{\lambda_{R a}}\right)^{\delta(r)}}
$$

sendo $X\left(\lambda_{R a}, r\right)$ a potência do sinal detectado corrigido pelo quadrado da distância $\left(P\left(\Delta \lambda_{R a}, r\right)\right)$ e o termo $\delta(r)$ é o coeficiente de Ångström definido em 3.1.36. Assim, tornase possível obter o perfil de extinção de aerossóis utilizando a equação 3.2.12 sem que seja feita qualquer suposição a priori da razão LIDAR, como no caso do LIDAR Elástico.

O coeficiente de retroespalhamento das partículas pode ser determinado usando os sinais elástico e inelásticos medidos, sendo necessários dois pares de sinais $P \lambda$ e $P \lambda_{R a}$ para 
uma altura $\mathrm{r}$ e $r_{o}$ de referência, sendo essa altura escolhida de tal maneira que seja garantida a presença de sinal molecular (Ansmann, Riebesell e Weitkamp, 1990):

$$
\frac{P(\lambda, r) P\left(\lambda_{R a}, r_{0}\right)}{P\left(\lambda, r_{0}\right) P\left(\lambda_{R a}, r\right)}
$$

Inserindo as equações correspondentes para os quatro sinais e manipulando algebricamente, obtemos o coeficiente de retroespalhamento por partículas pela técnica LIDAR Raman:

$$
\begin{gathered}
\beta_{a e r}(\lambda, r)=-\beta_{m o l}(\lambda, r)+\left[\beta_{a e r}\left(\lambda, r_{0}\right)+\right. \\
\left.\beta_{m o l}\left(\lambda, r_{0}\right)\right] \frac{P(\lambda, r) P\left(\lambda_{R a}, r_{0}\right)}{P\left(\lambda, r_{0}\right) P\left(\lambda_{R a}, r\right)} \frac{M D_{R a}(r)}{M D_{R a}\left(r_{0}\right)} \frac{\exp \left\{-\int_{r}^{r}\left[\alpha_{a e r}\left(\lambda_{R a}, r^{\prime}\right)+\alpha_{m o l}\left(\lambda_{R a}, r^{\prime}\right) d r^{\prime}\right\}\right.}{\exp \left\{-\int_{r_{0}}^{r}\left[\alpha_{a e r}\left(\lambda, r^{\prime}\right)+\alpha_{m o l}\left(\lambda, r^{\prime}\right) d r^{\prime}\right\}\right.}
\end{gathered}
$$

E assim, utilizando as equações 3.2.11 e 3.2.14 podemos determinar o valor da Razão LIDAR sem nenhuma suposição $a$ priori

$$
R L_{a e r}(\lambda, r)=\frac{\alpha_{a e r}(\lambda, r)}{\beta_{a e r}(\lambda, r)}
$$

\subsection{3 - Medidas da Razão de Mistura de Vapor de água}

A razão entre a massa de vapor de água e de ar seco em um determinado volume é chamada de razão de mistura de vapor de água (RMVA). Logo, a razão entre o sinal corrigido de espalhamento Raman de vapor de água e de nitrogênio é um indicativo da RMVA, a menos de uma constante de calibração do sistema, e pode ser representada da seguinte forma, incluindo os efeitos da temperatura:

$$
\frac{P\left(\Delta \lambda_{W, r}\right)}{P\left(\Delta \lambda_{N, r}\right)}=\frac{O_{W}(z) F_{W}[T(z)] M D_{W}(r)\left[d \sigma_{W}(\lambda, \pi) / d \Omega\right] \xi\left(\lambda_{W}\right)}{O_{N}(z) F_{N}[T(z)] M D_{N}(r)\left[d \sigma_{N}(\lambda, \pi) / d \Omega\right] \xi\left(\lambda_{N}\right)} \Delta \tau\left(\lambda_{W}, \lambda_{N}, r\right)
$$

Na qual a notação abreviada:

$$
\Delta \tau\left(\lambda_{W}, \lambda_{N}, r\right)=\exp \left\{-\int_{0}^{Z}\left[\alpha\left(\lambda_{W, r^{\prime}}\right)+\alpha\left(\lambda_{N, r^{\prime}}\right)\right] d r^{\prime}\right\}
$$

é usada para o termo de transmissão diferencial, que representa o fato da transmissão atmosférica diferir para os dois comprimentos de onda em questão. $P\left(\Delta \lambda_{W, X}\right)$ é a potência 
de saída do laser no comprimento de onda X para os canais de nitrogênio e vapor de água, $O_{X}(r)$ é a função de overlap. $\xi\left(\lambda_{X}\right)$ é a eficiência total do receptor óptico LIDAR no comprimento de onda Raman para o nitrogênio e o vapor de água, e inclui fatores como a óptica de transmissão, transmissão dos filtros envolvidos e eficiência quântica do detector. Como foi definido na equação 3.2.11, $\beta_{\text {mol }}(r, \lambda)=M D_{X}(r)\left[d \sigma_{X}(\lambda, \pi) / d \Omega\right]$ é o produto entre a densidade molecular (MD) e a seção de retroespalhamento Raman. Por fim, $F_{X}[T(r)]$ é a função de dependência com a temperatura definida como:

$$
F_{X}[T]=\int_{\Delta_{\lambda X}} \frac{\left[d \sigma_{X}\left(\lambda^{\prime}, \pi, T\right) / d \Omega\right] \xi\left(\lambda^{\prime}\right) d \lambda^{\prime}}{\left[d \sigma_{X}(\pi) / d \Omega\right] \xi\left(\lambda_{X}\right)}
$$

na qual X se refere ao espalhamento Rayleigh (caso em que as linhas rotacionais Raman carregam a dependência com a temperatura) ou o modo Raman vibracional das espécies moleculares X. O intervalo $\Delta_{\lambda X}$ é aquele no qual o sistema LIDAR apresenta transmissão significativa para a espécie $\mathrm{X}$.

Considerando que o $N_{2}$ existe em uma fração constante na baixa atmosfera (Whiteman, 2003):

$$
w=\frac{M W_{W} M D_{W}(r)}{M W_{\text {dry air }} M D_{\text {dry } \operatorname{air}(r)}} \cong \frac{M W_{W} M D_{W}(r)}{M W_{\text {dry air }} M D_{N}(r) / 0.78} \cong 0.485 \frac{M D_{W}(r)}{M D_{N}(r)}
$$

na qual $w$ é a razão de mistura de vapor de água (exceto por uma constante), $M W_{W}$ é o peso molecular do vapor de água (18 gramas/mol) e $M W_{\text {dry air }}$ é o peso molecular do ar seco $(28,4$ gramas/mol).

Combinando as equações 3.2.16 e 3.2.19, obtemos:

$$
w=k \frac{F_{W}[T(r)] P\left(\Delta \lambda_{W, r}\right)}{F_{N}[T(r)] P\left(\Delta \lambda_{W, r}\right)} \Delta \tau\left(\lambda_{W}, \lambda_{N}, r\right)
$$

onde $\mathrm{k}$ é a constante de proporcionalidade ou fator de calibração do sistema LIDAR Raman, e é representada por:

$$
k=0.485 \frac{O_{W}(z)\left[d \sigma_{W}(\lambda, \pi) / d \Omega\right] \xi\left(\lambda_{W}\right)}{O_{N}(z)\left[d \sigma_{N}(\lambda, \pi) / d \Omega\right] \xi\left(\lambda_{N}\right)}
$$

e carrega todas as características ópticas do sistema. 


\subsection{4 - Incerteza na medida da razão de mistura de vapor de água}

As incertezas na determinação da razão de mistura de vapor de água $\left(\sigma_{w}^{2}\right)$ usando o Raman LIDAR foram extensamente discutidas em Whiteman (2003). Basicamente, leva-se em consideração o erro randômico de todos os elementos da equação 3.2.16 e é obtido por propagação de erros a partir desta equação.

$$
\frac{\sigma_{w}^{2}}{w^{2}}=\frac{\sigma_{k}^{2}}{k^{2}}+\frac{\sigma_{R_{w}}^{2}}{R_{w}^{2}}+\frac{\sigma_{\Delta \tau}^{2}}{\Delta \tau^{2}}
$$

na qual $R_{w=} \frac{P\left(\lambda_{W, r}\right)}{P\left(\lambda_{N, r}\right)}$. A calibração do sistema Raman se mostrou estável por anos, e então o erro na constante pode ser considerado muito baixo. Os erros na transmissão diferencial também podem ser considerados muito baixos, usando a extinção de aerossóis do LIDAR Raman e a densidade molecular a partir da radiossondagem. Portanto, o erro na razão entre os sinais domina o erro na razão de mistura. Quantifica-se o erro no sinal usando análise estatística de uma distribuição de Poison.

Assumindo que $\mathrm{P}(\lambda, \mathrm{r})$ é o que já teve o ruído de fundo subtraído (chamado aqui B), podemos estender e assumir que $\mathrm{P}(\lambda, r)=\mathrm{S}(\lambda, \mathrm{r})$ - $\mathrm{B}(\lambda, \mathrm{r})$, e então teríamos:

$$
\begin{gathered}
\frac{\sigma_{R_{w}}^{2}}{R_{w}^{2}}=\frac{\sigma_{s w}^{2}+\sigma_{B w}^{2}}{\left(S_{w}-B_{w}\right)^{2}}+\frac{\sigma_{S N}^{2}+\sigma_{B N}^{2}}{\left(S_{N}-B_{N}\right)^{2}} \\
\sigma_{R_{w}}^{2}=\frac{\left(S_{w}-B_{w}\right)^{2}}{\left(S_{N}-B_{N}\right)^{2}}\left[\frac{\sigma_{s w}^{2}+\sigma_{B w}^{2}}{\left(S_{w}-B_{w}\right)^{2}}+\frac{\sigma_{S N}^{2}+\sigma_{B N}^{2}}{\left(S_{N}-B_{N}\right)^{2}}\right]
\end{gathered}
$$

Essa equação leva em consideração o erro no ruído de fundo, porque em condições diurnas o ruído pode ser alto o suficiente para introduzir erros nos resultados. Em condições noturnas, pode-se desprezar este termo, e portanto o erro final no vapor de água é dado por:

$$
\sigma_{R_{w}}^{2}=\frac{\left(P_{w}\right)^{2}}{\left(P_{N}\right)^{2}}\left[\frac{\sigma_{S w}^{2}}{\left(P_{w}\right)^{2}}+\frac{\sigma_{S N}^{2}}{\left(P_{N}\right)^{2}}\right]
$$

$\sigma_{S w}^{2}$ e $\sigma_{S N}^{2}$ são derivados diretamente da potência do sinal adquirido pelo LIDAR, e o tratamento estatístico é o de uma distribuição de Poison. Aproxima-se $\sigma=\sqrt{N_{p}(r)} / N_{p}(r)$, onde Np é o número de fótons contados pelo sistema, corrigidos para o tempo morto da fotomultiplicadora de maneira tal que $N_{p}=N_{c} /\left(1-N_{c} \mu\right)$, onde $N_{c}$ é o número de fótons 
contados e $\mu$ é o tempo morto do detector, que caracteristicamente é da ordem de 10ns para um sistema de contagem de 100Mhz (Whiteman, 2006). A contagem de fótons a partir da frequência do canal de contagem de fótons do sinal do LIDAR pode ser obtida dividindo-se o sinal pela frequência de pulsação do laser e multiplicando-se pelo número de disparos do laser.

\subsection{5 - A calibração das medidas de vapor de água}

A calibração do Raman LIDAR foi extensamente discutida na literatura. (Vaughan et al, 1988, Whiteman, 2003, Leblanc at al, 2008, Moss et al, 2012). Whiteman et al (1992) mostroaram que uma única constante de calibração pode ser usada para converter a razão entre os canais de nitrogênio e vapor de água no LIDAR Raman em razão de mistura de vapor de água, expressa em massa de água dividida por massa de ar seco, em g/kg.

Existem três abordagens principais para obter a constante de calibração. A primeira necessita de um conhecimento acurado da transmissão óptica do sistema LIDAR e a razão entre as seções de espalhamento do vapor de água e do nitrogênio (Venable, 2011), e é chamado de calibração por primeiros princípios. Nesta calibração independente, é feito um mapeamento utilizando uma lâmpada de calibração acoplada a um sistema de translação programável, objetivando obter a constante que carrega as características ópticas do sistema, como visto na equação 3.2.21. O método de calibração independente leva em consideração características de eficiência de detecção do sistema, que está relacionada aos elementos ópticos, como os filtros, espelhos e telescópio.

Outra alternativa é comparar os perfis da razão entre os sinais do LIDAR com perfis bem conhecidos de vapor de água obtidos com o uso de outros instrumentos. O uso de radiossondas é o mais difundido. O terceiro procedimento é comparar a água precipitável total obtida pela integração vertical dos perfis de vapor de água obtidos pelo LIDAR com sistemas GPS colocados ou com radiômetros de micro-ondas. Quando usado um procedimento externo, a acurácia da calibração segue a do instrumento usado como referência. Atualmente, a acurácia das melhores radiossondagem, GPS e radiometria de micro-ondas é estimada em 5\%, 7\% e 10\%, respectivamente (Whiteman, 1992).

No caso da calibração com o uso de radiossondagem, o processo pode ser feito usando um ajuste entre os valores obtidos pela radiossonda e os valores obtidos pelo LIDAR, 
em uma faixa de altitude onde haja atmosfera bem misturada (Moss et al, 2012). No caso de radiossondagens colocadas, procuram-se as radiossondas que tenham sofrido pouco desvio na horizontal em relação ao LIDAR. Esse ajuste é feito por meio de uma regressão linear ou com um teste de mínimos quadrados, como na equação que segue:

$$
\min =\sum_{i=1}^{n}\left(\operatorname{sonda}_{i}-\left(K * L I D A R_{i}\right)\right)^{2}
$$

onde $n$ é cada um dos dados do LIDAR ou da radiossondagem interpolados para uma mesma resolução espacial, dentro da faixa de altitude de referência (Moss et al, 2012).

\subsection{6 - Medidas de aerossol}

A razão de espalhamento por aerossóis (Aerosol Scattering Ratio, ASR) - é usada para quantificar a razão entre o espalhamento Mie (do aerossol) e o espalhamento molecular, sendo definida pela razão entre a soma do coeficiente de retroespalhamento molecular e de aerossóis e o coeficiente de retroespalhamento molecular, a saber:

$$
\operatorname{ASR}(\lambda, z)=\frac{\beta_{t o t}(\lambda, z)}{\beta_{m o l}(\lambda, z)}=\frac{\beta_{a e r}(\lambda, z)+\beta_{m o l}(\lambda, z)}{\beta_{m o l}(\lambda, z)}=1+\frac{\beta_{a e r}(\lambda, z)}{\beta_{m o l}(\lambda, z)}
$$

onde o coeficiente de retroespalhamento molecular $\beta_{m o l}(\lambda, z)$ foi definido na equação 3.2.11.

É possível, com o uso do LIDAR Raman, quantificar a ASR de forma direta, pois LIDAR Raman mede um sinal que é proporcional à densidade do nitrogênio (ou da molécula sendo medida pelo LIDAR) e o valor desse sinal pode ser utilizado diretamente no denominador da 3.2.27. O LIDAR elástico não fornece tal informação, sendo necessária a utilização de métodos de inversão, como por exemplo o de Klett, já discutido anteriormente.

A ASR é calculada a partir da razão entre os sinais obtidos no canal elástico e o sinal obtido no canal Raman do $N_{2}$ (ou da molécula sendo utilizada como gás de referência):

$$
\frac{P\left(\Delta \lambda_{, r}\right)}{P\left(\Delta \lambda_{W, r}\right)}=\frac{O_{L}(r)}{O_{N}(r)} \frac{\xi\left(\lambda_{L}\right)}{\xi\left(\lambda_{N}\right)} \frac{F_{L}[T(r)] \beta_{\text {aer }}^{\pi}(\lambda, r)+\beta_{m o l}^{\pi}(\lambda, r)}{F_{N}[T(r)] M D_{N}(r)\left[d \sigma_{N}(\lambda, \pi) / d \Omega\right]} \Delta \tau\left(\lambda, \lambda_{N}, r\right)
$$


O coeficiente de retroespalhamento Raman para a molécula de $N_{2}$ é definido em 3.2.11 e é proporcional ao coeficiente de retroespalhamento Rayleigh para o ar, pois $N_{2}$ é um gás bem misturado na baixa atmosfera. Essa relação pode ser escrita da seguinte forma:

$$
\beta_{\mathrm{N}}(\mathrm{r}, \lambda)=\mathrm{C}_{\mathrm{N}} \beta_{\mathrm{mol}}(\mathrm{r}, \lambda)
$$

Onde $\beta_{\mathrm{N}}$ é o retroespalhamento devido às moléculas de nitrogênio. $\mathrm{O}$ fator de proporcionalidade $C_{N}$ pode ser calculado para diferentes tipos de fontes de laser dimensionando os valores da seção de espalhamento a partir do $337,1 \mathrm{~nm}$ e do fato que o $\mathrm{N}_{2}$ forma uma parcela constante na atmosfera (Whiteman, 2003).

As equações 3.2.27 e 3.2.28 podem ser combinadas da seguinte forma:

$$
\begin{aligned}
\operatorname{ASR}(\lambda, r)-1 & =\frac{\beta_{a e r}^{\pi}(r, \lambda)}{\beta_{m o l}^{\pi}(r, \lambda)} \\
& =C_{N}(\lambda) F_{N}[T(r)] \frac{O_{N}(r)}{O_{L}(r)} \frac{\xi\left(\lambda_{N}\right)}{\xi(\lambda)} \frac{P(\Delta \lambda, r)}{P\left(\Delta \lambda_{N}, r\right)} \Delta \tau\left(\lambda, \lambda_{N}, r\right)-F_{L}[T(r)]
\end{aligned}
$$

Suprimindo-se a função de overlap, $O_{N}(r)$ e a eficiência óptica $\xi\left(\lambda_{N}\right)$ por meio da introdução de um termo $C_{N}^{*}(\lambda)$ que os contenha, obtém-se:

$$
\begin{gathered}
\operatorname{ASR}(\lambda, r)-1=\frac{\beta_{\text {aer }}^{\pi}(r, \lambda)}{\beta_{\text {mol }}^{\pi}(r, \lambda)} \\
=C_{N}^{*}(\lambda, r) F_{N}[T(r)] \frac{P(\Delta \lambda, r)}{P\left(\Delta \lambda_{N}, r\right)} \Delta \tau\left(\lambda, \lambda_{N}, r\right)-F_{L}[T(r)]
\end{gathered}
$$

onde

$$
C_{N}^{*}(\lambda)=C_{N}(\lambda) \frac{O_{N}(z)}{O_{L}(z)} \frac{\xi\left(\lambda_{N}\right)}{\xi(\lambda)}
$$

Percebe-se então que, uma vez conhecida a ASR, é possível obter o sinal de retroespalhamento por aerossóis, já que o sinal molecular pode ser obtido diretamente do canal do nitrogênio. 


\section{3 - Higroscopicidade de aerossóis atmosféricos}

\subsection{1 - A teoria de Köhler}

Um dos principais componentes do aerossol atmosférico é a água condensada, que pode significar metade do volume das partículas em umidades relativas superiores a $80 \% \mathrm{e}$ ser a espécie dominante em umidades relativas maiores que 90\%. (Kreidenweis, 2014).

O aumento de tamanho das partículas de aerossóis devido ao ganho de água (crescimento higroscópico) tem influência no espalhamento direto da radiação solar (efeito direto), mas também tem influência no chamado efeito indireto, relacionado à capacidade dessas partículas de funcionar como núcleos de condensação de nuvens (CCN), ou seja, a capacidade dessas partículas de absorverem água até se tornarem gotas de nuvens.

Essa característica depende da natureza química da população de aerossol e é bem conhecido que aerossóis mais higroscópicos têm maior tendência a funcionarem como CCN. Há partículas, como o black carbon, que funcionam mais como absorvedores, levando a uma diminuição do albedo total da Terra. (Dubovik, Holben e Eck, 2002).

A baixas umidades relativas, partículas de aerossóis contendo sais permanecem sólidas. Conforme a umidade relativa aumenta, essas partículas se mantêm sólidas até que um limiar (que é característico de cada aerossol) é alcançado. Nesse nível de umidade relativa (conhecido como Umidade Relativa de Deliquescência - DRH), a partícula sólida espontaneamente absorve água, normalmente num crescimento rápido, produzindo uma solução aquosa saturada. Se a umidade relativa aumenta, há adicional condensação no sal, para manter o equilíbrio termodinâmico. Se houver uma diminuição da umidade relativa, a evaporação ocorre, mas em geral não existe cristalização na solução quando a DRH é alcançada. Este comportamento é conhecido como histerese, isto é, o ponto de deliquescência e cristalização são diferentes. (Kreidenweis, 2014; Seinfeld e Pandis, 2006; Tardif, 2002)

Para quantificar os fenômenos e descrever a condensação de vapor de água em uma gota, seja ela de água pura ou uma solução salina, levando em consideração o ganho de água pela partícula em ambientes de diferentes umidades e sua ativação até uma gota de nuvem, foi desenvolvida uma teoria na década de 1920 pelo sueco Hilding Köhler. 
Na teoria clássica de Köhler, e até recentemente, apenas compostos inorgânicos eram considerados de importância para o crescimento higroscópico das partículas. Entretanto, muitos estudos recentes mostram que compostos orgânicos, em alguns casos, podem afetar o crescimento higroscópico das partículas de maneira significante. (Seinfeld e Pandis, 2006; Sveningson, Rissler e Swuietlicki , 2006)

A umidade do ar pode ser descrita de diversas maneiras (razão de mistura, a umidade relativa e absoluta), sendo que a umidade relativa (UR) é a mais utilizada e é definida como a razão entre a pressão de vapor atual e a pressão de vapor de saturação, expressa em porcentagem

$$
U R=\frac{e}{e_{s}} 100 \%
$$

onde e é a pressão de vapor atual e es a pressão de vapor de saturação.

A pressão de vapor de saturação é a pressão do vapor de água sobre uma superfície plana, quando há equilíbrio (o mesmo potencial químico em ambas as fases). O equilíbrio depende apenas da temperatura e varia exponencialmente com ela.

As equações de Köhler levam em consideração dois efeitos no equilíbrio entre a fase líquida e a fase gasosa: o efeito da curvatura (efeito Kelvin) e o efeito do soluto (lei de Raoult).

No caso de uma gota líquida, a superfície é curva, o que leva a um aumento na pressão de vapor devido ao aumento na tensão superficial. Esse fenômeno é especialmente importante para gotas pequenas, como $D_{p}$ (diâmetro da gota) $<0.1 \mu \mathrm{m}$, e se torna mais importante quanto menor é a temperatura. Como a pressão de vapor é maior na superfície curva, é necessária uma supersaturação do ambiente, para que a gota se mantenha em equilíbrio, e essa supersaturação é maior quanto menor é o diâmetro da gota. Esse aumento na pressão de vapor devido à curvatura é corrigido com a introdução do fator de correção Kelvin $\left(\mathbf{C}_{\mathbf{k}}\right)$, no cálculo da pressão de vapor de uma superfície plana. O efeito Kelvin é uma função do peso molecular da água $\boldsymbol{M}_{\boldsymbol{w}}$, da tensão superficial da solução $\boldsymbol{\sigma}_{\boldsymbol{w}}$, temperatura, $\boldsymbol{T}$, densidade da solução, $\boldsymbol{\rho}_{\boldsymbol{w}}$, e diâmetro da gota, $\boldsymbol{D}_{\boldsymbol{p}}$, de acordo com a equação:

$$
C_{K}=\exp \left(\frac{4 M_{w} \sigma_{w}}{R T \rho_{w} D_{p}}\right)
$$


Imaginemos, no caso de uma gota de água pura, que ocorra a seguinte situação: uma gota em um ambiente supersaturado ganha algumas moléculas de água, fazendo com que seu diâmetro sofra um acréscimo infinitesimal. Esse acréscimo faz com que haja uma diminuição infinitesimal na pressão de vapor. Como a umidade relativa do ambiente não mudou, há deposição de mais moléculas de água na gota, fazendo com que ela cresça indefinidamente. Agora imaginemos a condição oposta: uma gota em equilíbrio perde algumas moléculas, fazendo com que o diâmetro diminua infinitesimalmente. Isso causaria um aumento infinitesimal da pressão de vapor, causando a saída de mais moléculas da gota, e ela diminuiria até se extinguir.

Esses dois argumentos mostram que uma gota de água pura tem um equilíbrio absolutamente instável. Em realidade, na atmosfera, as gotas não se apresentam puras, sempre contendo solutos dissolvidos (Seinfeld e Pandis, 2006).

Consideremos então um sistema binário constituído por dois componentes: sal dissolvido em água líquida. A pressão de vapor de equilíbrio neste caso diminui porque o potencial químico do solvente em uma solução é menor do que aquela do solvente puro (o potencial químico é função da fração molar do solvente, que é menor nas soluções). Isso é corrigido pela lei de Raoult.

Então, o novo equilíbrio de saturação $\mathrm{p} / \mathrm{p}_{\mathrm{s}}$, levando em consideração os efeitos da curvatura e da presença do soluto, pode ser definido como:

$$
\ln \left(\frac{p\left(D_{p}\right)}{p s}\right)=\frac{4 M_{w} \sigma_{w}}{R T \rho_{w} D_{p}}-\frac{6 n_{s} M_{w}}{\pi \rho_{w} D_{p}{ }^{3}}
$$

onde $n_{s}$ é o número de mols do solvente.

Essa é a conhecida formulação de Köhler, e o primeiro termo à direita na equação 3.3.3 leva em consideração o efeito da curvatura e o segundo termo o efeito do soluto.

Como pode ser observado na figura 3.10, mostrando ambos os efeitos, o efeito da curvatura é grande para gotas pequenas, e prevalece sobre o efeito do soluto, até que é alcançado o diâmetro limite para ativação (ponto de deliquescência). 
Se a partícula contém material solúvel, a pressão de vapor declina com o aumento do número de partículas do soluto e é a razão para que gotas se formem sobre o material particulado presente na atmosfera. É por isso também que uma pequena supersaturação é necessária para que haja o crescimento das gotas menores, pois a presença de solutos ajuda na diminuição da pressão de vapor. Essa é a explicação também para a formação de gotas a partir de partículas mais solúveis, que se comportam mais facilmente como CCN.

Os compostos orgânicos são de grande importância nas propriedades higroscópicas das partículas. Eles podem afetá-la de duas maneiras principais: influenciando o número de íons disponíveis, o que diminuiria a atividade da água, ou no caso de substâncias tensoativas, diminuindo a tensão superficial provocada pelo efeito Kelvin (Rissler, 2003).

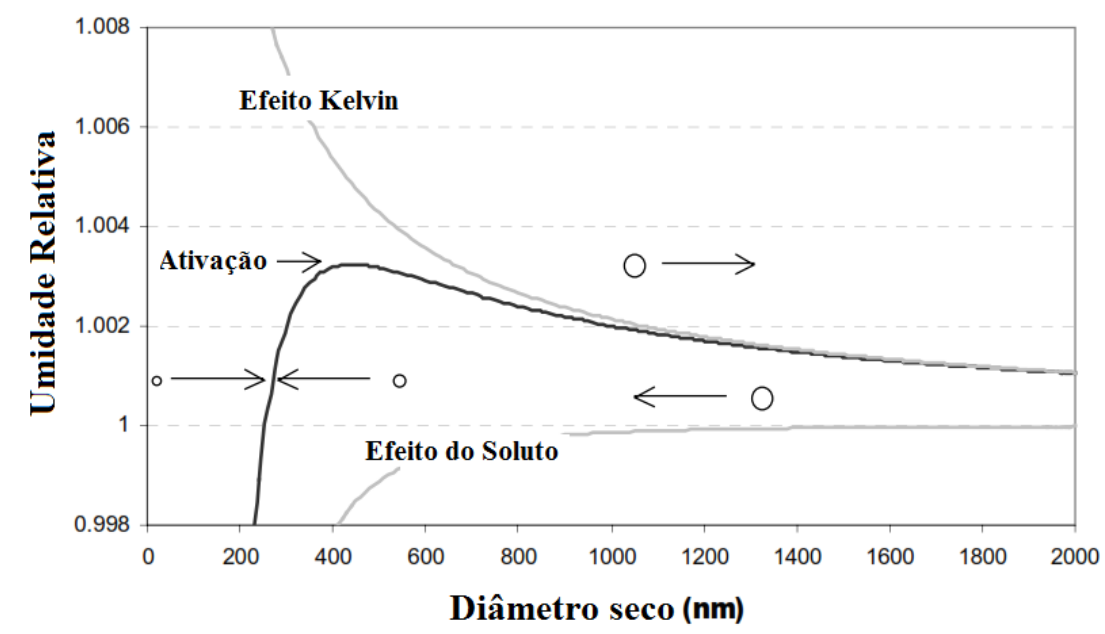

Figura 3.10 - Equilíbrio resultante para o crescimento higroscópico de uma partícula de sulfato de amônia de $40 \mathrm{~nm}\left(\left(\mathrm{NH}_{4}\right)_{2} \mathrm{SO}_{4}\right)$. Adaptado de: (Rissler, 2003)

\subsection{2 - O fator de crescimento por higroscopicidade e sua determinação com o LIDAR}

Nas últimas décadas, uma grande variedade de técnicas experimentais tem sido usada para medir os efeitos do crescimento higroscópico do material particulado. (Hänel, 1976; Kotchenruther e Hobbs, 1998; Feingold e Morley, 2003; Zieger et al., 2013). Essas técnicas se baseiam no aumento do diâmetro das partículas ou em medidas indiretas, avaliando os efeitos na massa ou propriedades ópticas.

Partículas de aerossóis reagem de maneira diferente na presença de umidade, indo de um comportamento hidrofóbico a um comportamento higroscópico. Há dois tipos de comportamento: monotônico, quando a partícula reage continuamente para todos os valores de UR (umidade relativa), e deliquescente, quando a partícula permanece praticamente seca 
até certo valor de UR, chamado ponto de deliquescência, quando a transição de sólido para líquido começa a acontecer. Sais inorgânicos e alguns compostos orgânicos podem formar partículas sólidas (cristais) em baixas umidades relativas. Se a partícula é seca e sólida (como por exemplo $\mathrm{NaCl}$ ), ela começará a ganhar água a uma umidade relativa bem definida, chamada umidade relativa de deliquescência (DRH). A partícula continuará ganhando água se a umidade relativa for aumentada, para manter o equilíbrio termodinâmico, seguindo a curva de Köhler. A partícula evaporará se a umidade relativa diminuir, porém a cristalização não ocorrerá na $\mathrm{DRH}$, e permanecerá supersaturada até que ocorra a cristalização numa umidade chamada umidade relativa de eflorescência. Esse fenômeno é chamado histerese e é mostrado na figura 3.11

Portanto, o estado físico da população de aerossóis influencia no comportamento higroscópico. Além disso, as propriedades como distribuição de tamanho, parâmetros ópticos e composição química influenciam diferentemente o comportamento conforme a UR aumenta ou então diminui. (Santarpia e Collins, 2014; Carrico, 2010). Esses fenômenos podem afetar a avaliação dos impactos radiativos de aerossóis.

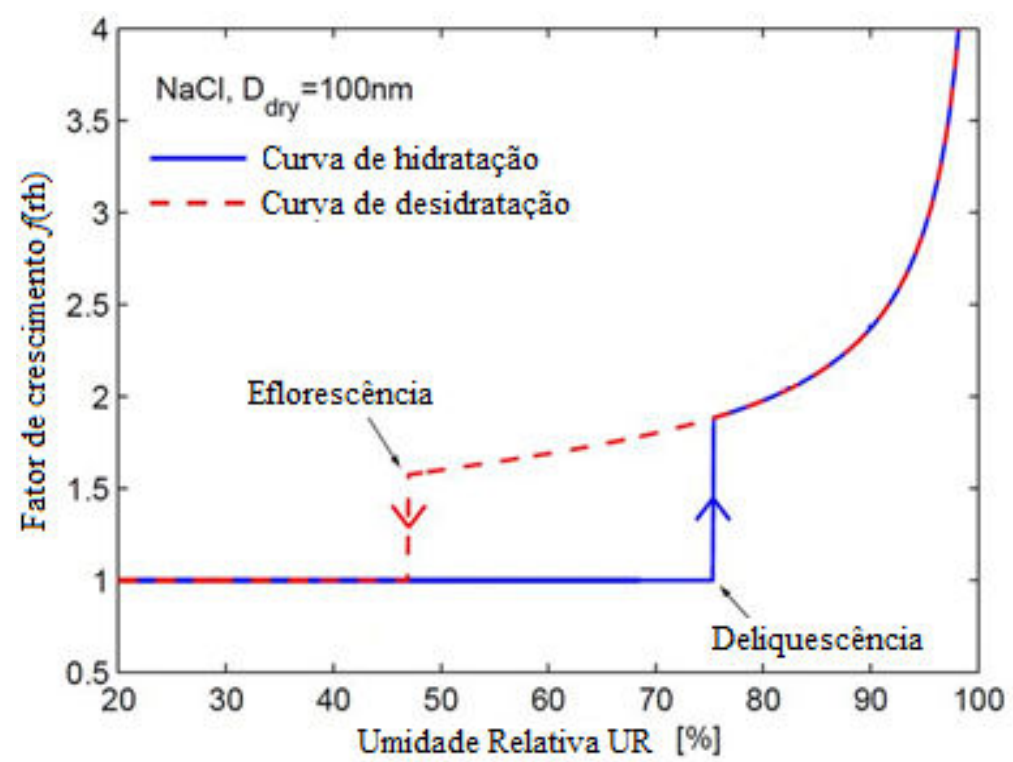

Figura 3.11 - Crescimento higroscópico de uma partícula de $\mathrm{NaCl}$ de diâmetro inicial Ddry $=100 \mathrm{~nm}$, mostrando uma típica curva de histerese. (Granados-Munõz, 2014)

As propriedades ópticas, como coeficiente de extinção ou retroespalhamento são bastante dependentes da umidade relativa para aerossóis higroscópicos. A quantificação do efeito da umidade relativa nestas propriedades é necessária para estimar adequadamente a forçante radiativa devida aos aerossóis (Charlson, 1992; Haywood and Boucher, 2000; Im e 
Saxena, 2001; Ross et al, 1008). Van Dorland et al (1997) estimaram que a forçante radiativa média anual global de aerossóis de sulfato é $-0.36 \mathrm{~W} / \mathrm{m}^{2}$, quando assumimos uma umidade relativa média uniforme de $80 \%$ e $-0.32 \mathrm{~W} / \mathrm{m}^{2}$ quando variações locais são consideradas. Kotchenruther, Hoobs e Hegg (1999) mostraram que os aerossóis presentes na costa oeste dos Estados Unidos a uma umidade relativa de $80 \%$ são ao menos duas vezes mais eficientes na forçante radiativa quando comparados aos aerossóis em uma umidade relativa de $30 \%$.

Esta dependência das propriedades ópticas foi analisada em detalhes há algumas décadas. (Hänel, 1976). Como todos os parâmetros necessários à solução da equação de Köhler nem sempre são conhecidos, uma parametrização mais simples foi proposta por Hänel e amplamente adotada na literatura. O aumento no diâmetro das partículas de aerossóis devido ao seu crescimento higroscópico é conhecido como fator de crescimento por higroscopicidade, e usualmente é definido da seguinte forma:

$$
f_{(R H)}=\frac{\beta i}{\beta r e f}
$$

na qual $\beta_{\text {ref }}$ é o coeficiente de retroespalhamento a uma umidade relativa de referência e $\beta_{i}$ é o coeficiente de retroespalhamento de aerossóis submetidos a níveis de umidade relativa maiores que o de referência, e que se espera ser também maior que o de referência (pode ser outro parâmetro óptico, como a extinção). De fato, o retroespalhamento dos aerossóis apresenta tanto uma dependência do índice de refração como do tamanho da partícula. Há uma diminuição no índice de refração conforme o aumento da umidade relativa, mas este efeito não é suficiente para compensar o efeito do crescimento do diâmetro da partícula, e o efeito do tamanho domina, causando o aumento do retroespalhamento (Feingold e Morley, 2003)

A umidade relativa de referência é também chamada de "seca", porque os estudos de higroscopicidade de aerossóis são tradicionalmente feitos em câmaras de umidade controlada, onde uma amostra da população de aerossóis é seca e depois submetida a umidades relativas crescentes, em condições controladas. Esses valores de referência estão tipicamente entre $20 \%$ e $40 \%$. São mais comumente usados os Tandem Differential Mobility Analysers (H-TDMA) (B bretchtel e Kreidenweis, 1999), ou nefelômetros (Zeiger et al, 2013; Kotchenruther, Hobbs e Hegg, 1999; Ross, Hobbs e Holben; 1998), com componentes gerados em laboratório ou amostras padrão de aerossóis. As limitações das câmaras 
acontecem pela condensação de água nos espelhos refrigerados, impedindo que o estudo do crescimento por higroscopicidade seja feito em umidades relativas superiores a $85 \%$, região onde o crescimento dos aerossóis é mais pronunciado. (Feingold e Morley, 2003)

Feingold e Morley (2003) mostraram a habilidade de um LIDAR de comprimento de onda único em prover informação sobre o ganho de água por aerossóis em uma camada limite planetária com cobertura de nuvens e bem misturada. A habilidade de verificar o fator de crescimento higroscópico com um LIDAR de comprimento de onda único é baseada no fato de que, se uma população de aerossóis está mudando sua distribuição de tamanho, então espera-se verificar uma mudança nos valores medidos de retroespalhamento e no coeficiente de extinção. (MacKinnon, 1969)

O método LIDAR para determinação do crescimento higroscópico tem inúmeras vantagens, incluindo o fato de que o aumento do retroespalhamento devido a mudanças no RH é medido sob condições ambiente e não perturbadas e as medidas podem ser feitas até muito próximo da saturação.

Usando a parametrização proposta por Hänel, o fator de crescimento por higroscopicidade pode ser ajustado à seguinte equação:

$$
\frac{\beta i}{\beta r e f}=\left(\frac{1-R H}{1-R H_{r e f}}\right)^{-\gamma}
$$

na qual o fator exponencial $\gamma$ é um fator de ajuste empírico e é tão maior quanto mais higroscópica for a população de aerossóis.

Durante o NASA Discover-AQ (descrito em detalhes no capítulo 4), Ziemba et al (2011) estudaram o comportamento higroscópico dos aerossóis no corredor WashingtonBaltimore usando nefelômetros a bordo de avião. Foi possível modelar a extinção de aerossóis do ambiente $\left(\alpha_{\text {scat,amb }}\right)$ usando $f_{(R H)}$ e uma medida da umidade relativa do ambiente $R H_{a m b}$ por meio das seguintes equações:

$$
\alpha_{\text {scat }, a m b}=\alpha_{\text {scat }, d r y}\left[\frac{1-\frac{R H_{a m b}}{100}}{1-\frac{R H_{d r y}}{100}}\right]^{-\gamma}
$$




$$
\gamma=\frac{\ln \left[\frac{\alpha_{\text {scat }, \text { wet }}}{\alpha_{\text {scat }, d r y}}\right]}{\ln \left[\frac{100-R H_{\text {dry }}}{100-R H_{\text {wet }}}\right]}
$$

Percebe-se então que o parâmetro empírico de ajuste depende da umidade relativa de referência adotada para o conjunto de dados. 


\section{4 - Instrumentação}

\section{1 - O Sistema Raman LIDAR do CLA IPEN}

O sistema LIDAR utilizado neste estudo é chamado MSP-Lidar I (LIDAR do Município de São Paulo) e pertence à Rede Latino-americana de LIDAR (Guerrero-Rascado, 2014) (LALINET - http: //lalinet.org/), que por sua vez é uma rede que contribui para o programa Global Atmosphere Watch (GAW) da World Meteorological Organization (WMO) (http://www.wmo.int/pages/prog/arep/gaw/GAW_contr_networks.html).

É uma Raman LIDAR de múltiplos comprimentos de onda, operado pelo Grupo de Aplicações de Lasers em Pesquisa Ambiental do Centro de Lasers e Aplicações (CLA), do Instituto de Pesquisas Energéticas e Nucleares (IPEN), em São Paulo (2356' S, 46॰74' O, $740 \mathrm{~m}$ acima do nível do mar). É um sistema coaxial monoestático, apontado para o zênite, operando com um laser comercial Nd-YAG da Quantel, modelo Brillant B, com um comprimento de onda fundamental de $1064 \mathrm{~nm}$, e com geração de segundo harmônico em $532 \mathrm{~nm}$ e terceiro harmônico em $355 \mathrm{~nm}$, respectivamente, a uma taxa de repetição de $10 \mathrm{~Hz}$. A energia de saída por pulso é de $850 \mathrm{~mJ}$ para $1.064 \mathrm{~nm}, 400 \mathrm{~mJ}$ para $532 \mathrm{~nm}$ e $230 \mathrm{~mJ}$ para $355 \mathrm{~nm}$. A duração do pulso é de $6 \pm 2 \mathrm{~ns}$. A figura 4.1 esquematiza a configuração do sistema MSP-LIDAR 1.

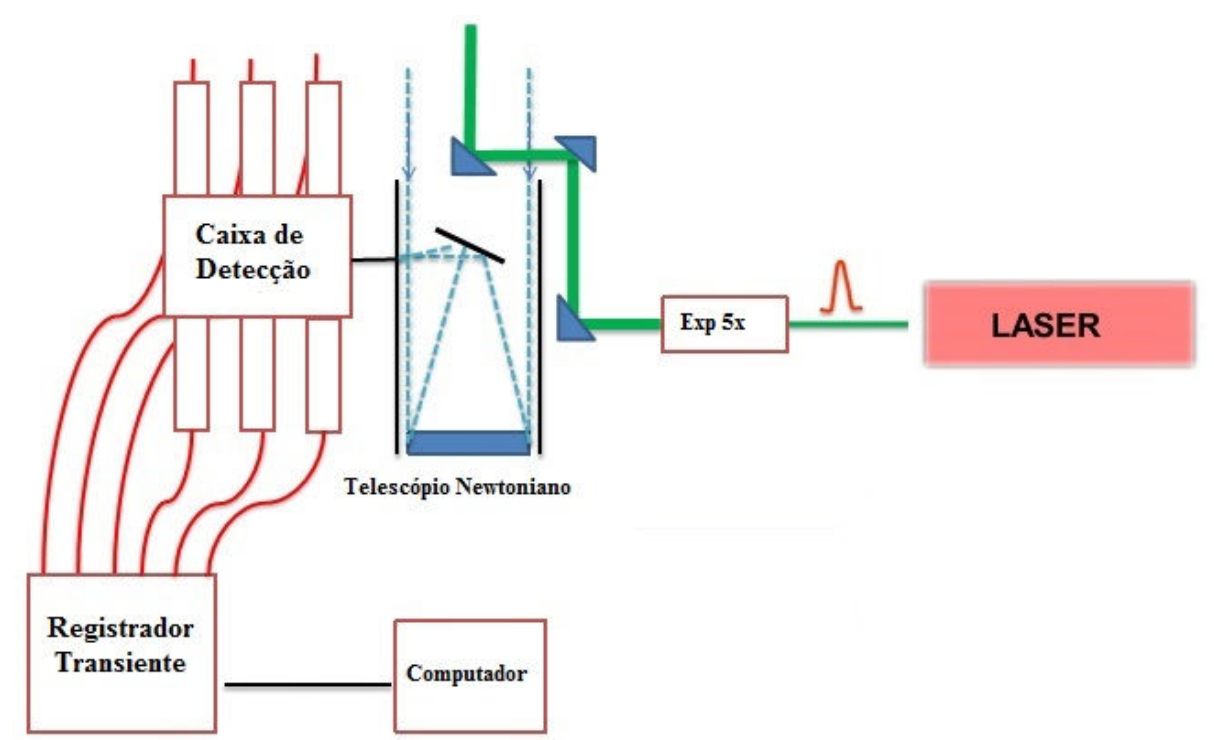

Figura 4.1 - Representação esquemática do sistema MSP-LIDAR I 
O feixe de laser tem um diâmetro médio de $9 \mathrm{~mm}$ e é dirigido para um expansor de feixe (expande os três comprimentos de onda), o qual aumenta o diâmetro do feixe em cerca de 5 vezes, com uma divergência de menos de $0,1 \mathrm{mrad}$. O feixe de laser expandido é então dirigido para a atmosfera por meio de um segundo conjunto de espelhos (periscópio).

Um telescópio de diâmetro $30 \mathrm{~cm}$ (distância focal de 1,5m) é usado para coletar a luz retroespalhada do laser. O campo visual do telescópio (FOV) pode ser ajustado, utilizando um pequeno diafragma. O sistema é atualmente utilizado com um FOV fixado em 0,1 mrad, o que permite a sobreposição (overlap) completa entre o campo visual do telescópio e do feixe de laser em altitudes superiores a 1000m acima do nível do solo. Este valor de FOV, em conformidade com o sistema eletrônico de detecção, permite a radiossondagem da atmosfera até a troposfera livre. A caixa de detecção identifica a radiação retroespalhada e os separa em 6 diferentes canais (o elástico 355nm e os correspondentes sinais Raman do nitrogênio em $387 \mathrm{~nm}$ e de vapor de água em $408 \mathrm{~nm}$; e o elástico $532 \mathrm{~nm}$ e os correspondentes sinais Raman do nitrogênio em $607 \mathrm{~nm}$ e do vapor de água em $660 \mathrm{~nm}$ ) utilizando uma combinação de filtros de passa-alta e filtros de passa-baixa. Cada feixe separado é direcionado para filtros espectrais de banda estreita (532 \pm 1,0nm FWHM, $355 \pm 1,0 \mathrm{~nm}$ FWMH, $387 \pm 0.25 \mathrm{Nm}$ FWMH, $408 \pm 0,25 \mathrm{~nm}$ FWHM, $607 \pm 0,25 \mathrm{~nm}$ FWHM, $660 \pm$ 0,25nm FWHM) e, em seguida, dirigidos para tubos fotomultiplicadores (PMTs). Tubos fotomultiplicadores R7400 da Hamamatsu são utilizados para todos os canais, com exceção de $607 \mathrm{~nm}$ e $660 \mathrm{~nm}$, para os quais são usados tubos R9880U-20. O R9880U-20 tem uma melhor eficiência quântica (cerca de 20\%) na região entre 550-700nm, melhorando a razão sinal-ruído do fraco sinal Raman nestes comprimentos de onda.

Os sinais dos PMTs são digitalizados por um registrador transiente TR 20-80/160 para $532 \mathrm{~nm}$, TR $20-160$ para $355 \mathrm{~nm}, 387 \mathrm{~nm}$ e $408 \mathrm{~nm}$ e TR $20-40$ para $607 \mathrm{~nm}$ e $660 \mathrm{~nm}$, todos fornecidos pela LICEL. Eles são registrados tanto no modo analógico como em contagens de fótons. Correções de ruído de fundo a corrente escura são aplicadas antes da análise.

$\mathrm{Na}$ aquisição de dados para este trabalho apenas o canal $355 \mathrm{~nm}$ foi utilizado, e correspondentes canais Raman para o vapor de água e nitrogênio. A razão para esta escolha é que neste comprimento de onda a transmissão atmosférica é superior, melhorando a razão sinal-ruído para os canais Raman. Os dados foram adquiridos durante a noite (das 21:00 
UTC às 01:00 UTC), e integrados a cada 5 minutos. A resolução espacial vertical é de 15 metros.

\section{2 - Modificações no antigo sistema LIDAR para medidas de vapor de água}

Durante os anos de 2010 e 2011 várias adaptações foram feitas ao sistema LIDAR para que ele fosse capaz de detectar o vapor de água atmosférico e adquirisse a configuração descrita na seção anterior. Uma primeira tentativa de medida de vapor de água foi feita em 2010 com a caixa de detecção que originalmente compunha o sistema (Figura 4.3). Essa caixa e detecção possuía três canais, o de detecção do sinal elástico em 355nm (segundo harmônico do laser), e os sinais Raman do nitrogênio (387nm) e do vapor de água (408nm). Dois divisores de feixe, o primeiro transmitindo em $\lambda>360 \mathrm{~nm}$ e o segundo transmitindo em $\lambda=387 \mathrm{~nm}$ e refletindo em $\lambda=408 \mathrm{~nm}$ e um espelho transmitindo em $\lambda=355 \mathrm{~nm}$ formavam a primeira configuração (Figura 4.3a). Após testes com a caixa e verificados problemas como penetração de luz externa e a pequena potência do sinal de vapor de água detectado. Os dois divisores de feixe foram então substituídos por apenas um que transmitia em $\lambda>360 \mathrm{~nm}$, e o canal de vapor de água foi inativado (figura 4.3b) Também verificou-se a necessidade da substituição do laser para aumentar a energia do feixe emitido.
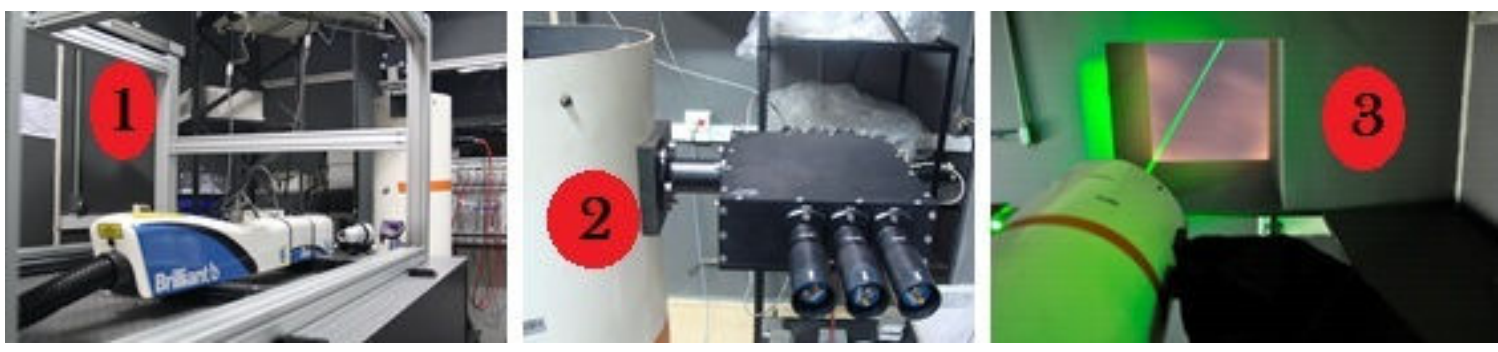

Figura 4.2 - 1) Módulo transmissor do sistema MSP-Lidar1, 2) Módulo receptor do sistema MSP-Lidar composto por um Telescópio Newtoniano, a caixa de detecção de sinal composta por 6 tubos fotomultiplicadores e filtros espectrais, 3) Visão do teto do laboratório com a emissão do feixe nos três comprimentos de onda, com a cor verde dada pelo segundo harmônico em 532nm.

O sistema passou então por uma remodelação, (processo FAPESP 2009/16001-0), compreendendo: a) substituição do laser, que era um laser comercial Brillant Quantel $\mathrm{Nd}$ :YAG, possuindo um comprimento de onda fundamental de $1064 \mathrm{~nm}$, com geradores de segundo e terceiro harmônicos, $532 \mathrm{~nm}$ e $355 \mathrm{~nm}$ respectivamente, funcionando a uma taxa de repetição de $20 \mathrm{~Hz}$. A energia de saída por pulso era de $100 \mathrm{~mJ}$ para o comprimento de 
onda de 532nm e 40mJ para 355nm. O novo laser é um laser comercial Nd-YAG da Quantel, modelo Brillant B, com um comprimento de onda fundamental de $1064 \mathrm{~nm}$, e com geração de segundo harmônico em $532 \mathrm{~nm}$ e terceiro harmônico em $355 \mathrm{~nm}$, respectivamente, a uma taxa de repetição de $10 \mathrm{~Hz}$. A energia de saída por pulso é de $850 \mathrm{~mJ}$ para $1.064 \mathrm{~nm}, 400 \mathrm{~mJ}$ para $532 \mathrm{~nm}$ e $230 \mathrm{~mJ}$ para $355 \mathrm{~nm}$; b) substituição do sistema de detecção, descrito mais detalhadamente na seção 4.2.1

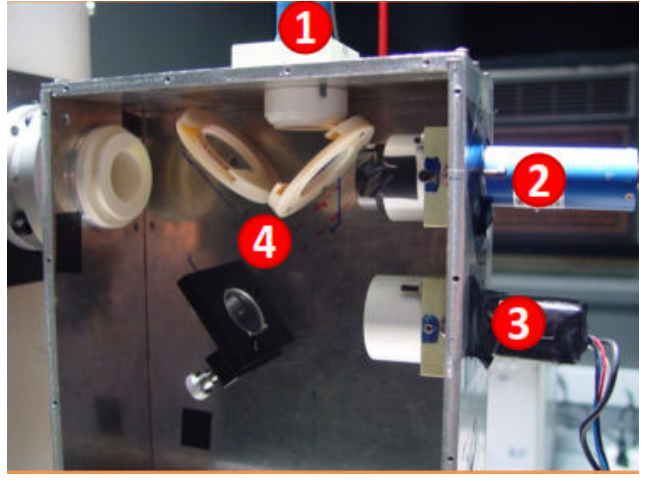

a)

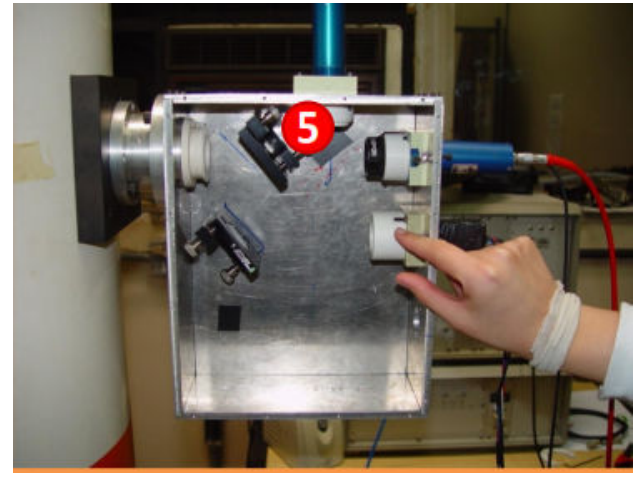

b)

Figura 4.3 - a) Antiga caixa de detecção do LIDAR, com três canais, mostrando o canal Raman de vapor de água em 408nm (1), o canal Raman do nitrogênio em 387nm (2) e o canal elástico 355nm (3), e os separadores de feixe e espelhos (4). b) Configuração da antiga caixa de detecção com o canal de vapor de água inativo (5)

\subsection{1 - O novo sistema de detecção}

O novo sistema de detecção (Figura 4.4) é um projeto da Raymetrics (http://www.raymetrics.gr/) executado pelo MetalCard (http://www.metalcad.com.br/). Ele é composto por seis tubos fotomultiplicadores para detecção dos sinais elásticos em $532 \mathrm{~nm}$ e $355 \mathrm{~nm}$, e os sinais Raman em $387 \mathrm{~nm}, 408 \mathrm{~nm}, 607 \mathrm{~nm}$ e $660 \mathrm{~nm}$. A caixa também contém os suportes para os filtros de interferência de banda estreita, lentes colimadoras e os separadores de feixe.

O sinal do laser retroespalhado na atmosfera retorna e é direcionado para o sistema de detecção, atingindo a íris da caixa de detecção, posicionada no foco do telescópio (Figura 4.5 -1). O primeiro divisor de feixes (Figura 4.5 - 2) direciona os comprimentos de onda acima de $510 \mathrm{~nm}$ para o ramo direito da caixa e os inferiores para o ramo esquerdo, onde são refletidos por um espelho (Figura 4.5 - 3). O lado direito da caixa então é responsável pela 
detecção dos sinais Raman em 607nm e em 660nm, assim como o elástico em 532nm, e o lado esquerdo da caixa é responsável pela detecção dos sinais Raman 387nm e 408nm, além do elástico em $355 \mathrm{~nm}$. O sinal elástico é removido primeiramente neste ramo para evitar fluorescência.

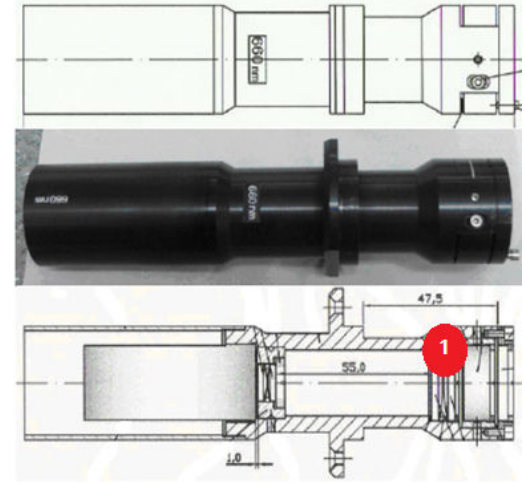

a)

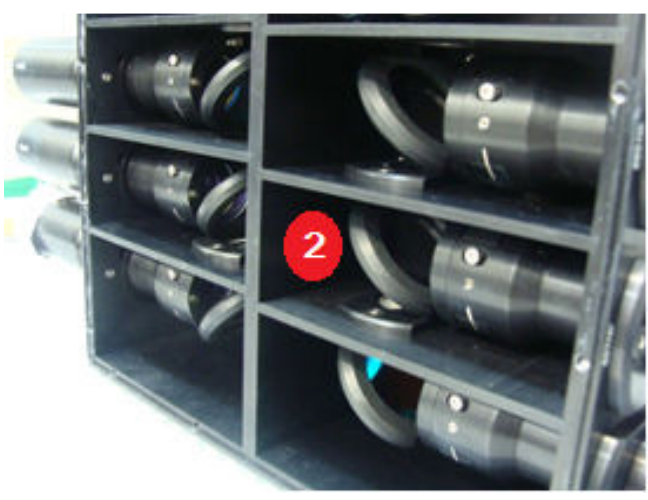

b)

Figura 4.4 - a) Esquema dos suportes para os tubos fotomultiplicadores, com espaço para o filtro de interferência. b) Visão próxima do suporte dos divisores (2).

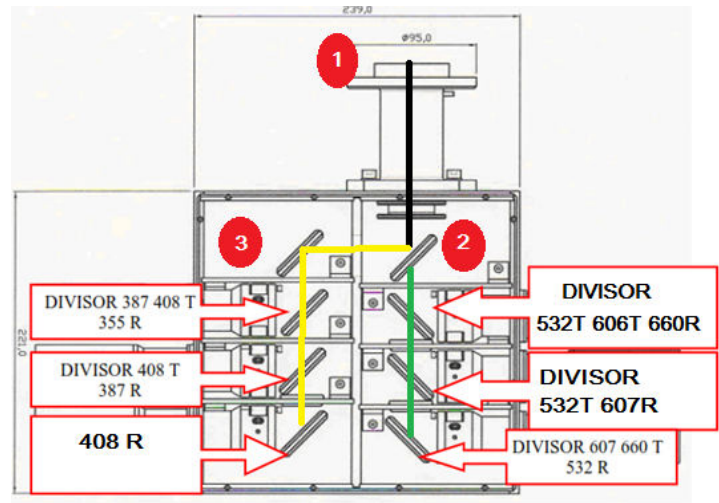

a)

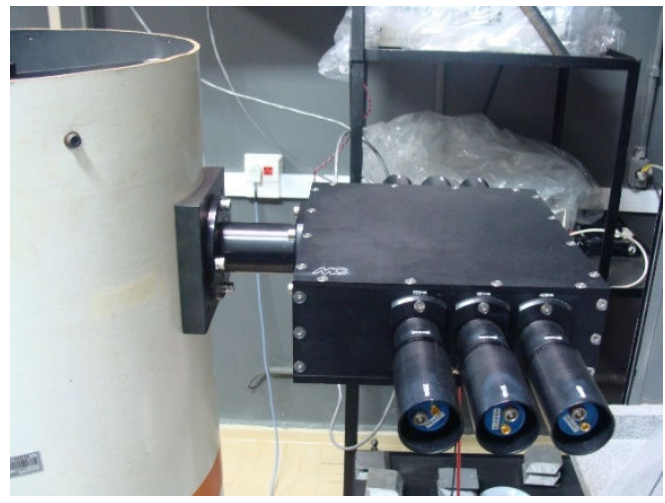

b)

Figura 4.5 - a) Esquema superior da caixa, mostrando a posição dos separadores de feixe (1). Iris da caixa (2). Divisor que reflete comprimentos de onda menores que $510 \mathrm{~nm}$. b) Caixa de detecção instalada no corpo do telescópio.

\section{3 - O sistema LIDAR Raman da Howard University (HURL)}

O HURL (Howard University Raman LIDAR) (Figura 4.6 e 4.7) está situado no campus da Universidade de Howard em Beltsville, Maryland, Estados Unidos, e foi projetado para realizar medidas de vapor de água e de aerossóis na atmosfera, tanto durante o dia como durante a noite. 
Este sistema LIDAR é composto de um laser Nd:YAG de três canais, modelo Continuum Lasers Precision 9500. Ele é capaz de operar no segundo, terceiro ou quarto harmônicos e é com mais frequência operado no terceiro harmônico $(354,7 \mathrm{~nm})$, fornecendo uma potência máxima de $14 \mathrm{~W}$ para esse comprimento de onda. A potência média de operação é de $7 \mathrm{~W}$. A divergência do feixe é de $0,5 \mathrm{mrad}$ e o perfil do feixe é próximo de uma gaussiana. O resfriamento é realizado por um sistema de refrigeração de $4 \mathrm{~kW}$ da Affinity. Filtros de banda estreita são utilizados para medir os sinais elásticos puros rotacionais Raman em 354,7nm, os sinais inelásticos Raman das moléculas de nitrogênio a $386,7 \mathrm{~nm}$, e das moléculas de vapor de água a 407,5nm.

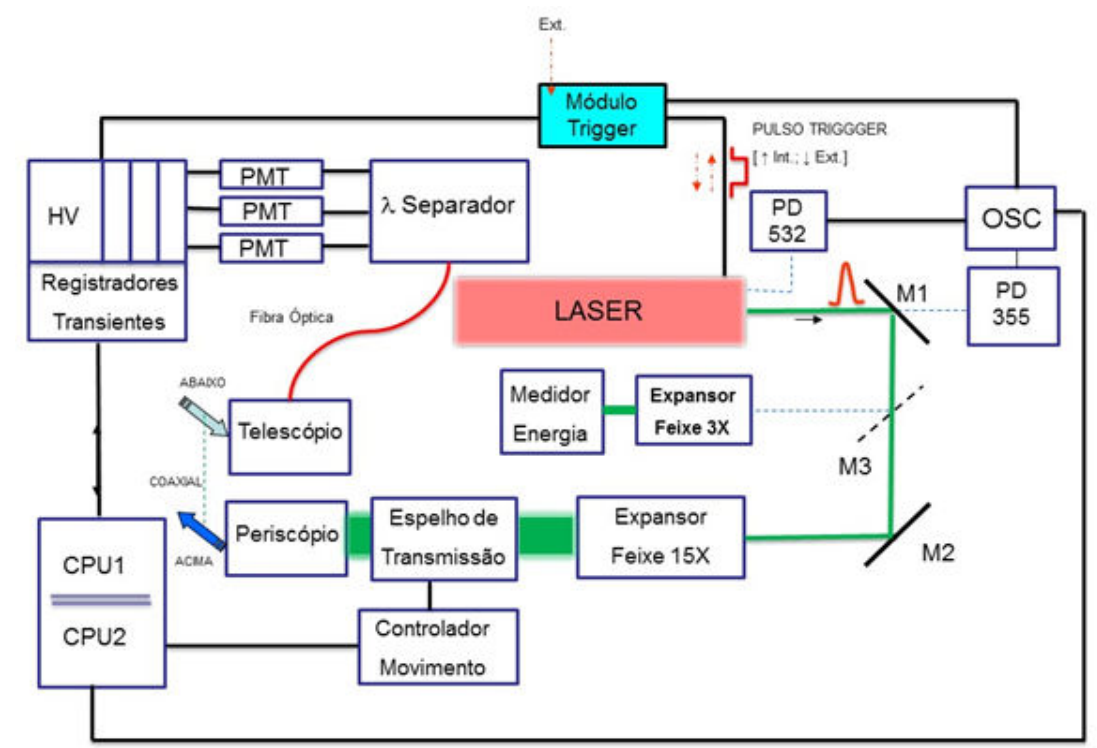

Figura 4.6 - Sistema LIDAR Raman da Howard University (HURL), mostrando a posição do laser e dos elementos ópticos. O espelho indicado em M3 é móvel, permitindo a realização de testes e medição de energia.

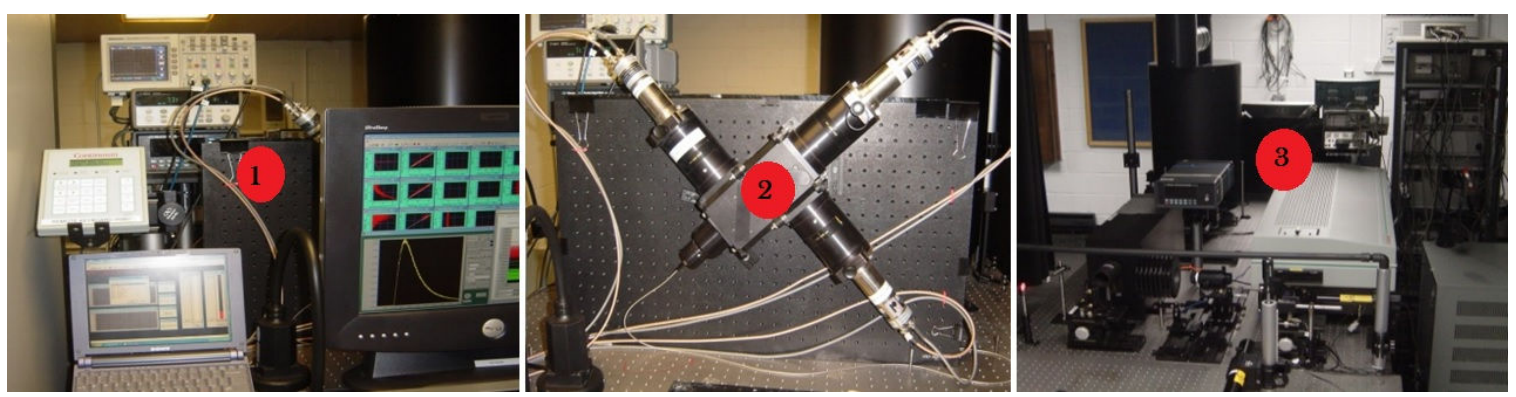

Figura 4.7 - Visão geral do sistema HURL mostrando: (1) Computadores de controle e osciloscópio. (2) Módulo separador do sinal de retorno e (3) Laser 
Uma das principais funções desse sistema é caracterizar a distribuição temporal e vertical do vapor de água e processos dinâmicos na camada limite para avaliação de modelos de mesoscala (Venable, 2011).

Tabela 2 - Descrição das principais características e componentes do Sistema HURL

\begin{tabular}{|c|c|}
\hline Característica & Descrição \\
\hline Geometria & Coaxial com o periscópio, apontado para o zênite. \\
\hline Laser & $\begin{array}{l}\text { Continuum Modelo } 9500 ; 3^{\circ} \text { harmônico do } \mathrm{Nd} \text { : YAG, } 354.7 \mathrm{~nm} \text {, taxa de repetição } \\
\text { de } 30 \mathrm{~Hz} \text {, divergência de } 0.5 \mathrm{mrad} \text { na saída do feixe, diâmetro do laser: } 9.5 \mathrm{~mm} \text {, } \\
\text { energia de } 350 \mathrm{~mJ} \text { por pulso. }\end{array}$ \\
\hline Telescópio & $\begin{array}{l}\text { Diâmetro 400mm, f\# 2.3, Distância Focal Efetiva 920mm, parabólico, Campo } \\
\text { Visual nominal } 250 \mathrm{mrad} \text {; Diâmetro de Abertura 230mm. }\end{array}$ \\
\hline Expansor de Feixe & $\begin{array}{l}15 \mathrm{x} \text {, difração limitada a } 25.4 \mathrm{~mm} \text { de diâmetro, lentes de entrada com } 500 \mathrm{~mm} \text { de } \\
\text { distância focal e duas lentes de saída com } 150 \mathrm{~mm} \text { de diâmetro, cada uma com } \\
1000 \mathrm{~mm} \text { de distância focal. }\end{array}$ \\
\hline $\begin{array}{l}\text { Módulo de } \\
\text { separação }\end{array}$ & $\begin{array}{l}\text { Sistema de } 3 \text { canais com filtros de interferência } 354.7 \mathrm{~nm}, 386.7 \mathrm{~nm} \text {, and } 407.5 \\
\mathrm{~nm} \text {, Lentes colimadoras: 2-Melles LQF066, 50mm de diâmetro. Filtros de Banda } \\
\text { Estreita } \sim 0.25 \mathrm{~nm}, \mathrm{~T} \sim 40 \% \text {, Beam Splitters: } \mathrm{T}>90 \% 380-420, \mathrm{R}>99 \% \text { off band; } \\
\mathrm{T}>90 \% 405, \mathrm{R}>99 \% 387 \mathrm{~nm}\end{array}$ \\
\hline PMT & Hamamatsu R1924P, 20mm de diâmetro \\
\hline $\begin{array}{l}\text { Softwares e } \\
\text { Aplicativos }\end{array}$ & $\begin{array}{l}\text { Licel/LabView Control Package via PCI-DIO32HS card; rotinas de análise de } \\
\text { dados em MATHEMATICA, HTBasic }\end{array}$ \\
\hline
\end{tabular}

O sistema de aquisição de dados consiste em um registrador transiente ótico da LICEL Corporation, que é capaz de registrar aquisições simultâneas de sinal analógico e modo contagem de fótons (PC). Uma vez que não linearidades podem ser significantes em certas taxas de contagem de fótons, a detecção combinada de contagem analógica - contador de fótons - pode aumentar o intervalo dinâmico significativamente. O sistema inteiro é controlado via uma placa PCI-DIO32HS de Interface Labview ${ }^{\circledR}$ (http://www.ni.com/labview/). Um software foi desenvolvido como parte deste trabalho em MATHEMATICA $^{\circledR}$ (http://www.wolfram.com/) para subtração de ruído de fundo e corrente escura, correção da função de overlap e correção dos efeitos da temperatura (efeitos estes não discutidos neste trabalho). Essa rotina também realiza o cálculo da ASR e da RMVA. 


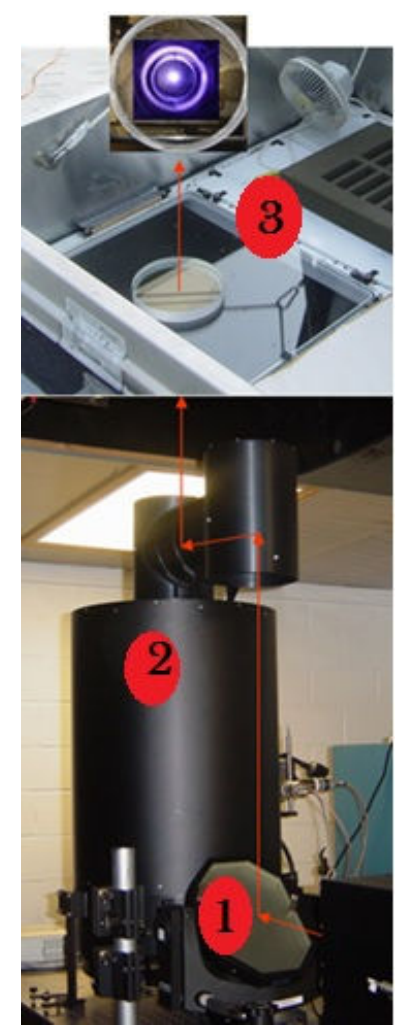

Figura 4.8 - Composição mostrando o espelho de transmissão (1), o corpo do telescópio (2) e a posição da janela de Starphire com a abertura de quartzo (3).

\section{4 - Radiossondas}

Uma radiossonda é um conjunto de equipamentos e sensores transportado por balões meteorológicos, os quais medem vários parâmetros atmosféricos e os transmitem a um aparelho receptor fixo. As radiossondas operam nas frequências de rádio de $403 \mathrm{MHz}$ ou $1680 \mathrm{MHz}$ e ambas as frequências podem ser ajustadas ligeiramente para mais ou para menos caso seja necessário.

Um balão de borracha ou látex é inflado com hélio ou hidrogênio e carrega a radiossonda na atmosfera. A máxima altitude alcançada é determinada pelo diâmetro e pela espessura do balão, que termina por romper-se. A maioria das radiossondas possuiu um pequeno paraquedas para amortecer a queda e uma etiqueta contendo informações para devolução do dispositivo, caso seja encontrado (o que é bastante raro, cerca de $15 \%$ dos dispositivos comuns são encontrados, segundo informações do NOAA (http://www.noaa.gov/). É possível ainda rastrear a posição das radiossondas usando um radar. O peso típico de uma radiossonda completa é $250 \mathrm{~g}$. Algumas radiossondas são 
carregadas em aviões e soltas ao invés de serem transportadas por balões. Essas radiossondas são chamadas de dropsondes.

As radiossondagens modernas se comunicam com um computador que armazena as variáveis em tempo real. Essas variáveis incluem: tempo de registro do dado, pressão, temperatura, temperatura de ponto de orvalho (dewpoint), velocidade do vento, altura, umidade relativa, razão de mistura de vapor de água, latitude e longitude, entre outros. Os dados coletados variam entre os modelos disponíveis no mercado.

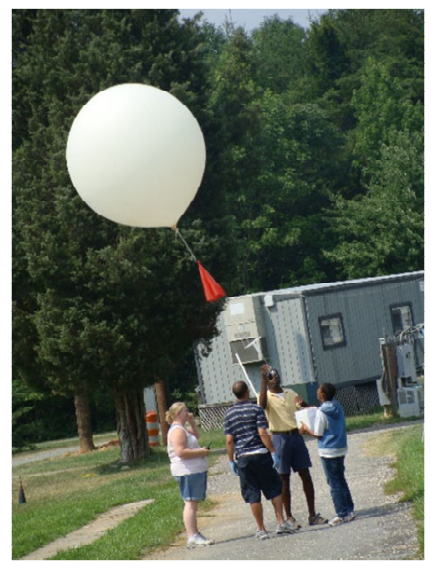

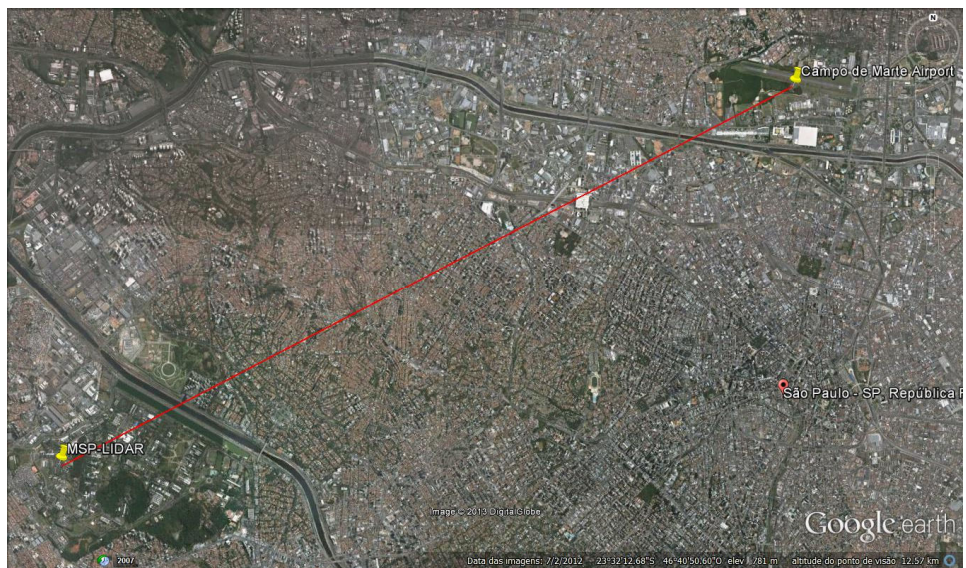

b

Figura 4.9 - a) Lançamento de uma radiossonda diurna no Campus de Pesquisas Atmosféricas da Howard University em Belltsville. b) Posição relativa entre o MSP-LIDAR1 e as radiossondagens liberadas no Campo de Marte

As radiossondas utilizadas neste trabalho para os dados de Washington-DC são do tipo Vaisala RS92 (http://www.vaisala.com) que operam em $400 \mathrm{MHz}$ ou $1680 \mathrm{MHz}$ dependendo do modelo. Em particular, foi utilizado o modelo RS92-SGP, que tem informações contínuas sobre velocidade do vento em alta resolução. Foram utilizadas com o propósito de calibração e fornecimento de parâmetros atmosféricos, como pressão e temperatura. As radiossondas utilizadas em Washington-DC foram lançadas no mesmo local do HURL e as que foram utilizadas em São Paulo são liberadas duas vezes ao dia (12UTC e 00UTC) no aeroporto Campo de Marte, distante $12 \mathrm{~km}$ do MSP-LIDAR1. 
Tabela 3 - Principais características da radiossonda RS92-SGP usadas em Washington-DC

\begin{tabular}{c|c}
\hline \hline Peso & $<90 \mathrm{~g}$ \\
\hline Tamanho & $94 \mathrm{~mm} \times 94 \mathrm{~mm}$ x 60mm \\
\hline Bateria & Dry Lithium \\
\hline Frequência & $<20 \mathrm{kHz}$ \\
\hline Desvio na frequência & $+/-5 \mathrm{kHz}$ \\
\hline Resulução na temperatura & $0.1^{\circ} \mathrm{C}$ \\
\hline Acurácia na temperatura & $<0.2^{\circ} \mathrm{C}$ \\
\hline Resolução na umidade & $1 \%$ \\
\hline Acurácia na umidade & $<5 \%$ \\
\hline Acurácia na pressão & $<1 \mathrm{hPa}$ \\
\hline Acurácia na altura geopotencial & $<20 \mathrm{~m}$ \\
\hline Acurácia na velocidade do vento & $<0.2 \mathrm{~m} / \mathrm{s}$ \\
\hline Acurácia na posição horizontal & $<5 \mathrm{~m}$ \\
\hline \hline
\end{tabular}




\section{1- Campanhas de aquisição de dados}

\subsection{1 - NASA DISCOVER-AQ}

DISCOVER-AQ (Deriving Information on Surface conditions from Column and Vertically Resolved Observations Relevant to Air Quality) é um experimento conduzido pela NASA que empregou vários instrumentos a bordo de dois aviões para realizar medidas de gases e material particulado em áreas metropolitanas em várias cidades da costa leste dos Estados Unidos. Espera-se também que o experimento contribua para aumentar o entendimento de como o programa de monitoramento da qualidade do ar desenvolvido pela EPA (United States Environmental Protection Agency) poderia ser utilizado para melhorar observações via satélite, contribuindo para previsão da qualidade do ar, melhor determinação de fontes de poluentes e flutuações nos níveis de emissão.

O primeiro seguimento do projeto foi o de coleta de dados, ocorrido ente 1 a 31 de julho de 2011, quando dois aviões sobrevoaram simultaneamente o corredor interestadual 95 entre Washington e Baltimore, coletando dados de ozônio, dióxido de nitrogênio, formaldeído, aerossóis e dióxido de enxofre (figura 5.1).

O primeiro avião voou a aproximadamente 8000 metros e usou tecnologia de sensoriamento remoto para obter amostras de ar da coluna abaixo dele. O outro avião voou a aproximadamente 300 metros coletando amostras de ar nesta altitude. Também realizou vôos em espiral, desde 1500 metros até 300 metros, sobre regiões monitoradas em terra pela EPA, pelo Departamento de Meio Ambiente de Maryland e por várias instituições acadêmicas, incluindo a Howard University. O propósito foi obter um perfil vertical de medidas de poluentes que será utilizado para determinar as ligações entre a poluição medida em superfície e a coluna medida pelo avião.

Os aviões - NASA Langley King Air B-200 e NASA P-3B — fizeram 20 vôos em julho, cada um com duração de 8 horas. Como o tempo aberto foi necessário às medidas, cada vôo foi agendado com 24 horas de antecedência. 
Durante os vôos, o sistema HURL permaneceu em operação contínua, nos dias 2, 3, $5,10,11,12,14,16,17,18,20,21,22,23,24,26,27,28,29,30$ de julho de 2011, por períodos variáveis. As operações foram determinadas pelo organograma dos vôos.

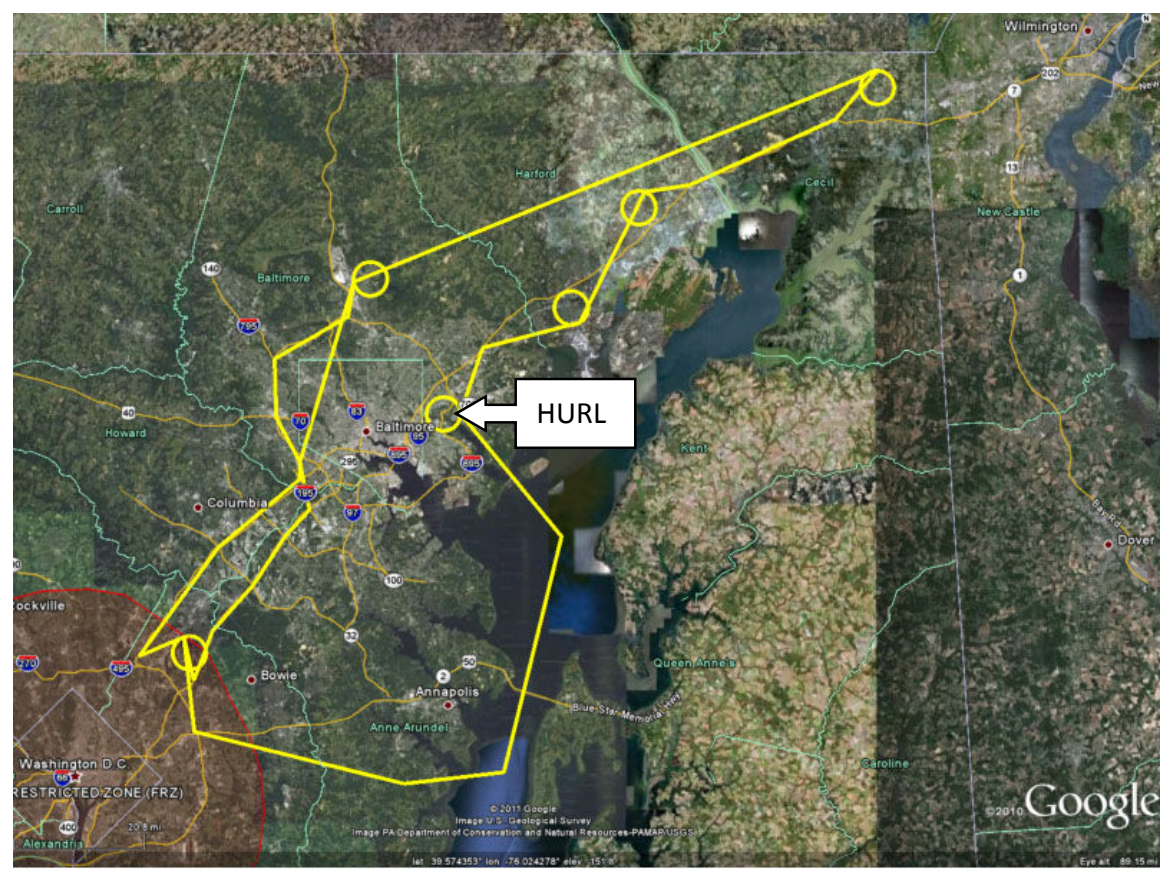

Figura 5.1 - Trajetória de vôo do avião P-3B e os locais onde havia vôo em espiral. O sistema HURL está localizado em um dos locais onde esses vôos eram realizados, na Universidade de Maryland, campus de Beltsville.

De posse dos dados, foram selecionados os dias que apresentavam as condições de interesse para o estudo da higroscopicidade de aerossóis, descritas na seção 5.2.

\subsection{2 - Campanhas de inverno 2012, 2013 e 2014}

Os meses de inverno em São Paulo são bastante secos, e, ao contrário dos meses de verão, nota-se uma menor nebulosidade e baixos índices pluviométricos. Essas características, associadas a uma alta concentração de aerossóis devido à baixa precipitação e à inversão térmica, tornam as condições apropriadas para o estudo da higroscopicidade com o LIDAR Raman, já que, apesar de nos meses de verão haver mais umidade, a alta nebulosidade e os altos índices de chuva tornam mais difíceis as ocorrências de dias propícios para as medidas com o instrumento, principalmente durante a noite.

Durante os meses de junho, julho, agosto e setembro de 2012, 2013 e 2014 foram realizadas campanhas de medida, objetivando: 1. Quantificar a razão de mistura de vapor de 
água utilizando o MSP-LIDAR 1; 2. Obter casos adequados para o estudo de higroscopicidade; 3. Realizar a calibração do sistema LIDAR em São Paulo utilizando o método comparativo de radiossondagem e calibração independente com lâmpada.

\section{2 - Escolha dos dados de interesse}

Como discutido na seção 3.3.3, espera-se que um aumento na umidade relativa acarrete um aumento no coeficiente de retroespalhamento de aerossóis, sendo que a relação entre esses dois fenômenos é determinada por características físico-químicas da população de aerossóis. Como o presente trabalho se concentra em uma área urbana, espera-se que o material particulado apresente um crescimento higroscópico intermediário entre aerossóis marinhos e aerossóis não higroscópicos, como os provenientes de queimada e os provenientes de poeira mineral.

A metodologia aqui adotada já foi antes descrita na literatura (Feingold e Grund, 1994; Feingold e Morley, 2003; Im e Saxena, 2001; Veselowski e Whiteman, 2009). Uma condição fundamental para o estudo da higroscopicidade é que a mesma mistura de aerossóis exista em todas as altitudes sendo consideradas. Isso é garantido se a atmosfera está bem misturada por convecção ou se aerossóis semelhantes estão sendo transportados para o sítio de medidas, o que pode ser garantido pela análise de retrotrajetória. Uma análise da razão de mistura de vapor de água é indicativa das condições de mistura da atmosfera, indicando uma atmosfera bem misturada caso seu valor seja constante com a altitude. O mesmo pode ser esperado se a temperatura potencial equivalente também é constante com a altitude.

Uma vez garantidas essas condições, faz-se uma análise dos valores de umidade relativa. Umidades relativas crescentes nas mesmas altitudes nas quais há constante razão de mistura de vapor de agua demonstram maior disponibilidade de água para o crescimento dos aerossóis. Logo, em uma atmosfera bem misturada, uma alteração do retroespalhamento obtido pelo LIDAR nesta região é indicativo de crescimento higroscópico.

A Figura 5.2 exemplifica as condições ideais obtidas para um dia de medidas em São Paulo, em 10 de setembro de 2012.

Durante o ano de 2012, houve medidas usando o MSP-LIDAR 1 em maio, julho, agosto, setembro e outubro. No ano de 2013, houve medida em fevereiro e de abril a dezembro. Em 2014, as medidas incluídas neste trabalho foram tomadas entre janeiro e 
julho. No total foram 63 dias de dados. Uma rotina foi construída em MATHEMATICA ${ }^{\circledR}$ para avaliar as condições de possível crescimento higroscópico utilizando exclusivamente os dados das radiossondagem lançadas à 00:00 UTC no Campo de Marte em São Paulo. Uma vez identificadas as condições a partir das radiossondas, os dados do LIDAR foram analisados em busca da variação crescente do retroespalhamento na mesma altitude nas quais as radiossondas apresentaram as condições favoráveis. Essa metodologia permitiu encontrar três casos para estudo do crescimento higroscópico, dois em 2013 e um em 2014. Esses dados estão apresentados no capítulo 6.

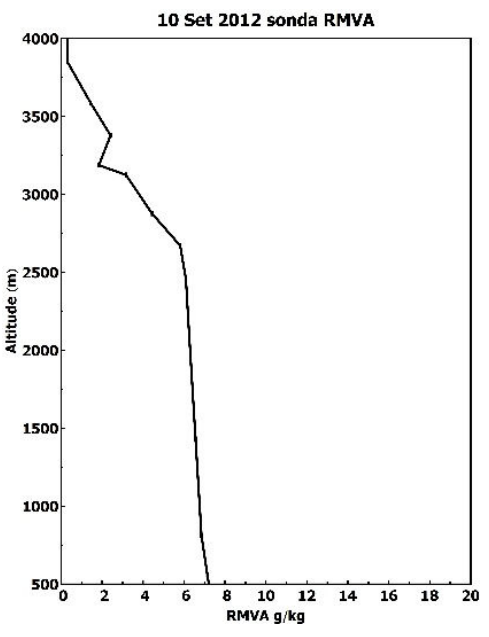

a)

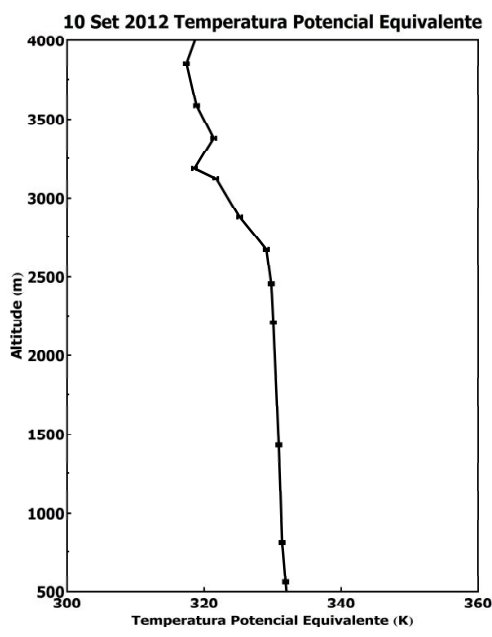

b)

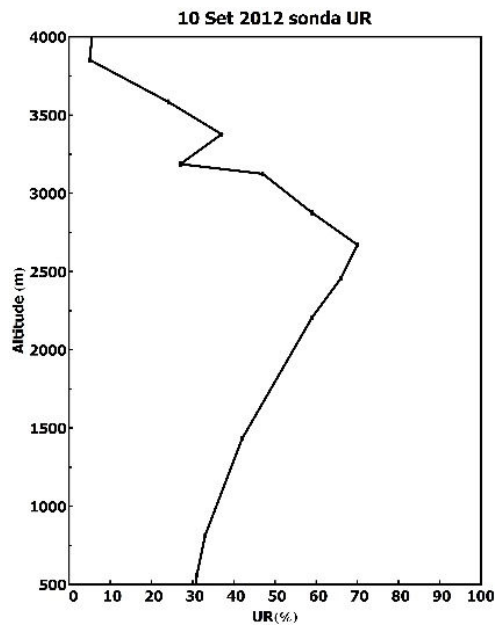

c)

Figura 5.2- Condições suficientes para uma atmosfera bem misturada, e para possível crescimento higroscópico, conforme dados de radiossondagem. a) Razão de mistura de vapor de água constante (em torno de $6 \mathrm{~g} / \mathrm{kg}$ ). b) Temperatura Potencial Equivalente constante (em torno de $330 \mathrm{~K}$ ). c) Umidade relativa crescente (entre $30 \%$ e $70 \%$ ).

A mesma metodologia foi aplicada na seleção dos dados do HURL, utilizando as radiossondagens lançadas diariamente e colocadas, com a diferença de que o retroespalhamento foi obtido a partir da razão de espalhamento de aerossóis (conforme descrito na seção 3.2.6), que é um produto da rotina de análise desenvolvida localmente na Universidade de Howard.

\section{3 - Metodologia de Calibração}

Como discutido na seção 3.2.3, os perfis de razão de mistura de vapor de água podem ser obtidos a partir da razão entre os canais de nitrogênio e vapor de água, a menos de uma constante, que pode ser obtida independentemente ou com o uso de um instrumento. 
Neste trabalho, utilizamos a segunda abordagem, comparando os perfis do LIDAR com radiossondagem. No caso do HURL em Washington DC, as radiossondagens foram lançadas no mesmo lugar onde se encontra o HURL, tanto durante o dia como durante a noite.

Quando os dados do HURL são tomados, é usada uma constante de calibração padrão, que precisa ser recalculada utilizando a radiossondagem. Para tanto, é necessário selecionar um conjunto de dados tomados simultaneamente à liberação da radiossondagem, dividir os dados do HURL pela calibração padrão (para obter novamente apenas a razão entre os sinais de retorno de vapor de água e de nitrogênio) e realizar uma regressão linear com os dados da radiossonda para obter a nova constante. Isso é feito no processamento posterior dos dados e é um dos produtos das rotinas de análise do HURL

Para a determinação da constante de calibração do MSP-LIDAR I, um algoritmo desenvolvido pelo Instituto Interuniversitario de Investigación del Sistema Tierra en Andalucía (IISTA-CEAMA), em Granada (Navas-Guzmán et al, 2014), foi utilizado. Este algoritmo perfaz uma regressão linear convencional pelo método dos mínimos quadrados. Os dados utilizados estão compreendidos entre $1 \mathrm{~km}$ e $3 \mathrm{~km}$ acima do nível do solo, região onde o vapor de água é mais abundante e os erros das radiossondagens são menores (Ferrare et al., 1995), além de garantir um melhor ajuste entre o LIDAR e a radiossonda em caso de desvio da radiossonda com a altitude e evitar os erros devidos ao overlap em altitudes inferiores.

Um procedimento iterativo dentro deste algoritmo procura pelo melhor ajuste, fazendo o ajuste inicial, e computando o desvio padrão. Todos os pontos que se encontram mais distantes que um desvio são eliminados. Um novo ajuste então é feito, repetindo o processo até que a inclinação da curva de ajuste varie menos que 1\%. Se o número de pontos restantes é menor que $50 \%$ do número inicial de pontos, então o ajuste é considerado inválido, e um novo limite em altitude pode ser definido.

Os valores das constantes obtidas e respectivos desvios são apresentados nos resultados, no capítulo 6 .

\section{4- Softwares e algoritmos de análise}




\subsection{1 - Obtenção da razão de mistura de vapor de água e a RL do MSP-LIDAR I}

A determinação da razão de mistura de vapor de água é feita a partir da razão entre as potências dos sinais dos canais Raman de nitrogênio e vapor de água, corrigidos para a diferente transmissão diferencial e a menos de uma constante, conforme descrito nas equações 3.2.16 e 3.2.17.

Para a obtenção da razão de mistura de vapor de água, do retroespalhamento e da razão LIDAR a partir dos dados do MSP-LIDAR I, um software desenvolvido pelo Physics Instrumentation Center, Moscou, Rússia foi utilizado. Este software possui uma interface interativa, e possibilita a obtenção de parâmetros ópticos, como coeficiente de extinção e retroespalhamento, com o uso de diferentes métodos, razão LIDAR, razão de mistura de vapor de água (com a opção de valores de pressão e temperatura a partir de modelos ou dados de radiossondagem), entre outras informações.

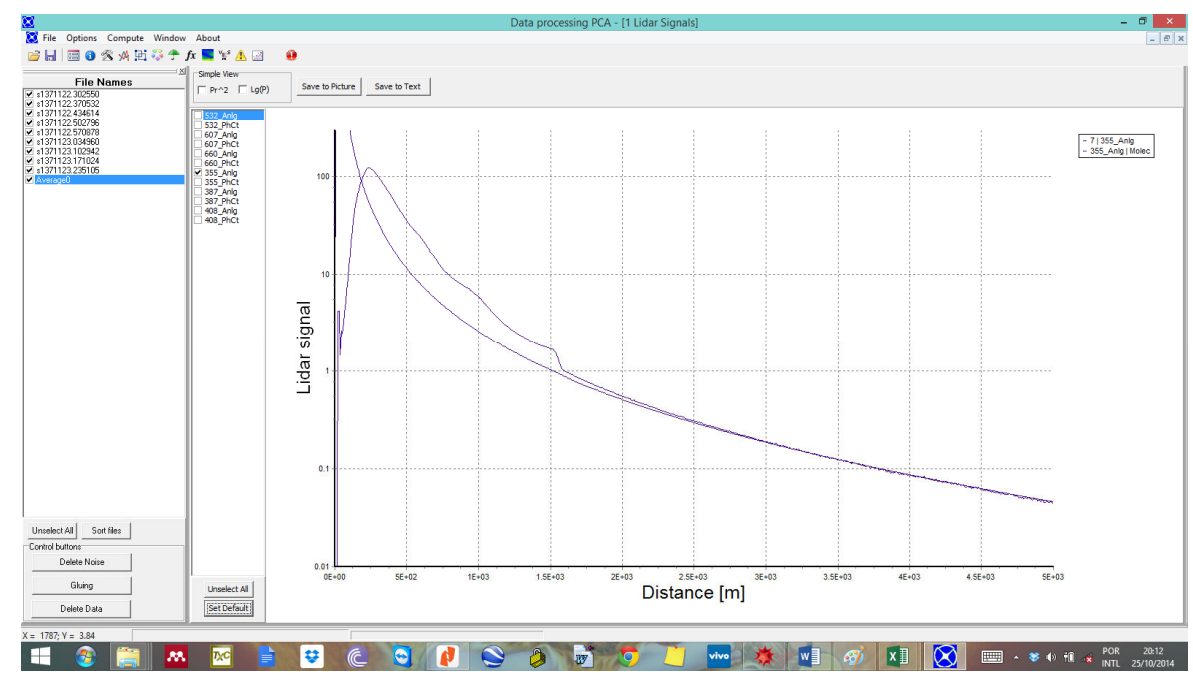

Figura 5.3 - Print da interface do software de análise, mostrando um sinal LIDAR característico em $355 \mathrm{~nm}$ (aerossóis) e a linha base do sinal molecular obtidos com a radiossondagem

A razão de LIDAR (RL) também pode ser obtida por meio deste programa. Essa grandeza é útil na estimativa do tipo de aerossol e também na homogeneidade da camada de aerossóis estudada com o LIDAR Raman (Müller et al, 2007).

\subsection{2 - O algoritmo HYGROW}


De posse dos dados de vapor de água e umidade relativa de ambos os sistemas LIDAR (MSP-LIDAR I e HURL), um algoritmo foi desenvolvido em MATHEMATICA ${ }^{\circledR}$ para chegar ao ajuste do fator de crescimento por higroscopicidade a partir dos dias de interesse. Esse algoritmo apresenta várias etapas, e está sumarizado nas subseções seguintes:

\section{a) Verificação das condições atmosféricas para identificação de crescimento higroscópico}

As radiossondagens lançadas às 00:00UTC em dias nos quais houve medidas noturnas obtidas pelo MSP-LIDAR I (63 casos) e as lançadas durante o DISCOVER-AQ (80 casos) foram verificadas para as condições de crescimento higroscópico por meio da avaliação dos perfis de razão de mistura de vapor de água, temperatura potencial equivalente e umidade relativa.

\section{b) A obtenção da umidade relativa a partir da razão de mistura de vapor de água}

A determinação da umidade relativa utilizando-se a razão de mistura de vapor de água é feita de posse de alguns parâmetros atmosféricos. Como descrito na 3.3.1, a umidade relativa é uma relação entre a pressão de vapor de água para determinada condição de pressão e temperatura atmosféricas e a pressão de vapor de saturação, definida como a máxima quantidade de vapor de água suportada por uma determinada massa de ar submetida às mesmas condições de pressão e temperatura.

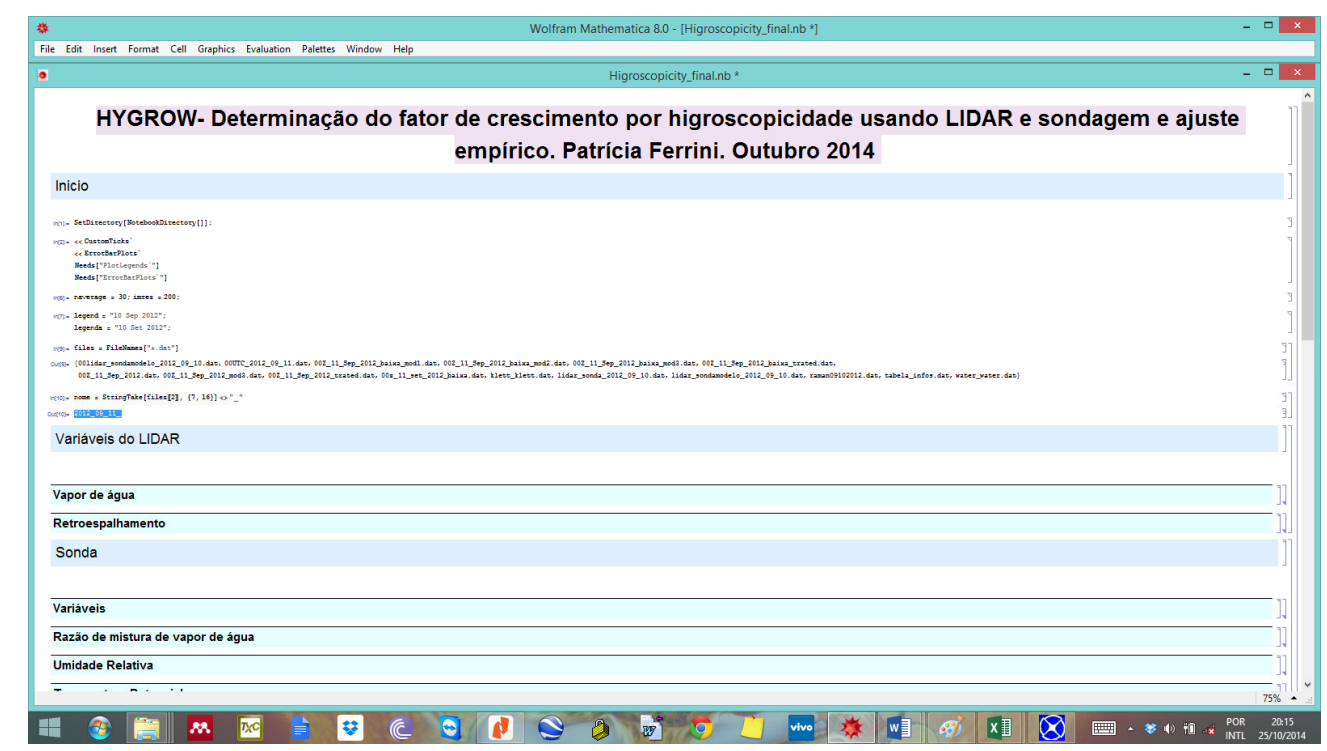

Figura 5.4 - Print da interface do algoritmo de análise HYGROW 
A pressão de vapor é definida por Rogers e Yau (1988):

$$
e(r)=\frac{p(r) m \mathrm{H}_{2} \mathrm{O}}{0.622+\mathrm{mH}_{2} \mathrm{O}}
$$

na qual $e(r)$ é a pressão de vapor, $p(r)$ é a pressão atmosférica que deve ser determinada a partir da radiossondagem ou de modelo e $\mathrm{mH}_{2} \mathrm{O}$ é a razão de mistura de vapor de água (obtido neste caso pelo LIDAR).

Algumas equações são comumente utilizadas na literatura para determinação da pressão de vapor de saturação da água. Neste trabalho, foram escolhidas duas equações para efeito de comparação. Primeiramente, a equação obtida nas tabelas meteorológicas Smithsonianas (TS) (List ,1951) utilizadas nos trabalhos de Mattis e Ansmann (2002):

$$
e_{w}(r)=6,107 \exp \left\{\frac{m a[T(r)-273]}{m b+[T(r)-273]}\right\}
$$

na qual $e_{w}(r)$ é a pressão de vapor de saturação, ma=17.84 ou 17.08 e mb $=245.4$ ou 234.2, para temperaturas acima e abaixo de 273K, respectivamente. (List ,1951) e T(z) é a temperatura em Kelvin obtida a partir das radiossondagem.

Uma outra formulação utilizada é a de Hyland e Wexler (1983) (HW), que segue abaixo:

$$
\begin{aligned}
& \log _{w}(r)=\frac{-0.5674535910^{4}}{T(r)}+0.63925247 \times 10^{1}-0.96778430 \times 10^{-2} T(r)+ \\
& 0.62215701 \times 10^{-6} T^{2}(r)+0.20747825 \times 10^{-8} T^{3}(r)- \\
& 0.94840240 \times 10^{-12} T^{4}(r)+0.41635019 \times 10^{1} \log (T)(r)
\end{aligned}
$$

Outras formulações existem na literatura e gráficos comparativos entre estas equações e a equação de Goff-Gratch (List, 1951) estão resumidas na Figura 5.5. Nota-se que há uma concordância entre elas para valores até $0^{\circ} \mathrm{C}$, a partir do qual pode ser encontrada grande divergência.

Como a altitude de seleção dos dados está abaixo de $2500 \mathrm{~m}$, observou-se a concordância entre as equações avaliadas. Utilizou-se neste trabalho a equação 5.4.3, e uma rotina foi desenvolvida em MATHEMATICA ${ }^{\circledR}$ para os cálculos. 
As equações envolvidas no cálculo do retroespalhamento por aerossóis a partir da ASR foram explicadas nas seções 3.2.6. Os dados do HURL (Figura 5.6) são analisados em uma rotina localmente desenvolvida, que não oferecem o retroespalhamento como produto. Então, para este trabalho, uma rotina foi desenvolvida em MATHEMATICA ${ }^{\circledR}$ para, a partir da ASR fornecida como produto do HURL obter o retroespalhamento.

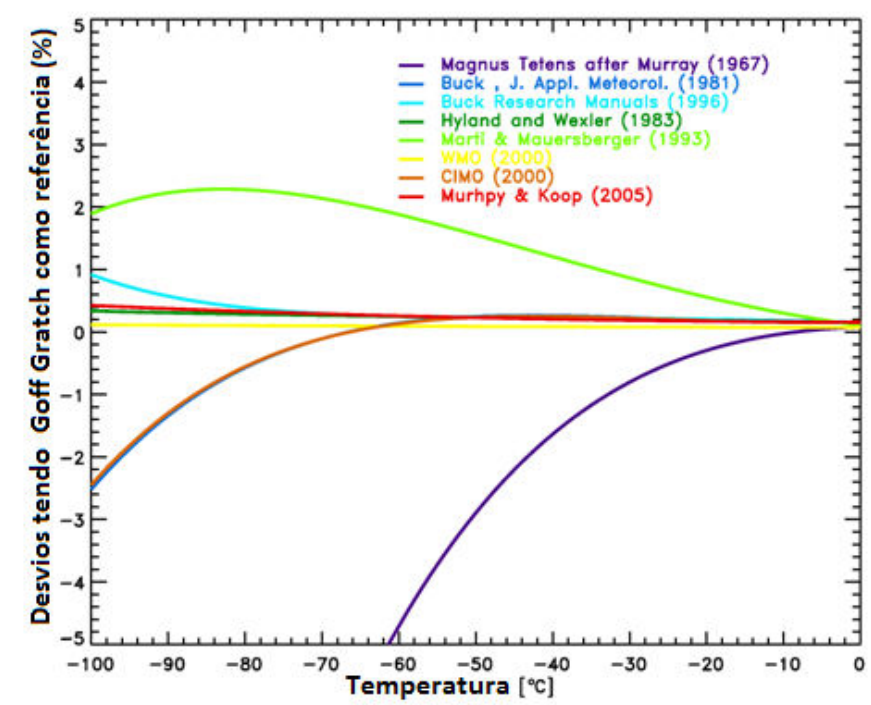

Figura 5.5 - Comparação entre as equações descritas na literatura para cálculo da pressão de vapor de saturação do vapor de água sobre a água líquida com a equação de Goff-Gratch. Fonte: http://128.138.136.5/ voemel/vp.html.
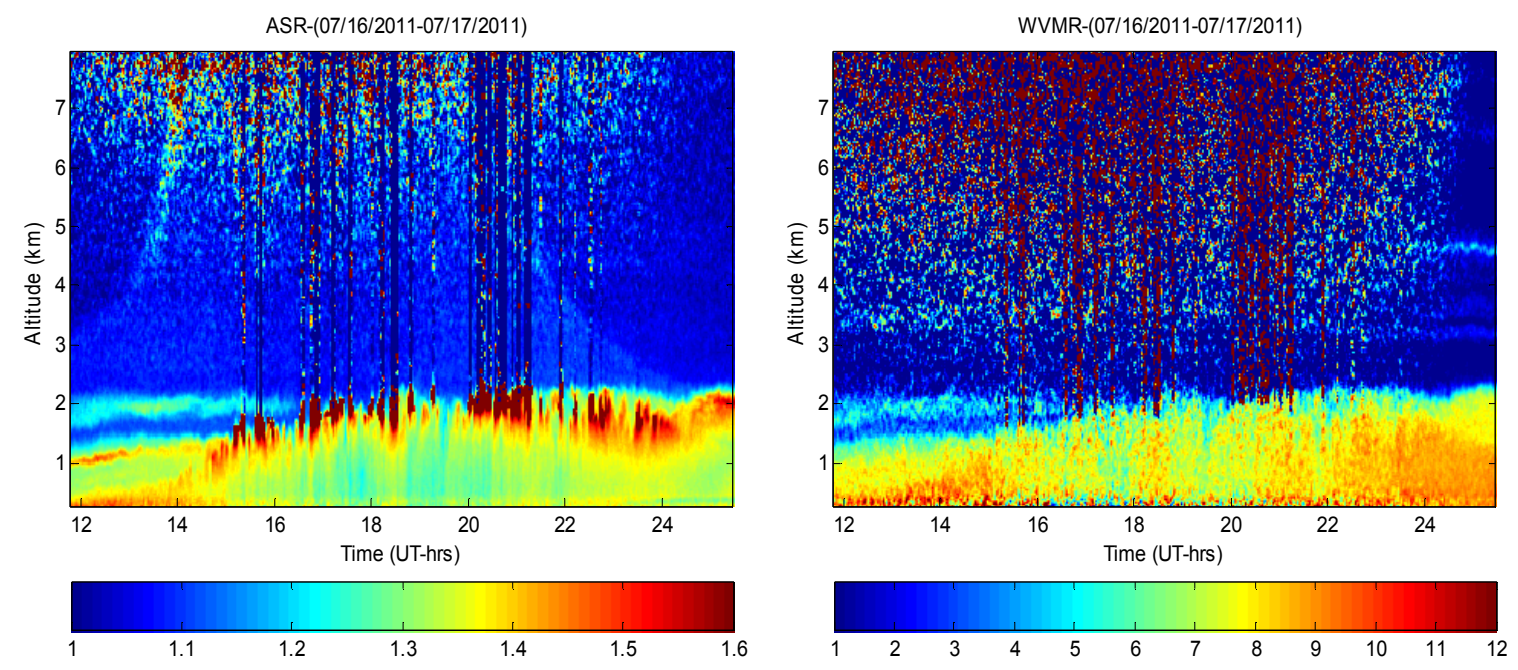

Figura 5.6 - Produtos do HURL: ASR (aerossol scattering ratio) e WVMR (water vapor mixing ratio) em 17/07/2011. Pode-se ver o aumento do retroespalhamento (esquerda) com atenuação do sinal elástico e atenuação do sinal Raman (direita). 
O fator de crescimento por higroscopicidade e o ajuste empírico foram definidos nas equações 3.3.4 e 3.3.5, repetidas aqui por motivos de esclarecimento:

$$
\begin{gathered}
f_{(R H)}=\frac{\beta i}{\beta r e f} \\
\frac{\beta i}{\beta r e f}=\left(\frac{1-R H}{1-R H_{\text {ref }}}\right)^{-\gamma}
\end{gathered}
$$

Para determinação de $f_{(R H)}$ e de $\gamma$, foram escolhidos os dias que apresentavam as condições de atmosfera bem misturada, com crescente umidade relativa e crescente retroespalhamento encontrado pelo LIDAR, num determinado intervalo de altitude. O coeficiente da equação de ajuste proposta por Hänel (1976), foi determinado para os valores de umidade relativa de referência encontrados para cada dia. Como o valor de $\gamma$ depende da umidade relativa de referência adotada, uma parametrização foi necessária, e escolhemos o valor de referência $\mathrm{RH}=40 \%$, para permitir a comparação com outros trabalhos encontrados na literatura. A parametrização é feita da seguinte forma: ajusta-se o valor de $\gamma$ com a umidade relativa de referência encontrada nos dados. A partir daí, calcula-se o valor de $f_{(R H)}$ com essa umidade relativa. Em sequência, todos os dados são divididos por este valor, e um novo $\gamma$ é ajustado. As diferenças entre os dados parametrizados e não parametrizados, bem como os diferentes valores de $\gamma$ ajustados estão discutidos nos resultados (capítulo 6).

\section{5 - O modelo HYSPLIT}

As retrotrajetórias calculadas neste trabalho foram feitas com o modelo HYSPLIT (HYbrid Single-Particle Lagrangian Integrated Trayectory) (Draxler e Rolph, 2003), desenvolvido em conjunto pela Agência Nacional de Administração Oceânica e Atmosférica dos Estados Unidos (NOAA) e Agência de Meteorologia da Austrália, que descreve, por simulação computacional, tanto as trajetórias de massas de ar quanto os processos de dispersão e deposição de partículas e trajetória de aerossóis, como poeira vulcânica. O modelo pode ser rodado em uma interface web interativa ou atravez de um executável que pode ser baixado diretamente do site (www.arl.noaa.gov/HYSPLIT). 
Neste trabalho, retrotajetórias de 48 horas de massas de ar chegando a São Paulo e a Beltsville em diferentes níveis de altitude de interesse foram computadas usando a interface web do modelo HYSPLIT_v4. A base de dados Global Data Assimilation System (GDAS) foi usada como base de dados meteorológica para todos os dias.

\section{6 - Considerações gerais sobre o conjunto de dados}

Os resultados apresentados no capítulo seguinte correspondem aos anos de 2013 a 2014 para os dados obtidos em São Paulo e ao período do Julho de 2011 para os dados obtidos em Washington DC. Ao todo, foram 63 dias de dados noturnos analisados em São Paulo, ao longo de três anos. Para os dados de Washington DC, foram analisados 80 casos, todos dentro do mesmo mês, e o critério de seleção em ambos os conjuntos de dados foi a detecção de potenciais casos de crescimento higroscópico, como descrito na seção 5.2. Além destes critérios, a qualidade dos dados de ambos os sistemas LIDAR foi avaliada (usando como critério o bom alinhamento do sistema e a potência de operação constante). Desta maneira, segundo o critério estabelecido, os casos encontrados onde a análise do crescimento higroscópico foi possível são raros, tanto em um local como em outro, resumindo-se a três casos em São Paulo e dois casos em Washington, que serão discutidos detalhadamente no capítulo 6.

Os perfis de vapor de água do MSP-LIDAR I foram obtidos utilizando o software descrito em 5.4, e o perfil de umidade relativa a partir da metodologia descrita em 5.4.2. Já para os dados do HURL, a razão de mistura de vapor de água é um produto do software de análise usado localmente (já usando a calibração obtida com as radiossondagens), assim como a razão de espalhamento de aerossóis (ASR). O perfil de retroespalhamento do HURL foi obtido a partir da ASR. Os dados da razão de mistura de vapor de água obtidos com o MSP-LIDAR I foram calibrados usando as radiossondagem, por meio do algoritmo iterativo de calibração descrito em 5.3

Para todos os dias analisados, retrotrajetórias de 48 horas foram calculadas usando o modelo HYSPLIT, nas respectivas altitudes de interesse e terminando no momento em que as radiossondagens foram lançadas. Esse modelo auxilia na avaliação da origem das massas de ar, podendo ser usado na inferência da possível composição dos aerossóis que transporta. 
Os perfis verticais de temperatura potencial equivalente e razão de mistura de vapor de água foram verificados para identificação da constância necessária para uma atmosfera bem misturada. Uma vez preenchidas as condições, o fator de crescimento por higroscopicidade foi calculado de acordo com a equação 3.3.4, e ajustados de acordo com a equação 3.3.5. Esses valores foram então comparados com os dados obtidos na literatura, principalmente com o valor obtido por Veselovski e Whiteman (2009) na costa Leste dos Estados Unidos, utilizando a extinção de aerossóis como parâmetro óptico. No estudo desenvolvido por Veselovski e Whiteman foi obtido o valor de $f_{\alpha}(90 \%)=5$, na presença de um aerossol continental típico, usando uma umidade relativa de referência de $60 \%$. Conforme já discutido, os valores de $\gamma$ dependem da composição química dos aerossóis, da distribuição de tamanho e também da umidade relativa de referência. Como além dos estudos feitos por Veselovski e Whiteman e Granados-Muñoz (2014), não existem muitos outros estudos feitos com LIDAR na avaliação da higroscopicidade de aerossóis publicados nos últimos anos, uma comparação se faz necessária com os dados obtidos a partir de estudos controlado em câmaras para poder contextualizar os resultados. Estes estudos estão baseados no coeficiente de espalhamento total dos aerossóis e não no coeficiente de retroespalhamento, como usado aqui, e frequentemente comparam os valores de $f(85 \%)$ e $f(40 \%)$ ou menor.

Objetivando comparar os resultados encontrados neste trabalho e os resultados encontrados na literatura, foi necessária uma parametrização. Primeiramente, o valor de $\gamma$ foi obtido no ajuste dos dados do fator de crescimento por higroscopicidade nas umidades relativas de referência, que variam de acordo com o dia estudado. Em sequência, o valor de $f_{\beta}(40 \%)$ foi obtido usando este valor de $\gamma$. Todos os valores do fator de crescimento por higroscopicidade para cada dia foram então divididos pelo valor de $f_{\beta}(40 \%)$ encontrado teoricamente, levando a novos valores do fator de crescimento. Utilizando estes novos valores, $\gamma$ foi novamente ajustado. Este valor final pode ser usado então para efeitos de comparação.

Quanto ao uso do coeficiente de extinção ou do coeficiente de retroespalhamento, fizemos uma avaliação da configuração óptica em ambos os sistemas LIDAR usados neste estudo. O HURL é um sistema LIDAR Raman projetado e otimizado para estudo de vapor de água, medida esta que é uma razão entre os canais de vapor de água e nitrogênio. Essa divisão faz com que os efeitos do overlap para ambos os canais acabem sendo compensados. 
Quando se olha apenas para o canal de aerossóis, os efeitos do overlap ficam evidentes, e no caso do sistema HURL, este overlap total está em cerca de 1500 metros. Já para o MSPLIDAR I este valor está em revisão. Isso faz com que os efeitos do overlap incompleto sejam muito grandes em altitudes menores, causando uma distorção nos valores obtidos nas propriedades ópticas, principalmente na extinção. Optamos então pelo uso do retroespalhamento em ambos os sistemas. Apesar de medirem propriedades ópticas diferentes, Feingold e Morley (2003) encontraram muito boa concordância entre os valores de $f_{\beta}$ e $f_{\alpha}$ em um intervalo de umidade relativa entre $85 \%$ e $95 \%$.

Para avaliação da incerteza em $\gamma$ foi feita uma análise de sensibilidade. Com a radiossondagem, usando 5\% UR de incerteza total dos valores de umidade relativa (variância fornecida pelo fabricante). Para os sistemas LIDAR, primeiramente foi calculada a incerteza no vapor de água, e depois propagada esta incerteza para a umidade relativa, levando a uma incerteza total de $10 \%$. Estes valores foram então utilizados para o cálculo da incerteza em $\gamma$

Para todos os dias analisados, as retrotrajetórias do modelo HYSPLIT foram traçadas tendo como referência as altitudes de interesse para cada dia, porém várias altitudes foram utilizadas levando às mesmas trajetórias, o que mostra uma origem homogênea dos aerossóis para os casos estudados. 


\section{6 - Resultados e Discussão}

\section{1 - Dados do MSP-LIDAR I}

Os dados Raman noturnos do MSP-LIDAR I vêm sendo obtidos desde junho de 2012. Após a modificação do sistema de detecção para que ele fosse capaz de detectar os sinais Raman de nitrogênio e vapor de água, testes de alinhamento e qualidade do sinal foram feitos. Os sinais Raman provenientes do comprimento de onda de 532nm $(607 \mathrm{~nm}$ para o nitrogênio e $660 \mathrm{~nm}$ para o vapor de água) têm menor transmissividade atmosférica quando comparados aos sinais provenientes de $355 \mathrm{~nm}$ (387nm para o nitrogênio e $407 \mathrm{~nm}$ para o vapor de água), e as fotomultiplicadoras que detectam os sinais na região do amarelo tiveram que ser substituídas, por modelos de maior eficiência quântica, em 2013. Mesmo com essa modificação, os sinais apresentam uma baixa relação sinal-ruído, de maneira que neste trabalho apenas os ramos no ultravioleta foram utilizados.

Para todos os dias de dados do MSP-LIDAR I foram utilizadas radiossondagem lançadas do campo de Marte a 00:00 UTC. Os dados foram tomados das 21:00 UTC à 01:00 UTC do dia subsequente. Para a análise, foi considerada a média dos dados tomados entre 00:00 UTC e 00:30 UTC, concomitantes ao lançamento da radiossondagem. Em conformidade com o descrito na metodologia, as condições atmosféricas medidas pelas radiossondagens foram avaliadas, em especial os parâmetros temperatura potencial equivalente, umidade relativa e razão de mistura de vapor de água. Os dados utilizados a partir das radiossondagens não possuem alta resolução espacial, já que não são os dados

crus, e sim os obtidos através da Universidade de Wyoming (http://weather.uwyo.edu/upperair/sounding.html), que possui os dados disponíveis apenas em certas altitudes, que variam de acordo com o dia estudado. Dados em alta resolução certamente seriam melhores para as análises, porém o lançamento das radiossondagens a partir do Campo de Marte está sob responsabilidade da Aeronáutica e os dados crus não estão disponíveis para a comunidade científica. A nomenclatura das radiossondas é feita seguindo o padrão ddmmaaaa e horário UTC, e portanto todas as radiossondagens utilizadas aqui recebem a data do dia seguinte ao dado tomado pelo LIDAR, à 00 UTC. 


\section{1 .1 - 03 de maio de 2013}

A avaliação dos dados da radiossondagem lançada em 04 de Maio de 2013 às 00 UTC mostra a presença de condições de crescimento higroscópico, como é possível observar na Figura 6.1. A faixa em destaque mostra a região onde foi possível observar melhor ajuste entre os dados da radiossondagem e do LIDAR (entre $862.5 \mathrm{~m}$ e $1627.5 \mathrm{~m}$ ) para a avaliação do crescimento higroscópico. Essa região foi escolhida por se observar um aumento do retroespalhamento do LIDAR, conforme mostrado na Figura 6.2 b. Para esse mesmo intervalo em altitude, nota-se um aumento da umidade relativa medida pela radiossondagem (Figura $6.1 \mathrm{c}$ ), entre $58 \%$ e $84 \%$. A temperatura potencial equivalente é constante e aproximadamente igual a 335K (Figura 6.1 b) na região de interesse, e a razão de mistura de vapor de água é constante e aproximadamente igual a 10g/kg (Figura 6.1 a).

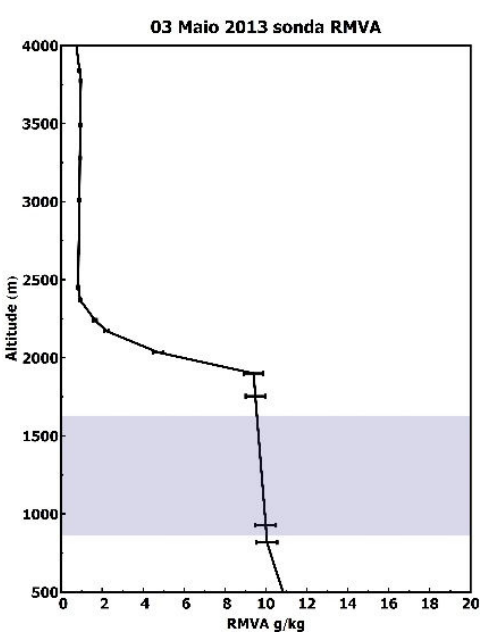

a)

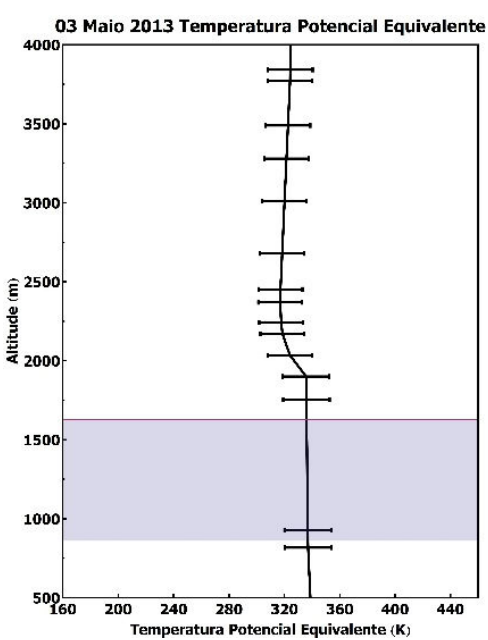

b)

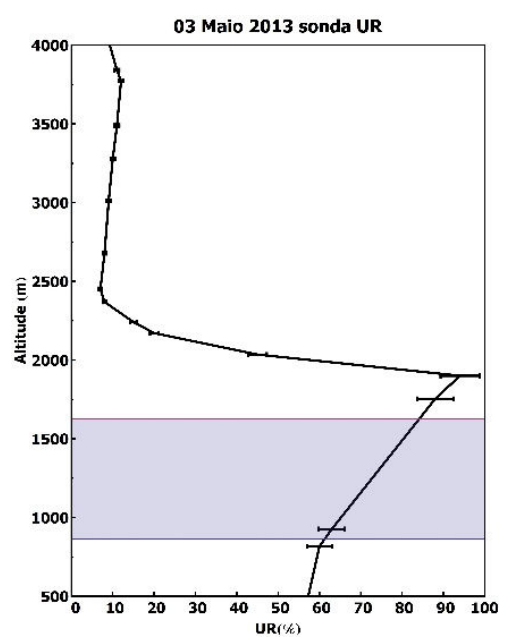

c)

Figura 6.1- Condições suficientes para uma atmosfera bem misturada, conforme dados de radiossondagem.

a) Razão de mistura de vapor de água constante (em torno de $10 \mathrm{~g} / \mathrm{kg}$ ). b) Temperatura Potencial Equivalente constante (em torno de $335 \mathrm{~K}$ ). c) Umidade relativa crescente (entre $58 \%$ e $84 \%$ ). A região em destaque compreende as altitudes entre $862.5 \mathrm{~m}$ e $1627.5 \mathrm{~m}$

A retrotrajetória de 48 horas obtida com o modelo HYSPLIT (Figura 6.2 a) mostra que as massas de ar na altitude de interesse têm origem mista entre continental limpo e marítimo, provavelmente ainda dentro da camada limite planetária. A variação no retroespalhamento obtido pelo LIDAR ficou no intervalo entre $0.00591 \backslash \mathrm{km} *$ sr e 0.0068 $1 \backslash \mathrm{km} * \mathrm{sr}(1,15$ vezes maior). 


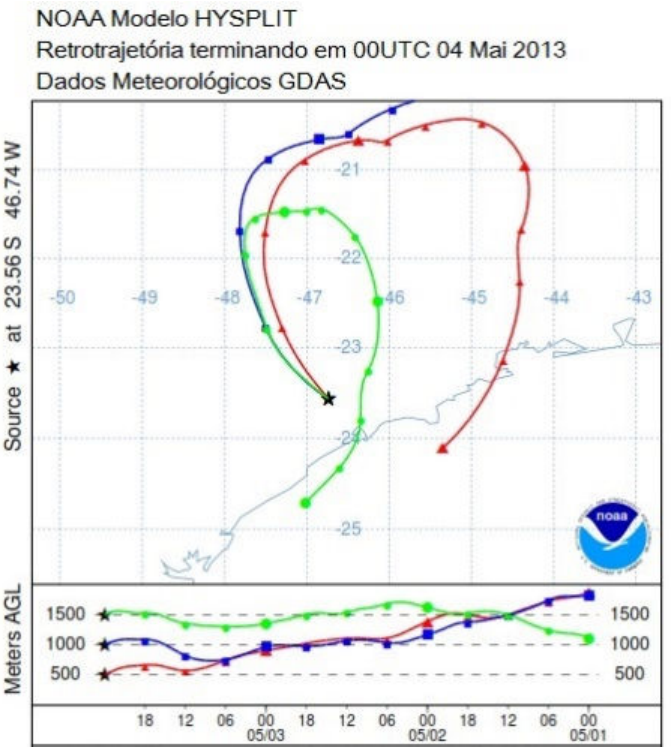

a)

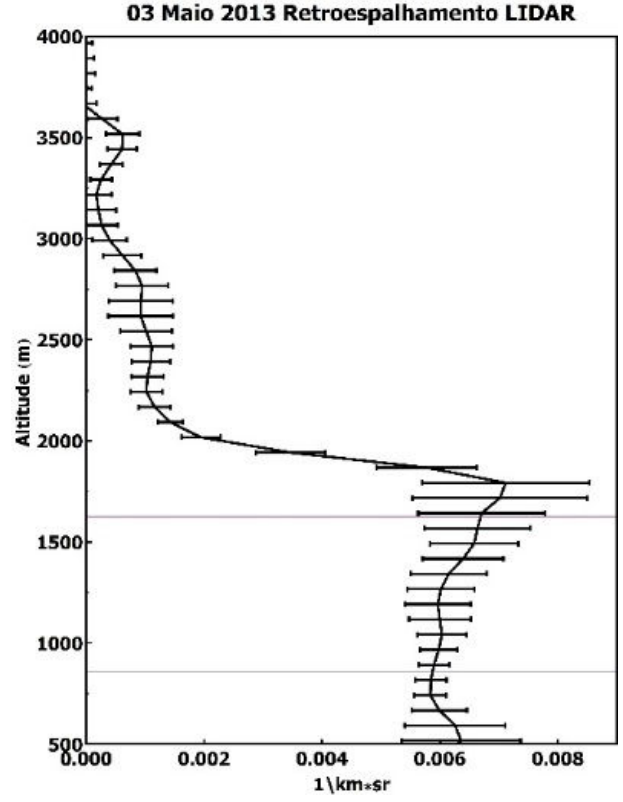

b)

Figura 6.2 - a) Retrotrajetória de 48 horas obtida com o modelo HYSPLIT, mostrando a origem continental limpa e marítima dos aerossóis. b) Retroespalhamento obtido com o LIDAR mostrando região onde há aumento do coeficiente de retroespalhamento, no intervalo entre $0.00591 \mathrm{kkm} * \mathrm{sr}$ e $0.00681 \backslash \mathrm{km} * \mathrm{sr}(1,15$ vezes maior). A região em destaque compreende as altitudes entre $862.5 \mathrm{~m}$ e $1627.5 \mathrm{~m}$

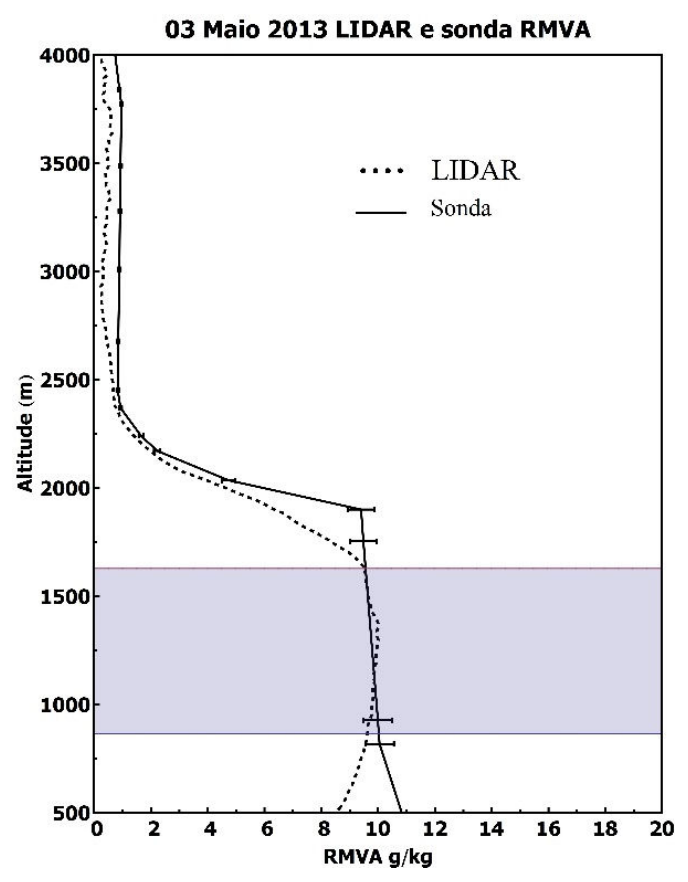

a)

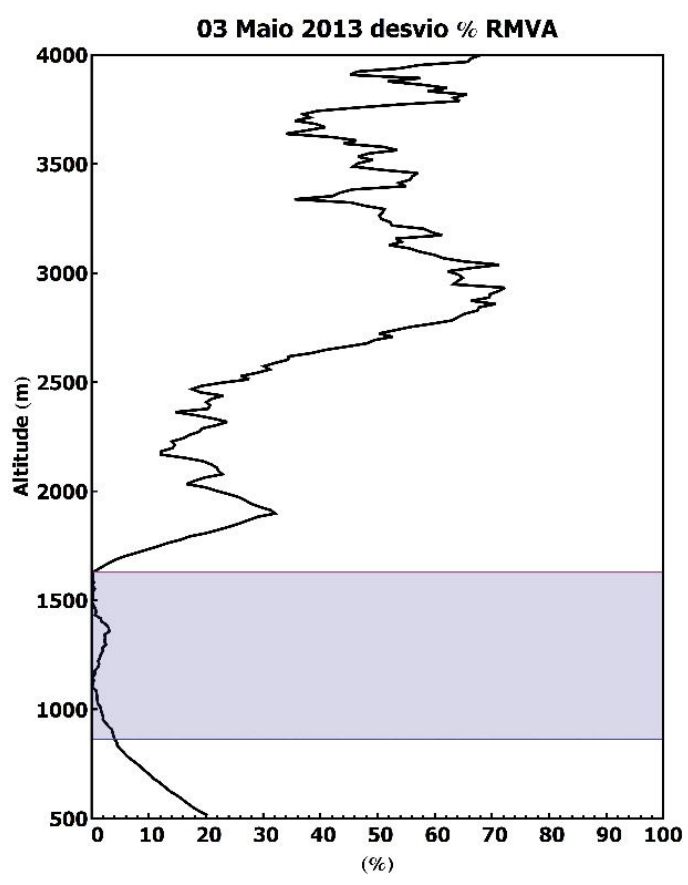

b)

Figura 6.3 - a) Comparação entre a razão de mistura de vapor de água obtida com a LIDAR e com a radiossondagem, após aplicada a constante de calibração. b) Perfil do desvio percentual da razão de mistura de vapor de água obtido com o LIDAR e com a radiossonda, mostrando que dentro da região de interesse essa variação é sempre menor que 5\%. 
A constante de calibração ajustada foi de $1.68 \pm 0.05$. O perfil da diferença percentual entre os valores para a razão de mistura de vapor de água obtidos pelo LIDAR e pela radiossondagem aparecem na Figura $6.3 \mathrm{~b}$, enquanto a figura $6.4 \mathrm{~b}$ mostra o mesmo desvio percentual obtido para a umidade relativa. Dentro da faixa de altitude de interesse são observados os menores desvios (menores que $5 \%$ ).

Apesar de haver um aumento do retroespalhamento e condições atmosféricas apropriadas até cerca de $1750 \mathrm{~m}$, a razão de mistura de vapor de água obtida com o LIDAR (Figura 6.4 a) cresce apenas até $1627.5 \mathrm{~m}$ e é a variável que define o limite em altitude nos quais os cálculos foram feitos.

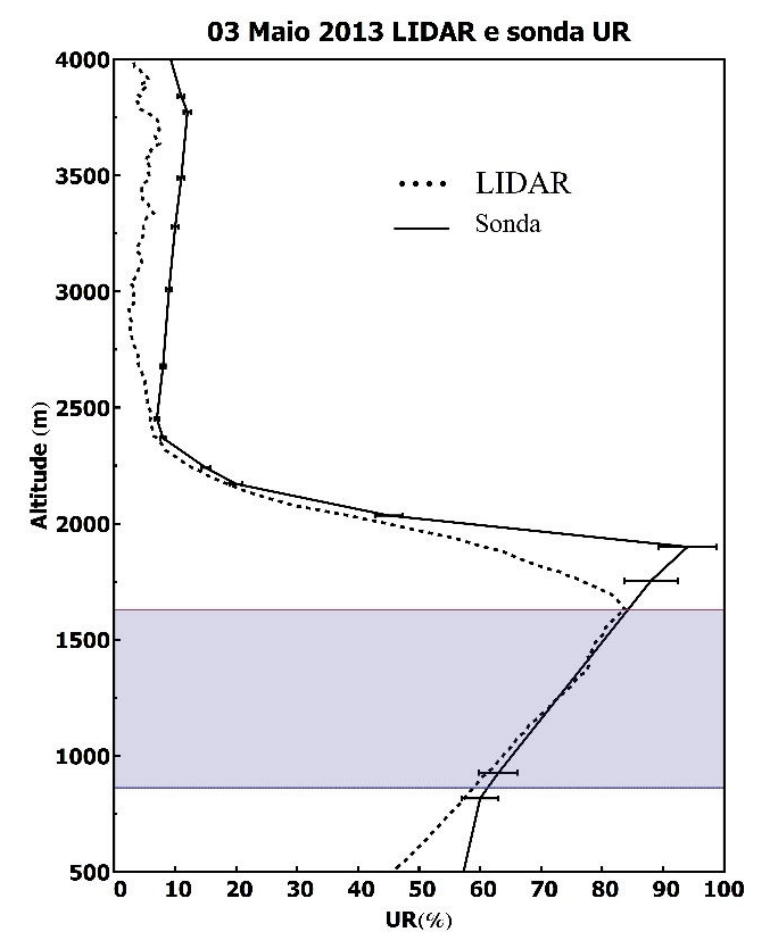

a)

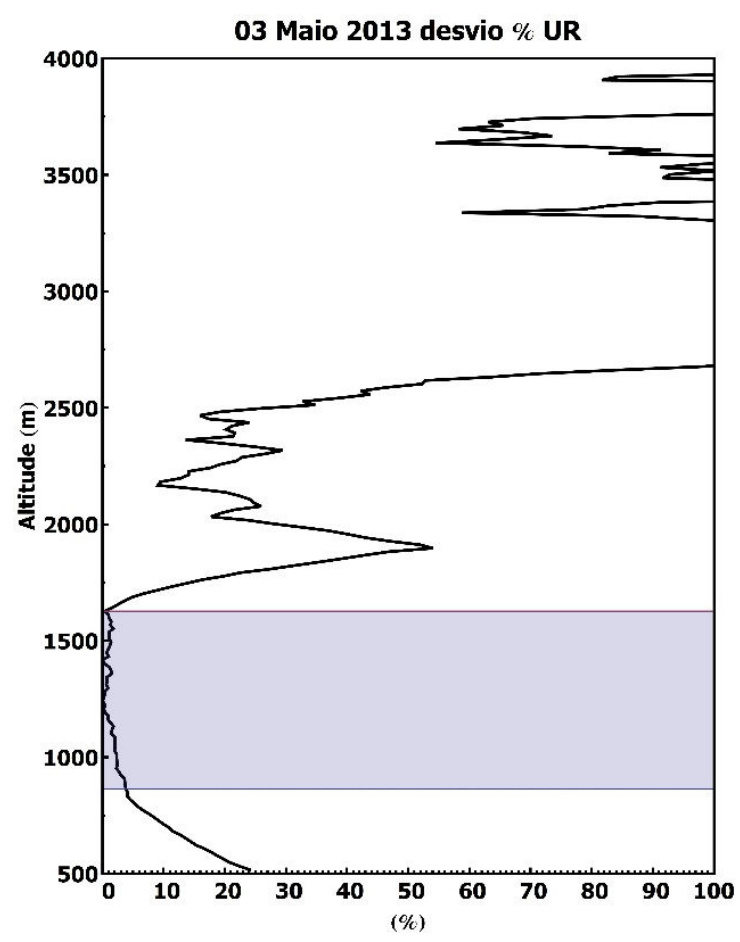

b)

Figura 6.4 - a) Comparação entre a umidade relativa obtida com o LIDAR e com a radiossondagem. Dentro da faixa de interesse para cálculo do crescimento higroscópico, a umidade relativa obtida com o LIDAR variou entre $58 \%$ e $84 \%$ e a obtida com a radiossonda variou entre $61 \%$ e $84 \%$. b) Perfil do desvio percentual da umidade relativa obtida com o LIDAR e com a radiossonda, mostrando que dentro da região de interesse essa variação é sempre menor que 5\%.

Após a identificação das condições necessárias para a atmosfera bem misturada e o retroespalhamento crescente obtido com o LIDAR, o fator de crescimento por higroscopicidade $f_{\beta}$ foi calculado de acordo com o descrito na equação 3.3.4. Os resultados foram então ajustados à curva descrita na equação 3.3.5 para obtenção do coeficiente $\gamma$. Após 
este ajuste, e objetivando comparar com outros trabalhos descritos na literatura, foi realizada a parametrização descrita na seção 5.4.2 d, tomando como referência o valor de $f_{\beta}(40 \%)$. Os umidogramas não parametrizado e o parametrizado aparecem na Figura 6.5. O $f_{\beta}(85 \%)$ foi evidenciado para comparação com os resultados encontrados na literatura.

A comparação dos valores obtidos para o MSP-LIDAR 1 com valores encontrados na literatura estão sumarizados na Tabela 04 e na Tabela 06.

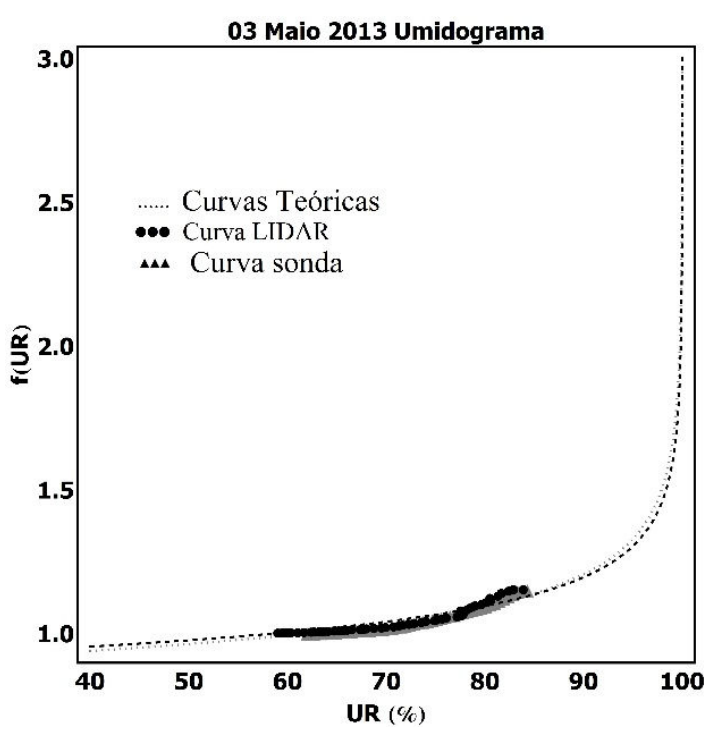

a) $\gamma_{\text {LIDAR }}=0.11 \pm 0.03, \gamma_{\text {radiossonda }}=0.14 \pm 0.02$

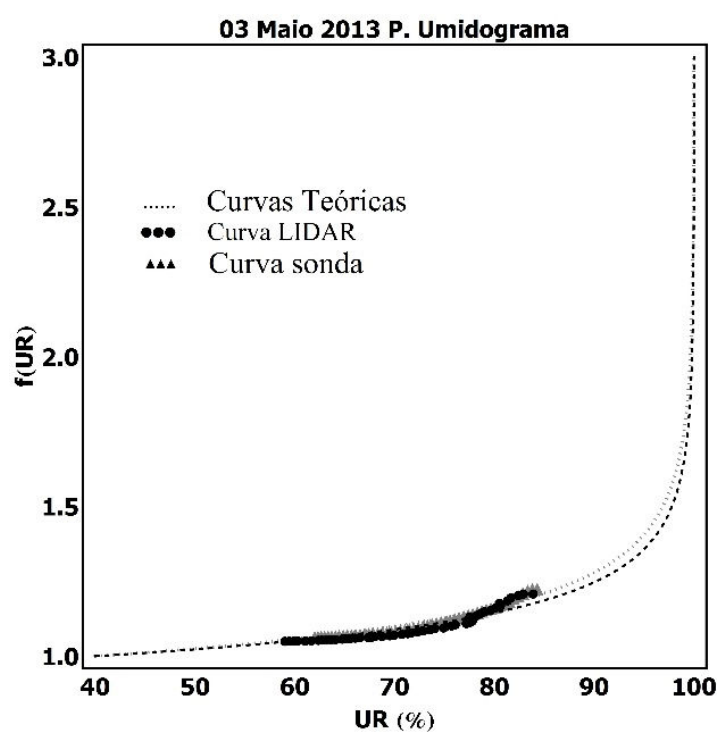

b) $\gamma_{\mathrm{p} \text { LIDAR }}=0.11 \pm 0.03, \gamma_{\mathrm{p} \text { radiossonda }}=0.13 \pm 0.01$

$$
\begin{aligned}
& f_{\beta} \operatorname{LIDAR}(85 \%)=1.16 \pm 0.04 \\
& f_{\beta} \operatorname{SONDA}(85 \%)=1.20 \pm 0.02
\end{aligned}
$$

Figura 6.5 - a) Umidograma não parametrizado mostrando o ajuste dos dados à curva teórica, e os valores ajustados de $\gamma$ para o LIDAR e para a radiossonda. b) Ajuste após parametrização, onde $f_{\beta}(40 \%)$ é igual a 1, e os valores de $\gamma$ parametrizado $\left(\gamma_{\mathrm{p}}\right)$ ajustados para o LIDAR e para a radiossonda

\subsection{2 - 12 de setembro de 2013}

A radiossondagem lançada em 13 de Setembro de 2013 às 00 UTC mostra a presença de condições para possível crescimento higroscópico, como é possível observar na Figura 6.6. A faixa em destaque mostra a região onde foi possível observar melhor ajuste entre os dados da radiossondagem e do LIDAR (entre $1721.25 \mathrm{~m}$ e $2036.25 \mathrm{~m}$ ) para a avaliação do crescimento higroscópico. Essa região foi escolhida por se observar um aumento do retroespalhamento do LIDAR, conforme mostrado na Figura 6.7 b. Para esse mesmo intervalo em altitude, nota-se um aumento da umidade relativa medida pela radiossondagem (Figura $6.6 \mathrm{c}$ ), entre $59 \%$ e $62 \%$. A temperatura potencial equivalente é constante e 
aproximadamente igual a 322K (Figura 6.6 b) na região de interesse, e a razão de mistura de vapor de água é constante e aproximadamente igual a $5.5 \mathrm{~g} / \mathrm{kg}$ (Figura $6.6 \mathrm{a}$ ).

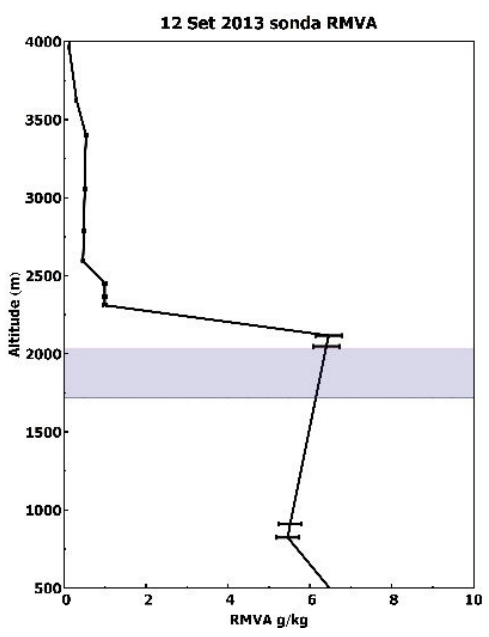

a)

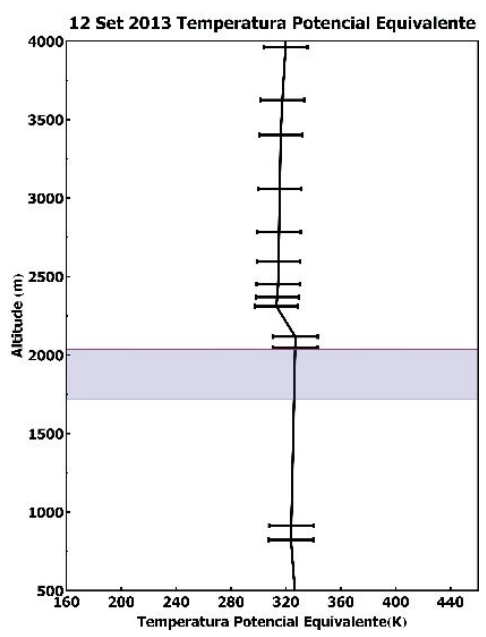

b)

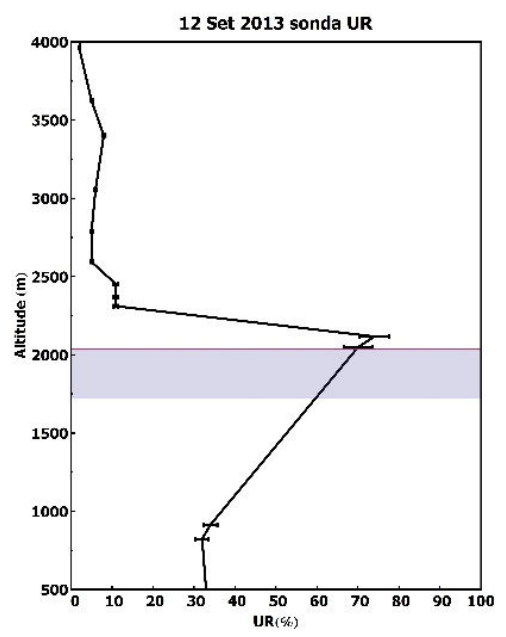

c)

Figura 6.6 - Condições suficientes para uma atmosfera bem misturada, e para possível crescimento higroscópico, conforme dados de radiossondagem. a) Razão de mistura de vapor de água constante (em torno de $6 \mathrm{~g} / \mathrm{kg}$ ). b) Temperatura Potencial Equivalente constante (em torno de $325 \mathrm{~K}$ ). c) Umidade relativa crescente (entre 59\% e 62\%). A região em destaque compreende as altitudes entre $1721.25 \mathrm{~m}$ e $2036.25 \mathrm{~m}$

A retrotrajetória obtida com o modelo HYSPLIT (Figura 6.7 a) mostra a origem continental limpa das massas de ar em todas as altitudes. O retroespalhamento obtido pelo LIDAR variou entre $0.00181 \mathrm{~km}^{*} \mathrm{sr}$ e $0.00221 \mathrm{~km} \mathrm{~km}^{*} \mathrm{sr}$ (1,22 vezes maior) na região de interesse.

Apesar das condições atmosféricas necessárias para a verificação do crescimento higroscópico estarem presentes em altitudes de cerca de $800 \mathrm{~m}$, o perfil do retroespalhamento obtido com o LIDAR aumenta a partir de $1721.25 \mathrm{~m}$, altitude em que a umidade relativa é de $59 \%$. Esse resultado sugere que o aumento do retroespalhamento dos aerossóis é identificável em regiões cuja umidade relativa ultrapassa um valor limite (ponto de deliquescência), não apresentando crescimento identificável em umidades relativas menores.

Para este dia, o valor da constante de calibração foi de $1.93 \pm 0.03$. O perfil da diferença percentual entre os valores para a razão de mistura de vapor de água obtidos pelo LIDAR e pela radiossondagem aparecem na Figura 6.8 b, enquanto a Figura 6.9 b mostra o mesmo desvio percentual obtido para a umidade relativa. Dentro da faixa de altitude de interesse são observados os menores desvios. 


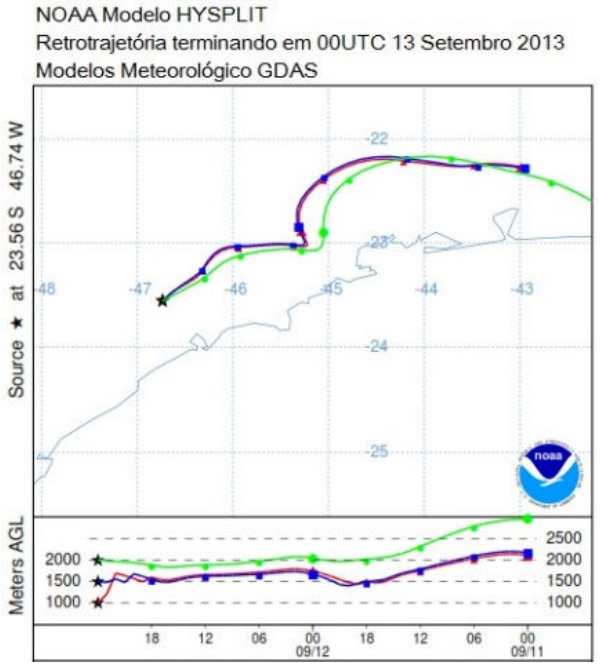

a)

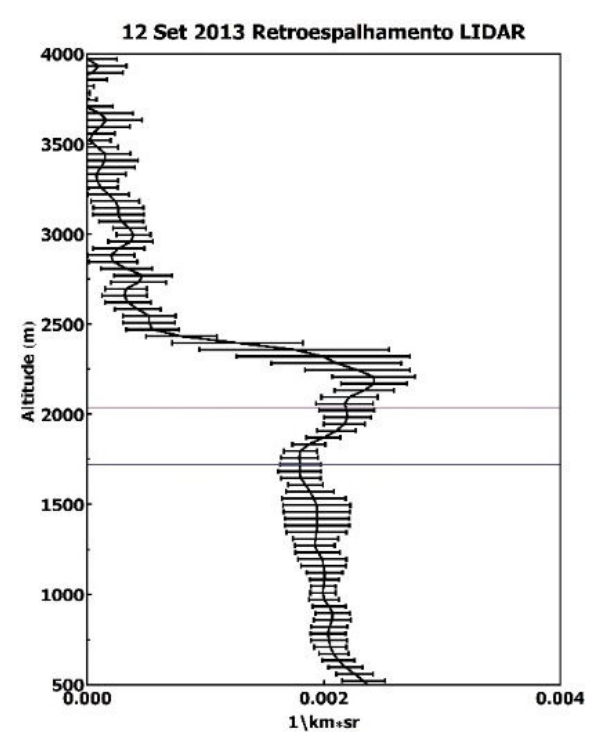

b)

Figura 6.7 - a) Retrotrajetória de 48 horas obtida com o modelo HYSPLIT, mostrando a origem continental limpa dos aerossóis em todas as altitudes. b) Retroespalhamento obtido com o LIDAR mostrando região onde há aumento do coeficiente de retroespalhamento, no intervalo entre $0.00181 \backslash \mathrm{km}^{*} \mathrm{sr}$ e $0.00221 \backslash \mathrm{km} * \mathrm{sr}$ (1,22 vezes maior). A região em destaque compreende as altitudes entre $1721.25 \mathrm{~m}$ e $2036.25 \mathrm{~m}$

Abaixo de 600 metros, aparecem as maiores diferenças, que possivelmente se devem às necessárias correções de overlap que devem ser futuramente aplicadas ao MSP-LIDAR 1.

O umidograma não parametrizado e o parametrizado estão apresentados na Figura 6.10. É possível perceber que os valores obtidos pelo LIDAR e pela radiossonda apresentam importante diferença, já que a umidade relativa obtida com os dois instrumentos apresenta variações superiores a $10 \%$.

A parametrização foi feita adotando-se o mesmo valor de referência, $f_{\beta}(40 \%)$

As diferenças encontradas entre o LIDAR e a radiossondagem podem ser explicadas pela baixa concentração de vapor de água na camada limite $(5 \mathrm{~g} / \mathrm{kg})$, já que setembro é um mês tradicionalmente bastante seco em São Paulo. Sob baixas concentrações de vapor de água, os erros associados às medidas com o LIDAR aumentam. 


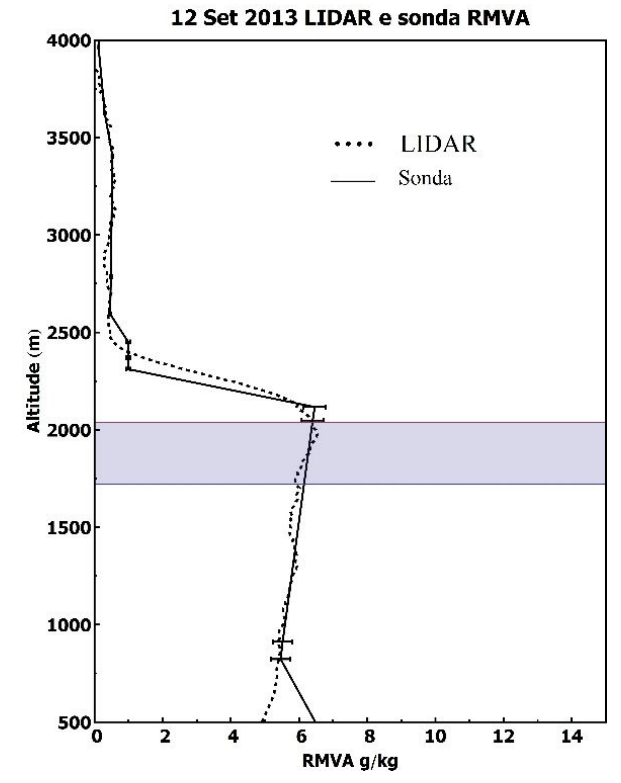

a)

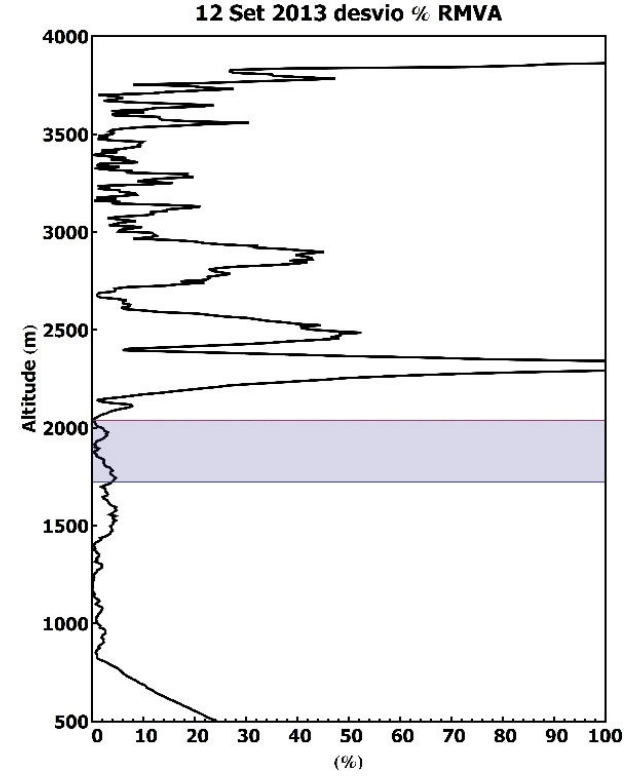

b)

Figura 6.8 - a) Comparação entre a razão de mistura de vapor de água obtida com a LIDAR e com a radiossondagem, após aplicada a constante de calibração. b) Perfil do desvio percentual da razão de mistura de vapor de água obtida com o LIDAR e com a radiossonda, mostrando que dentro da região de interesse essa variação é sempre menor que 5\%.

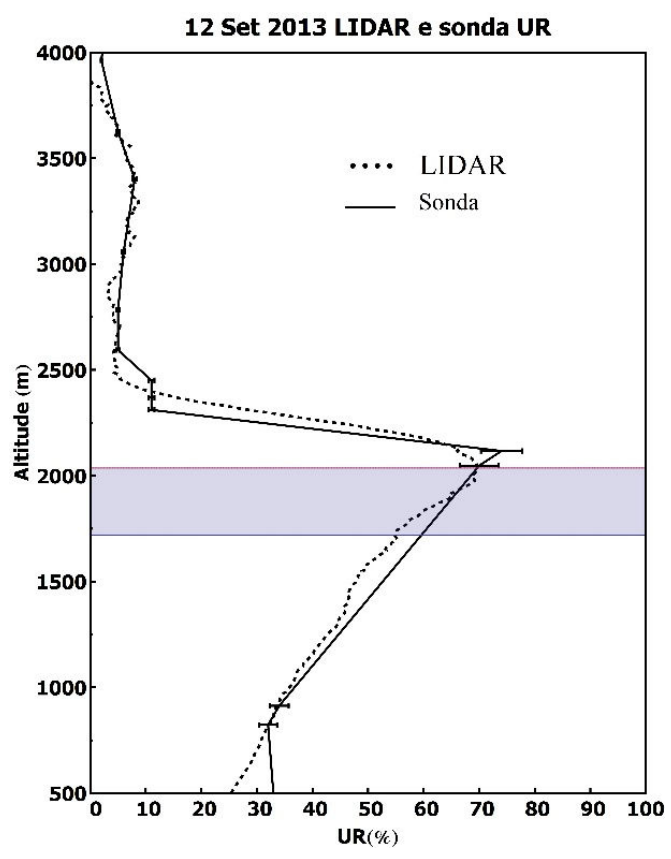

a)

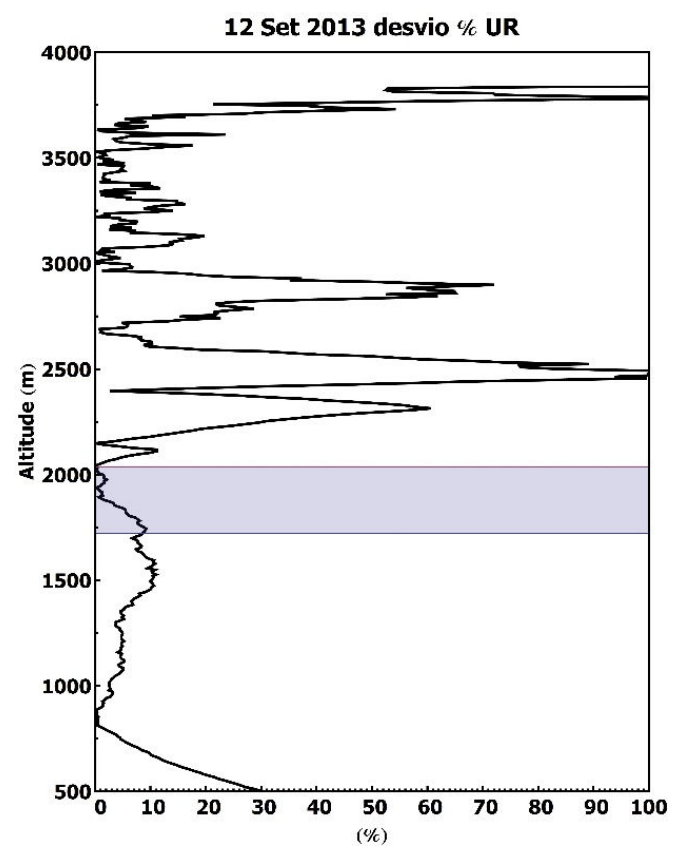

b)

Figura 6.9 - a) Comparação entre a umidade relativa obtida com o LIDAR e com a radiossondagem. Dentro da faixa de interesse para cálculo do crescimento higroscópico, a umidade relativa obtida com o LIDAR variou entre $54 \%$ e $69 \%$ e a obtida com a radiossonda variou entre $59 \%$ e $69 \%$. b) Perfil do desvio percentual da umidade relativa obtida com o LIDAR e com a radiossonda, mostrando que dentro da região de interesse essa variação atinge valores superiores a 10\% 

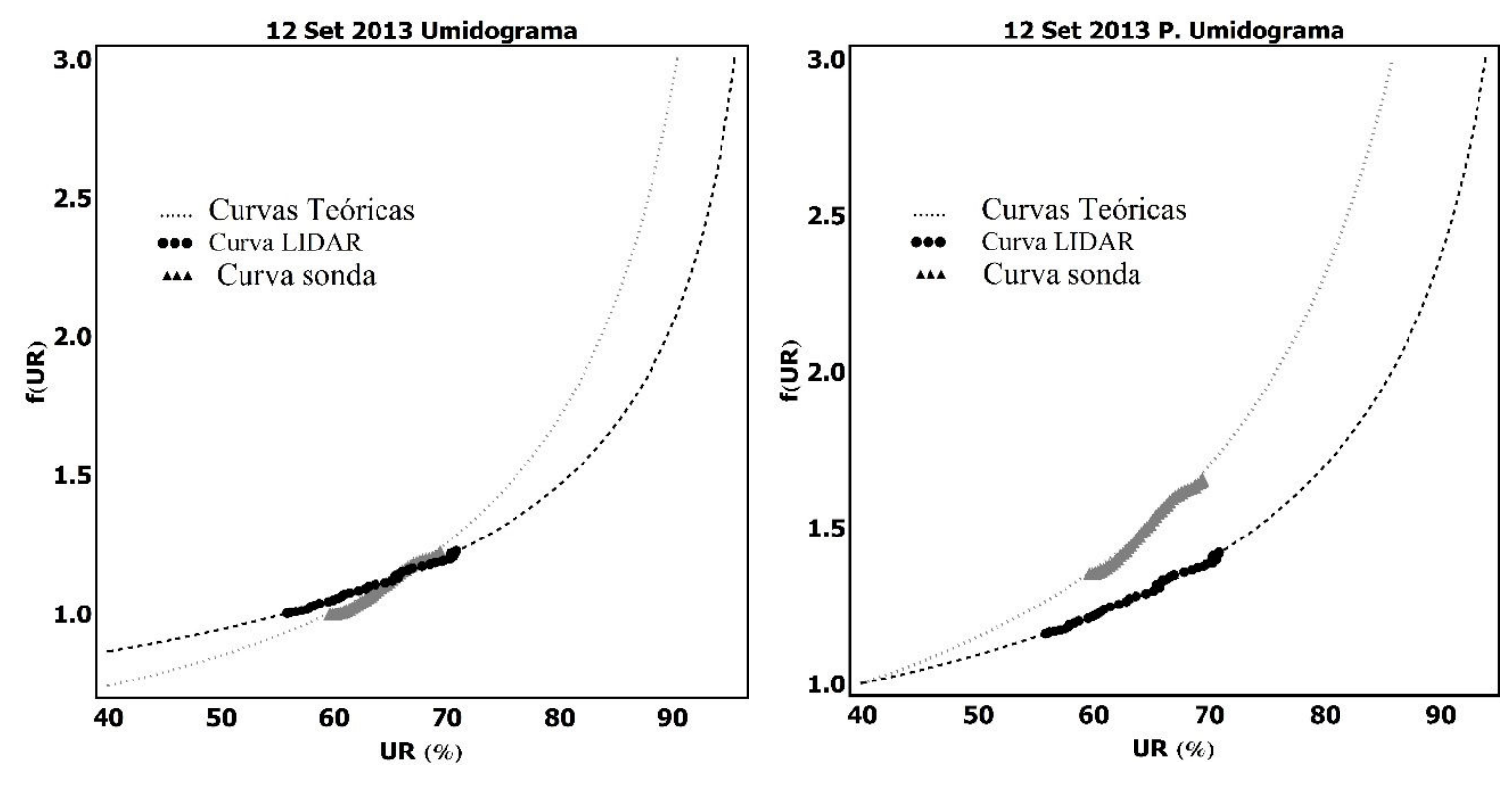

a) $\gamma_{\text {LIDAR }}=0.48 \pm 0.12, \gamma_{\text {radiossonda }}=0.76 \pm 0.05$

b) $\gamma_{\mathrm{p} \text { LIDAR }}=0.48 \pm 0.12, \gamma_{\mathrm{p} \text { radiossonda }}=0.76 \pm 0.05$

$$
\begin{aligned}
& f_{\beta} \operatorname{LIDAR}(85 \%)=1.95 \pm 0.30 \\
& f_{\beta} \operatorname{SONDA}(85 \%)=2.88 \pm 0.21
\end{aligned}
$$

Figura 6.10 - a) Umidograma não parametrizado mostrando o ajuste dos dados à curva teórica, e os valores ajustados de $\gamma$ para o LIDAR e para a radiossonda. b) Ajuste após parametrização, onde $f_{\beta}(40 \%)$ é igual a 1 , e os valores de $\gamma$ parametrizado $\left(\gamma_{\mathrm{p}}\right)$ ajustados para o LIDAR e para a radiossonda

\subsection{3 - 30 de Janeiro de 2014}

A avaliação dos dados da radiossondagem lançada em 31 de Janeiro de 2014 às 00 UTC mostra a presença de condições para a avaliação crescimento higroscópico, como é possível observar na Figura 6.11. A faixa em destaque mostra a região onde foi possível observar melhor ajuste entre os dados da radiossondagem e do LIDAR (entre $828.75 \mathrm{~m}$ e $1743.75 \mathrm{~m}$ ) para a avaliação do crescimento higroscópico. Essa região foi escolhida por se observar um aumento do retroespalhamento do LIDAR, conforme mostrado na Figura 6.12 b. Para esse mesmo intervalo em altitude, nota-se um aumento da umidade relativa medida pela radiossondagem (Figura $6.11 \mathrm{c}$ ), entre $46 \%$ e 68\%. A temperatura potencial equivalente é constante e aproximadamente igual a 335K (Figura 6.11 b) na região de interesse, e a razão de mistura de vapor de água é constante e aproximadamente igual a 9g/kg (Figura 6.11 a).

A retrotrajetória obtida com o modelo HYSPLIT (Figura 6.12) mostra que as massas de ar são de origem continental em todas as altitudes, porém com influência marítima acima de $1000 \mathrm{~m}$. O retroespalhamento na altitude de interesse aumentou de $0.00291 \backslash \mathrm{km} * \mathrm{sr}$ a $0.00421 \backslash \mathrm{km}^{*} \mathrm{sr}(1,45$ vezes maior). 


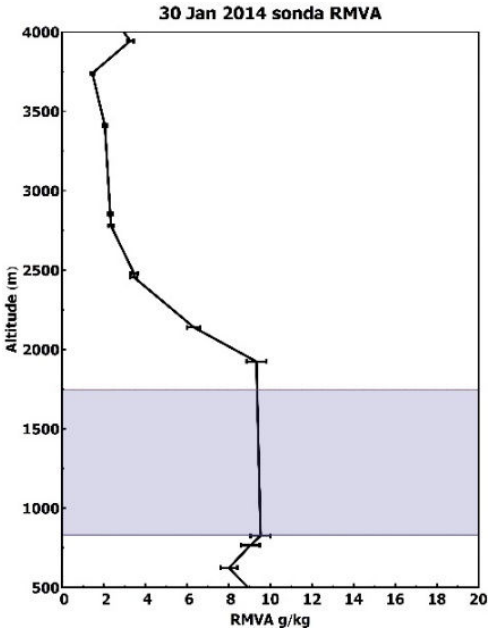

a)

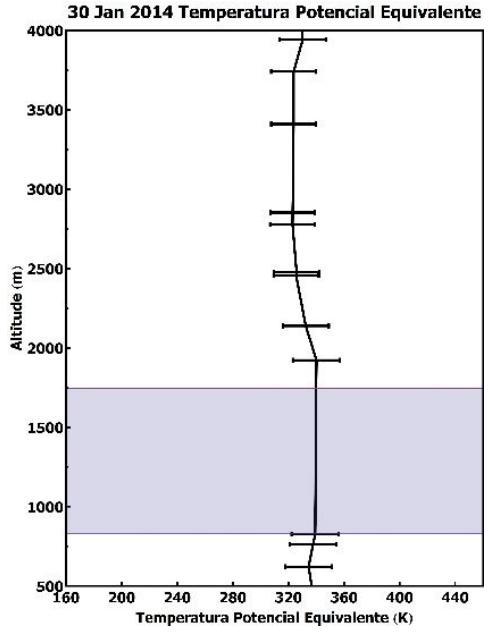

b)

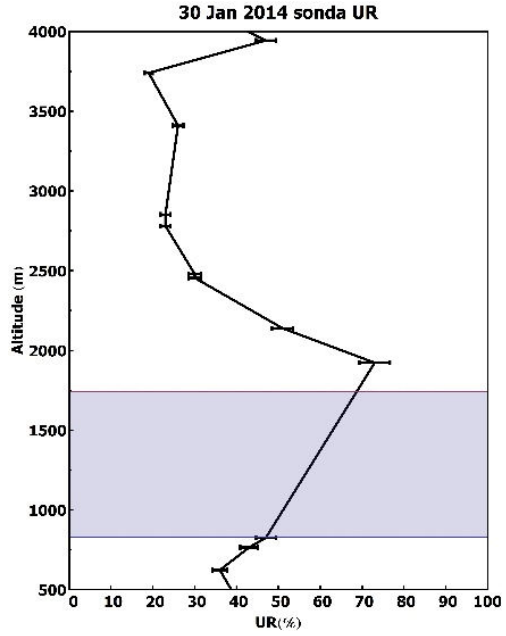

c)

Figura 6.11- Condições suficientes para uma atmosfera bem misturada, e para possível crescimento higroscópico, conforme dados de radiossondagem. a) Razão de mistura de vapor de água constante (em torno de $9 \mathrm{~g} / \mathrm{kg}$ ). b) Temperatura Potencial Equivalente constante (em torno de $335 \mathrm{~K}$ ). c) Umidade relativa crescente (entre $46 \%$ e $68 \%$ ). A região em destaque compreende as altitudes entre $828.75 \mathrm{~m}$ e $1743.75 \mathrm{~m}$

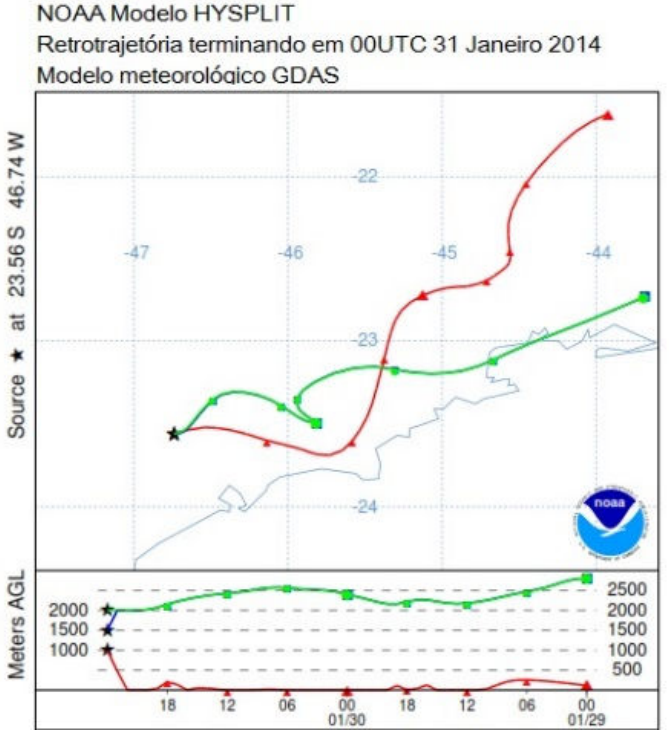

a)

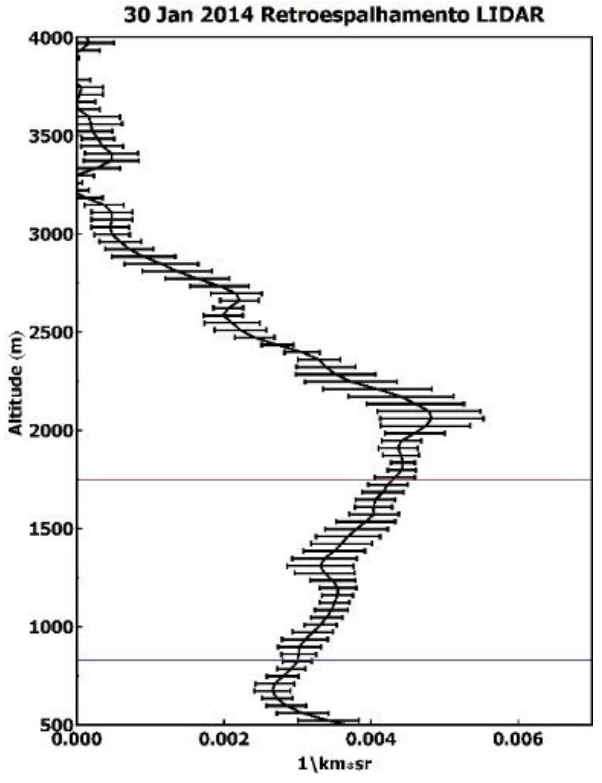

c)

Figura 6.12 - a) Retrotrajetória de 48 horas obtida com o modelo HYSPLIT, mostrando a origem continental limpa dos aerossóis superficiais e maior influência marítima nos aerossóis acima de 1000m. b) Retroespalhamento obtido com o LIDAR mostrando região onde há aumento do coeficiente de retroespalhamento, dadas as condições de atmosfera bem misturada. A região em destaque compreende as altitudes entre $828.75 \mathrm{~m}$ e $1743.75 \mathrm{~m}$ 
Para este dia, o valor da constante de calibração foi de $2.00 \pm 0.10$. O perfil da diferença percentual entre os valores para a razão de mistura de vapor de água obtidos pelo LIDAR e pela radiossondagem aparecem na Figura 6.13 b, enquanto a figura 6.14 b mostra o mesmo desvio percentual obtido para a umidade relativa. Dentro da faixa de altitude de interesse são observados os menores desvios (menores que 5\%).

Este caso apresenta o maior intervalo de altitude entre os casos estudados em São Paulo, mas dentro deste intervalo, a umidade relativa variou entre $46 \%$ e $68 \%$ (valores da radiossondagem) e $46 \%$ e $64 \%$ (valores obtidos com o LIDAR).

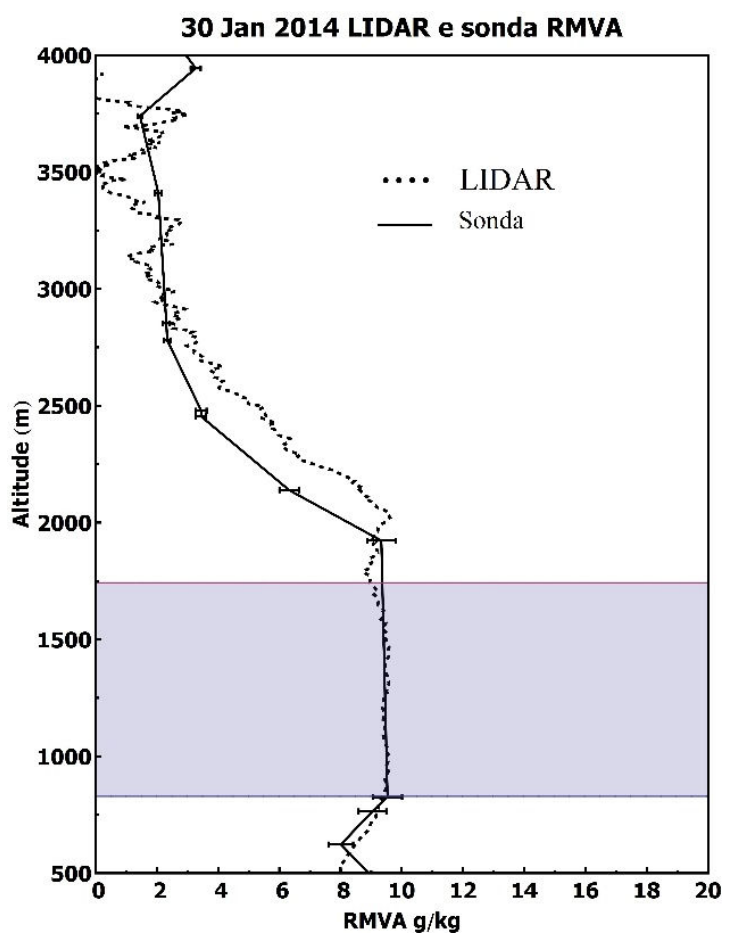

a)

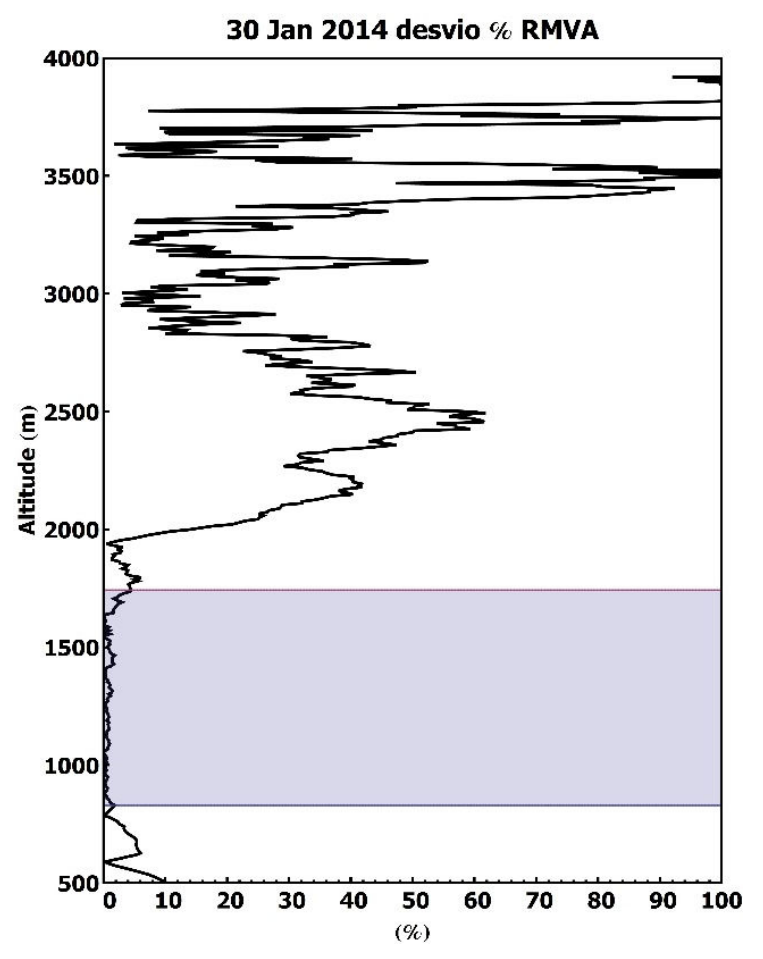

b)

Figura 6.13 - a) Comparação entre a razão de mistura de vapor de água obtida com a LIDAR e com a radiossondagem, após aplicada a constante de calibração. b) Perfil do desvio percentual da razão de mistura de vapor de água obtida com o LIDAR e com a radiossonda, mostrando que dentro da região de interesse essa variação é sempre menor que 5\%.

O umidograma não parametrizado e o parametrizado estão apresentados na Figura 6.15 . 

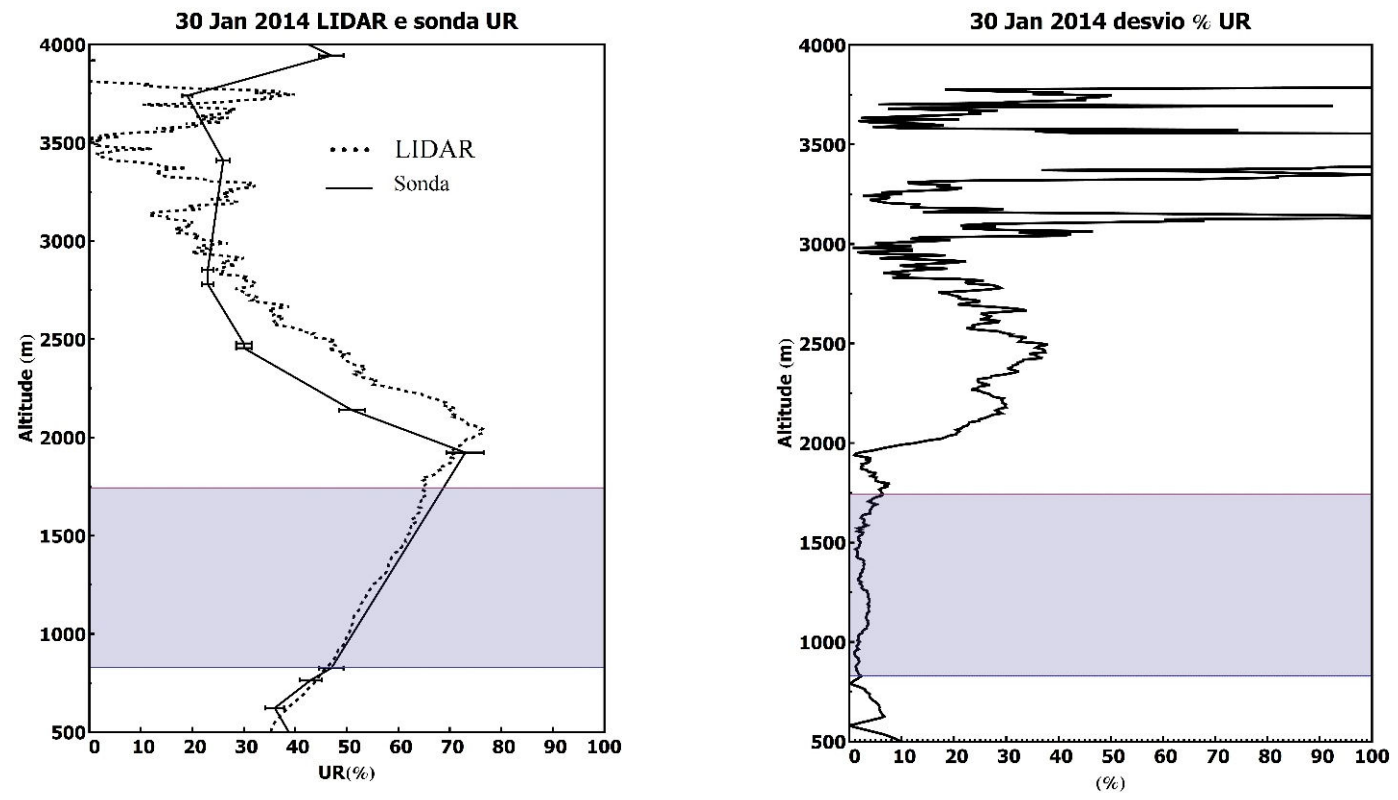

Figura 6.14 - a) Comparação entre a umidade relativa obtida com o LIDAR e com a radiossondagem. Dentro da faixa de interesse para cálculo do crescimento higroscópico, a umidade relativa obtida com o LIDAR variou entre $41 \%$ e $68 \%$ e a obtida com a radiossonda variou entre $39 \%$ e $70 \%$. b) Perfil do desvio percentual da umidade relativa obtida com o LIDAR e com a radiossonda, mostrando que dentro da região de interesse essa variação é sempre menor que 5\%.

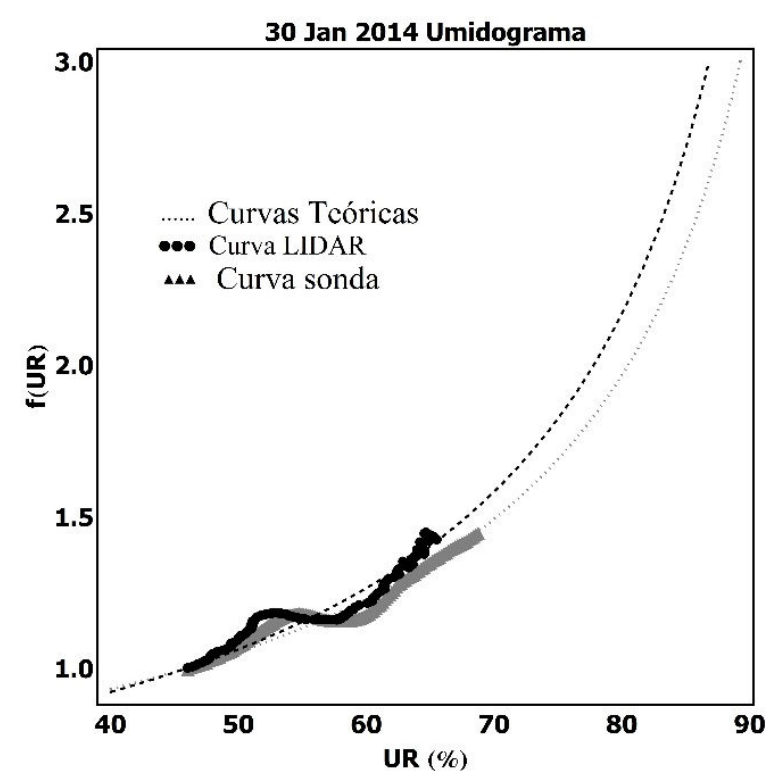

a) $\gamma_{\text {lidar }}=0.77 \pm 0.15, \gamma_{\text {radiossonda }}=0.68 \pm 0.04$

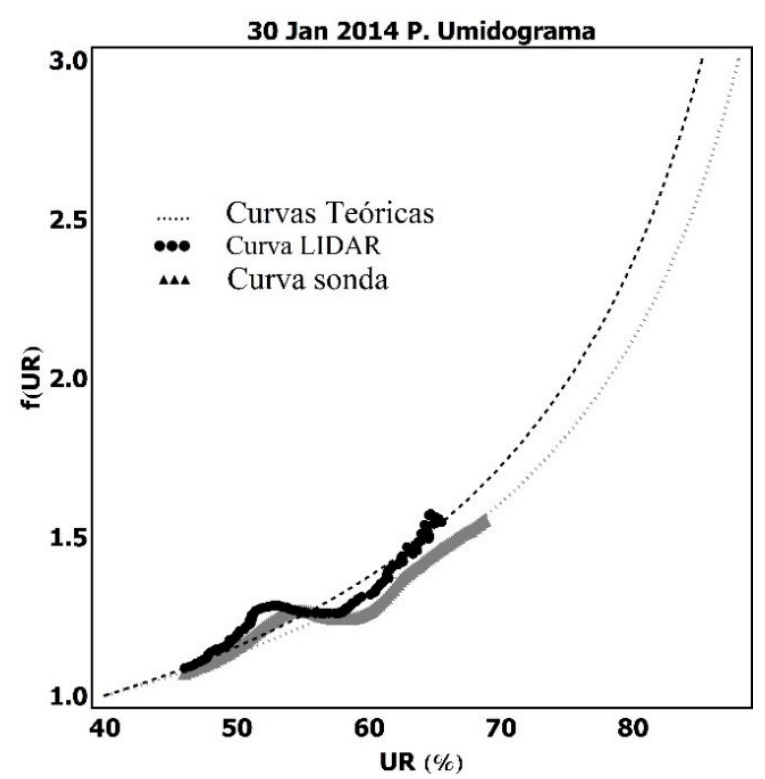

b) $\gamma \mathrm{p}_{\text {lidar }}=0.78 \pm 0.16, \gamma \mathrm{p}_{\text {radiossonda }}=0.68 \pm 0.04$

$$
\begin{aligned}
& f_{\beta} \operatorname{LIDAR}(85 \%)=2.96 \pm 0.58 \\
& f_{\beta} \operatorname{SONDA}(85 \%)=2.58 \pm 0.14
\end{aligned}
$$

Figura 6.15 - a) Umidograma não parametrizado mostrando o ajuste dos dados à curva teórica, e os valores ajustados de $\gamma$ para o LIDAR e para a radiossonda. b) Ajuste após parametrização, onde $f_{\beta}(40 \%)$ é igual a 1, e os valores de $\gamma$ parametrizado $(\gamma p)$ ajustados para o LIDAR e para a radiossonda 
Para os dias de estudo neste trabalho, uma constante de calibração média de $1.87 \pm 0.06$ (desvio de $3.2 \%$ ) foi encontrada. Trabalhos anteriores mostram desvios entre $2 \%$ e 5\% (Navas-Guzman, 2014, Whiteman, 2003; Mattis et al, 2002).

Os resultados obtidos para o $\gamma$ ajustado para o LIDAR e a radiossondagem estão sumarizados na Tabela 04 , bem como as altitudes de referência, os valores de $f_{\beta}(85 \%)$ e a origem das massas de ar.

A altitude inicial para o dia 30/01/2014 está abaixo da altitude esperada para o overlap total, porém, existe um grande intervalo de altitude acima do overlap esperado. Isso faz com que o ajuste do LIDAR seja menos discrepante, mas ainda assim é possível esperar que o resultado encontrado pela radiossondagem seja mais confiável.

Deve-se ainda lembrar que o LIDAR e as radiossondagens estão separados, e grandes variações no vapor de água atmosférico podem ocorrer em uma distância de $12 \mathrm{~km}$. Portanto, as diferenças entre os dois instrumentos ainda podem ser explicadas por este fato.

Existe ainda a constatação de que apenas um dia nos dados analisados (30/01) corresponde a um dado durante o verão em São Paulo, onde a umidade relativa é maior. Os outros dias são dados de estações secas, e portanto os erros na determinação do vapor de água pelo LIDAR são maiores.

Tabela 04 - Sumário dos resultados para os dias de medida do MSP-LIDAR I

\begin{tabular}{|c|c|c|c|c|c|c|c|c|c|c|}
\hline Data & $\begin{array}{c}\gamma \\
\text { LIDAR }\end{array}$ & $\gamma$ sonda & $\begin{array}{c}\text { Alt } \\
\text { inicial } \\
(\mathrm{m})\end{array}$ & $\begin{array}{c}\text { Alt } \\
\text { final } \\
(\mathrm{m})\end{array}$ & $\begin{array}{c}\text { UR } \\
\text { Inicial } \\
(\%)\end{array}$ & $\begin{array}{c}\text { UR } \\
\text { Final } \\
(\%)\end{array}$ & $\begin{array}{c}\text { Const. } \\
\text { Cal }\end{array}$ & $\begin{array}{c}\boldsymbol{f}_{\boldsymbol{\beta}}(85 \%) \\
\text { LIDAR }\end{array}$ & $\begin{array}{c}\boldsymbol{f}_{\boldsymbol{\beta}}(85 \%) \\
\text { sonda }\end{array}$ & Origem \\
\hline $03 / 05 / 2013$ & $0.11 \pm 0.03$ & $0.13 \pm 0.01$ & 862.5 & 1627.5 & 258 & 84 & $1.68 \pm 0.05$ & $1.16 \pm 0.04$ & $\bar{c}_{1.20 \pm 0.02}$ & $\begin{array}{l}\text { Urbano } \\
\text { Poluido }\end{array}$ \\
\hline $12 / 09 / 2013$ & $0.48 \pm 0.12$ & $0.76 \pm 0.05$ & 1721.25 & 2036.25 & 59 & 62 & $1.93 \pm 0.03$ & $1.95 \pm 0.30$ & $2.88 \pm 0.21$ & $\begin{array}{l}\text { Urbano } \\
\text { Poluido }\end{array}$ \\
\hline $30 / 01 / 2014$ & $0.78 \pm 0.16$ & $0.68 \pm 0.04$ & 828.75 & 1743.75 & 46 & 64 & $2.00 \pm 0.10$ & $2.96 \pm 0.58$ & $2.58 \pm 0.14$ & $\begin{array}{l}\text { Urbano } \\
\text { Poluido }\end{array}$ \\
\hline
\end{tabular}

\section{2 - Dados do HURL}

Para os dados obtidos em DC, as radiossondagem foram lançadas várias vezes ao dia e durante a noite durante os vinte e um dias onde os dados do HURL também estão disponíveis. Os dados analisados para obtenção do perfil de retroespalhamento foram 
integrados em 30 minutos concomitantes ao lançamento da radiossonda. A temperatura potencial equivalente não está disponível para estes dados, de maneira que foi avaliada a constância da razão de mistura de vapor de água.

Os dados da radiossondagem estavam disponíveis em alta resolução, o que permite uma calibração com maior acurácia.

\subsection{1 - 05 de Julho de 2011}

A avaliação dos dados da radiossondagem lançada em 05 de julho de 2011 às 18:06 UTC mostra a presença de condições para o crescimento higroscópico, como é possível observar na Figura 6.16. A faixa em destaque mostra a região onde foi possível observar melhor ajuste entre os dados da radiossondagem e do LIDAR (entre $843.75 \mathrm{~m}$ e $1503.75 \mathrm{~m}$ ) para a avaliação do crescimento higroscópico. Essa região foi escolhida por se observar um aumento do retroespalhamento do LIDAR, conforme mostrado na Figura 6.17 b. Para esse mesmo intervalo em altitude, nota-se um aumento da umidade relativa medida pela radiossondagem (Figura 6.16 b), entre $67 \%$ e $85 \%$. A razão de mistura de vapor de água é constante e aproximadamente igual a $11,5 \mathrm{~g} / \mathrm{kg}$ (Figura $6.16 \mathrm{~b}$ ).

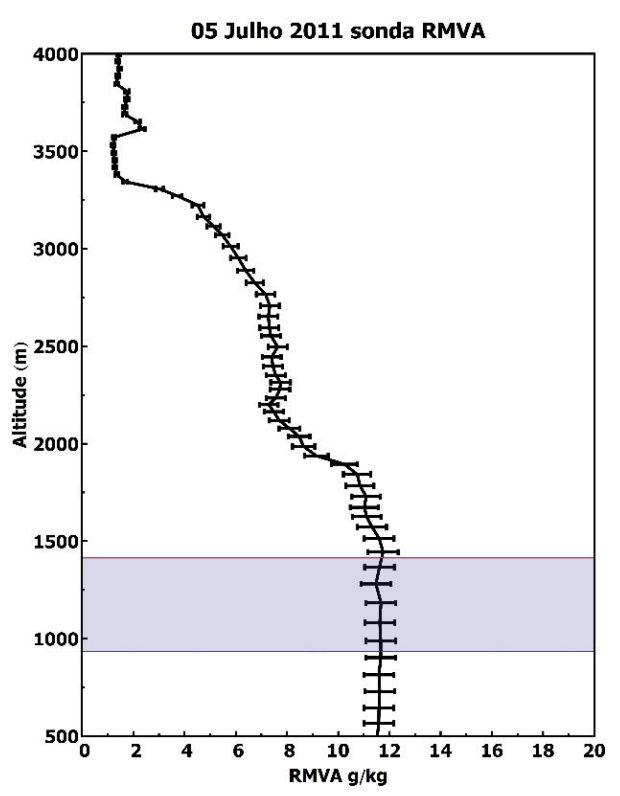

a)

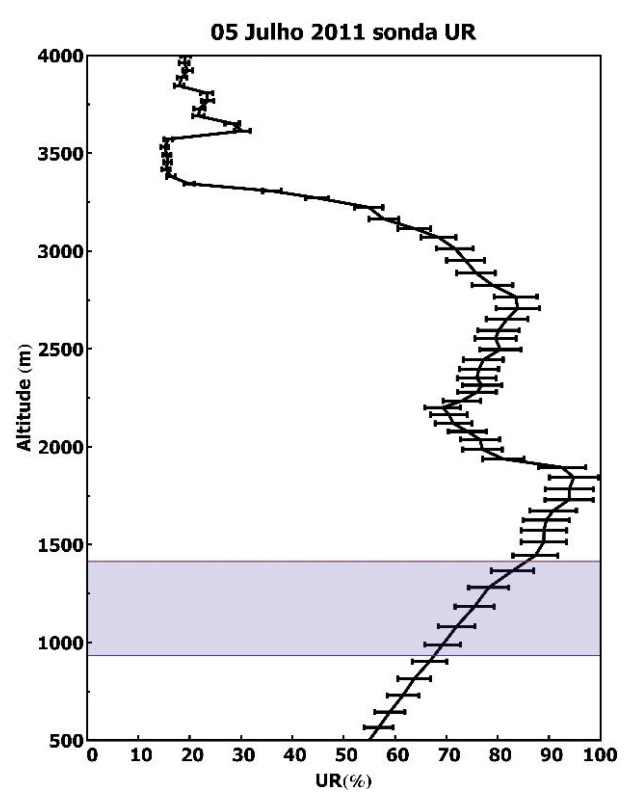

b)

Figura 6.16 - Condições suficientes para uma atmosfera bem misturada, e para possível crescimento higroscópico, conforme dados de radiossondagem. a) Razão de mistura de vapor de água constante (em torno de $7 \mathrm{~g} / \mathrm{kg}$ ). c) Umidade relativa crescente (entre 67 e $85 \%$ ). A região em destaque compreende as entre $843.75 \mathrm{~m}$ e $1503.75 \mathrm{~m}$ 
A retrotrajetória obtida com o modelo HYSPLIT (Figura 6.17) mostra que os aerossóis têm origem continental em todas as altitudes e o retroespalhamento obtido pelo LIDAR variou entre $0.00191 \mathrm{~km} * \mathrm{sr}$ e $0.0024 \backslash \mathrm{km} * \mathrm{sr}(1,26$ vezes maior).

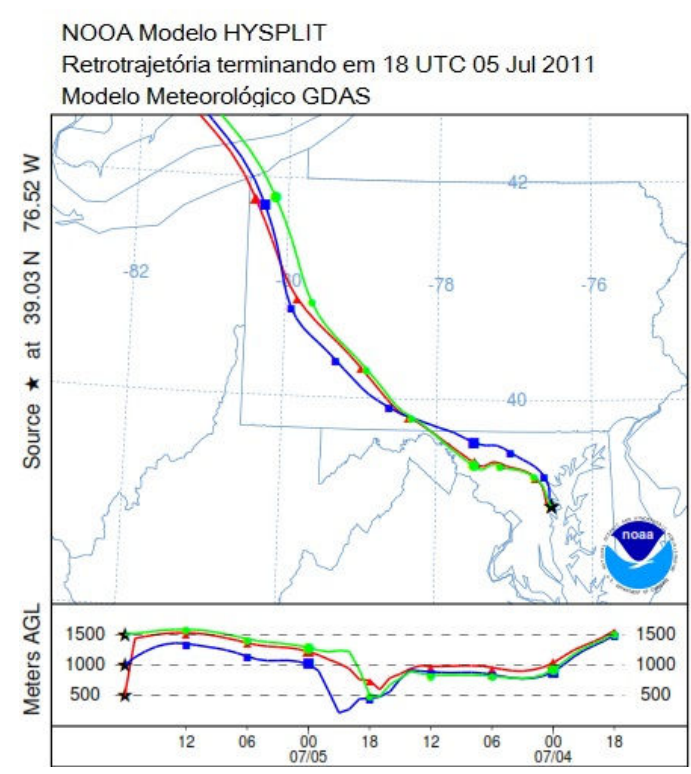

a)

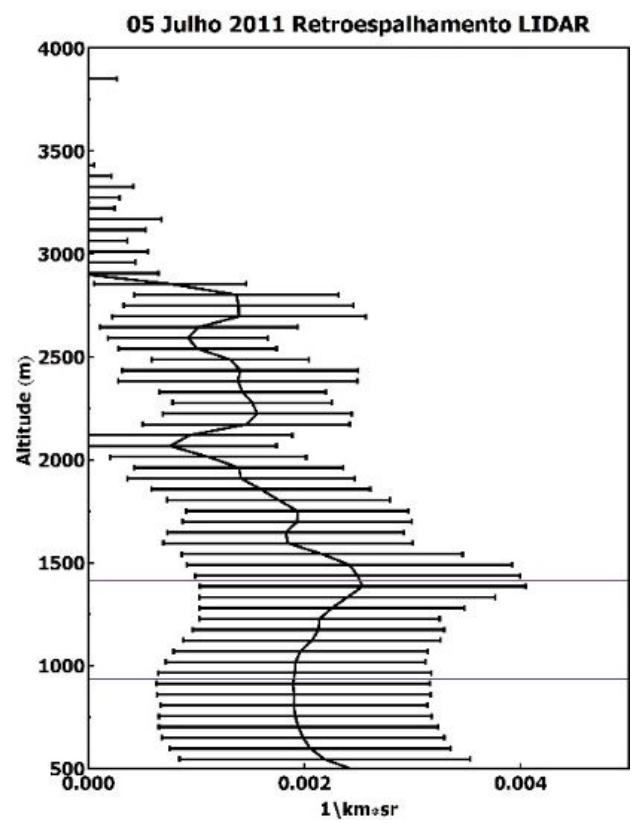

b)

Figura 6.17-a) Retrotrajetória de 48 horas obtida com o modelo HYSPLIT, mostrando a origem continental dos aerossóis em todas as altitudes b) Retroespalhamento obtido com o LIDAR mostrando região onde há aumento do coeficiente de retroespalhamento, dadas as condições de atmosfera bem misturada. A região em destaque compreende as altitudes entre $843.75 \mathrm{~m}$ e $1503.75 \mathrm{~m}$

O perfil da diferença percentual entre os valores para a razão de mistura de vapor de água obtidos pelo LIDAR e pela radiossondagem aparecem na Figura 6.18 b, enquanto a figura $6.19 \mathrm{~b}$ mostra o mesmo desvio percentual obtido para a umidade relativa. Dentro da faixa de altitude de interesse são observados os menores desvios (menores que 5\%).

O umidograma não parametrizado e o parametrizado estão apresentados na Figura 6.20. É possível perceber que os valores obtidos pelo LIDAR e pela radiossonda são concordantes, o que já era esperado devido ao bom ajuste na umidade relativa obtida com ambos instrumentos. A comparação dos valores obtidos com os valores para todos os dias do HURL, bem como valores encontrados na literatura estão sumarizados na Tabela 05 e na Tabela 06. 


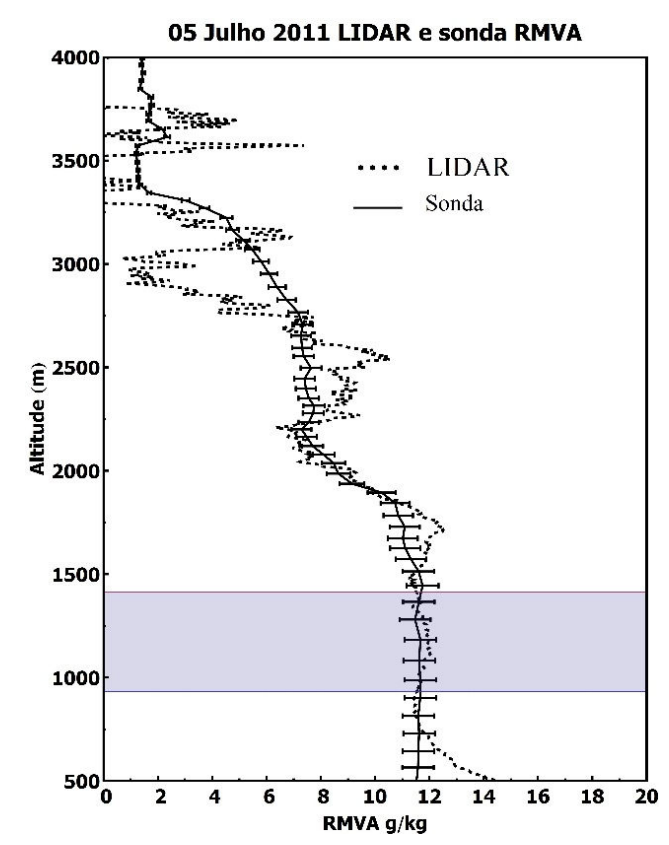

a)

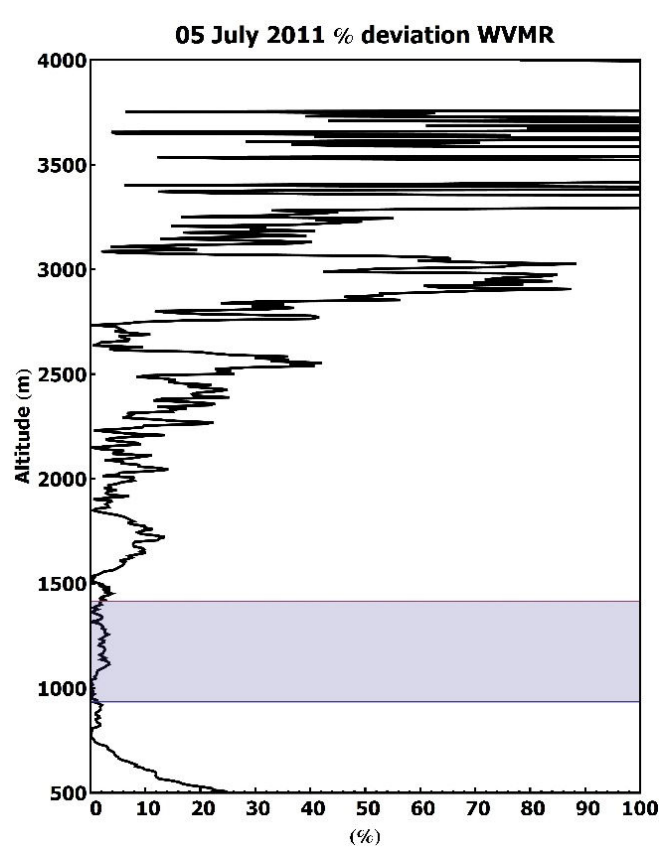

b)

Figura 6.18 - a) Comparação entre a razão de mistura de vapor de água obtida com a LIDAR e com a radiossondagem, após aplicada a constante de calibração. b) Perfil do desvio percentual da razão de mistura de vapor de água obtida com o LIDAR e com a radiossonda, mostrando que dentro da região de interesse essa variação é sempre menor que 5\%.

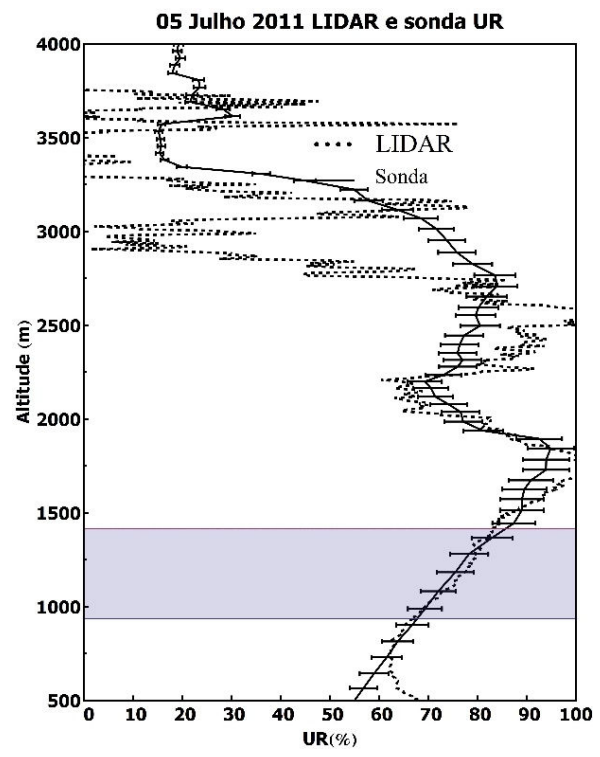

a)

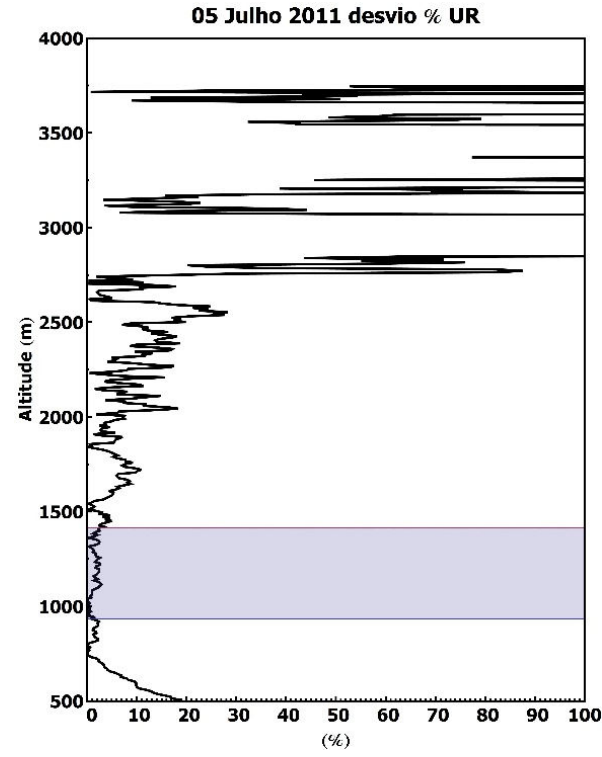

b)

Figura 6.19 - a) Comparação entre a umidade relativa obtida com o LIDAR e com a radiossondagem. Dentro da faixa de interesse para cálculo do crescimento higroscópico, a umidade relativa obtida com o LIDAR variou entre $66 \%$ e $83 \%$ e a obtida com a radiossonda variou entre $67 \%$ e $85 \%$. b) Perfil do desvio percentual da umidade relativa obtida com o LIDAR e com a radiossonda, mostrando que dentro da região de interesse essa variação é sempre menor que 5\%. 


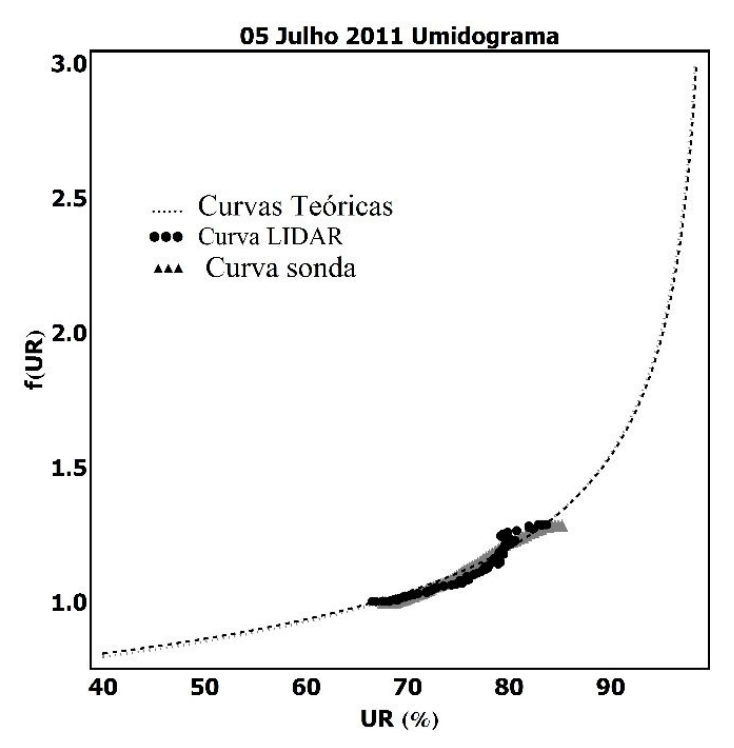

a) $\gamma_{\text {LIDAR }}=0.36 \pm 0.14, \gamma_{\text {radiossonda }}=0.37 \pm 0.04$

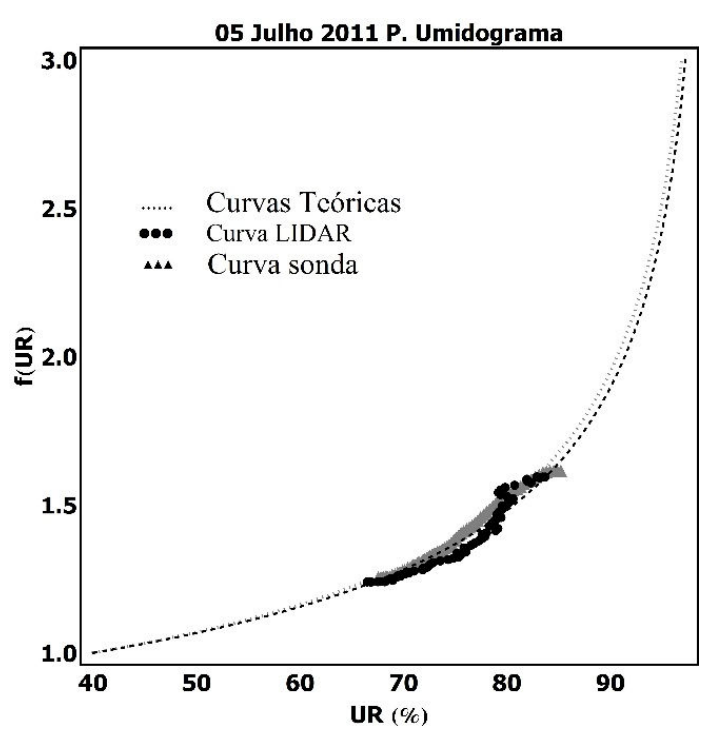

b) $\gamma_{\mathrm{p} \text { LIDAR }}=0.36 \pm 0.14, \gamma_{\mathrm{p} \text { radiossonda }}=0.37 \pm 0.04$

$$
\begin{aligned}
& f_{\beta} \operatorname{LIDAR}(85 \%)=1.64 \pm 0.28 \\
& f_{\beta} \operatorname{SONDA}(85 \%)=1.67 \pm 0.09
\end{aligned}
$$

Figura 6.20 - a) Umidograma não parametrizado mostrando o ajuste dos dados à curva teórica, e os valores ajustados de $\gamma$ para o LIDAR e para a radiossonda. b) Ajuste após parametrização, onde $f_{\beta}(40 \%)$ é igual a 1, e os valores de $\gamma$ parametrizado $\left(\gamma_{\mathrm{p}}\right)$ ajustados para o LIDAR e para a radiossonda

\subsection{2 - 21 de Julho de 2011}

A avaliação dos dados da radiossondagem lançada em 21 de Julho de 2011 às 18:41 UTC mostra a presença de condições para possível crescimento higroscópico, como é possível observar na Figura 6.21. A faixa em destaque mostra a região onde foi possível observar melhor ajuste entre os dados da radiossondagem e do LIDAR (entre $656.25 \mathrm{~m}$ e $1518.75 \mathrm{~m}$ ) para a avaliação do crescimento higroscópico. Essa região foi escolhida por se observar um aumento do retroespalhamento do LIDAR, conforme mostrado na Figura 6.22 b. Para esse mesmo intervalo em altitude, nota-se um aumento da umidade relativa medida pela radiossondagem (Figura 6.21 b), entre $61 \%$ e 87\%. A razão de mistura de vapor de água é constante e aproximadamente igual a $17 \mathrm{~g} / \mathrm{kg}$ (Figura $6.22 \mathrm{~b}$ ).

A retrotrajetória obtida com o modelo HYSPLIT (Figura 6.22) mostra a origem continental não poluída dos aerossóis em todas as altitudes e a variação no retroespalhamento obtido pelo LIDAR ficou entre $0.00091 \mathrm{~km} *$ sr e $0.00211 \mathrm{~km} * \mathrm{kr}$ (2.33 vezes maior).

O perfil da diferença percentual entre os valores para a razão de mistura de vapor de água obtidos pelo LIDAR e pela radiossondagem aparecem na Figura 6.22 b, enquanto a 
figura $6.23 \mathrm{~b}$ mostra o mesmo desvio percentual obtido para a umidade relativa. Dentro da faixa de altitude de interesse são observados os menores desvios (menores que 5\%).

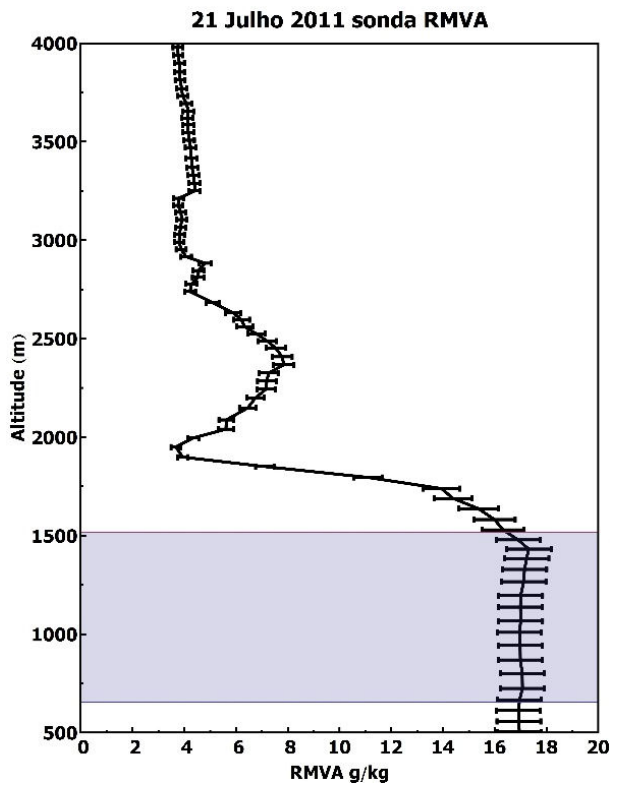

a)

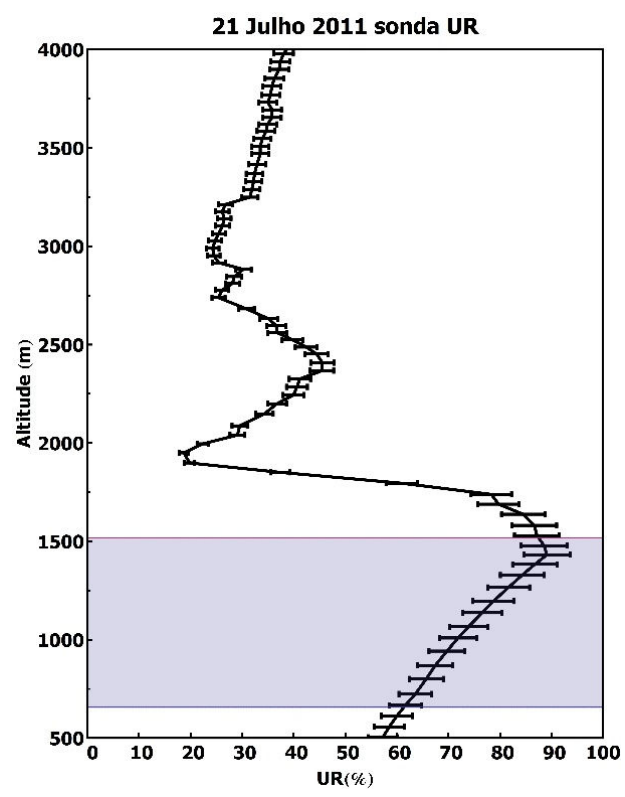

b)

Figura 6.21-Condições suficientes para uma atmosfera bem misturada conforme dados de radiossondagem.

a) Razão de mistura de vapor de água constante (em torno de $17 \mathrm{~g} / \mathrm{kg}$ ). b) Umidade relativa crescente (entre 61 e $78 \%$ ). A região em destaque compreende as altitudes entre $656.25 \mathrm{~m}$ e $1518.75 \mathrm{~m}$

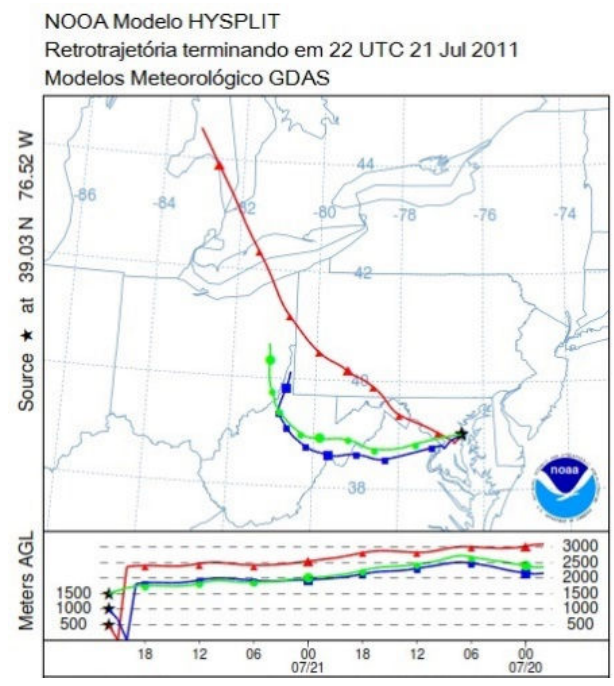

a)

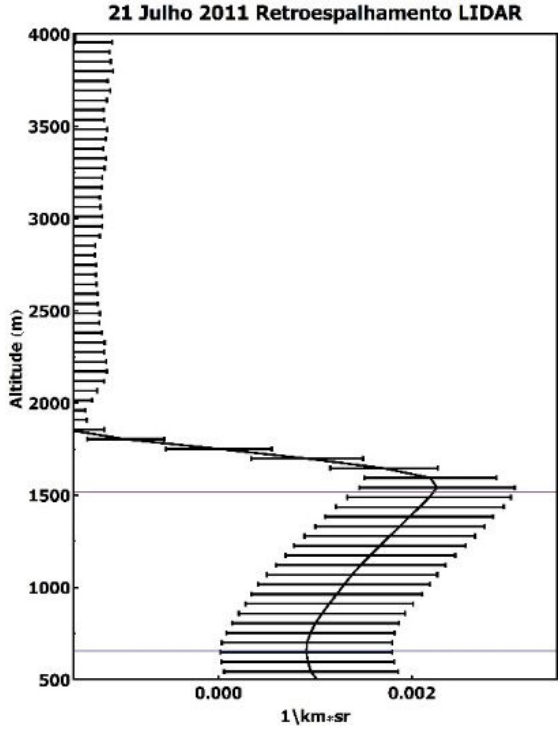

b)

Figura 6.22 - a) Retrotrajetória de 48 horas obtida com o modelo HYSPLIT, mostrando a origem continental limpa dos aerossóis em todas as altitudes b) Retroespalhamento obtido com o LIDAR mostrando região onde há aumento do coeficiente de retroespalhamento, dadas as condições de atmosfera bem misturada. A região em destaque compreende as altitudes entre $656.25 \mathrm{~m}$ e $1518.75 \mathrm{~m}$ 


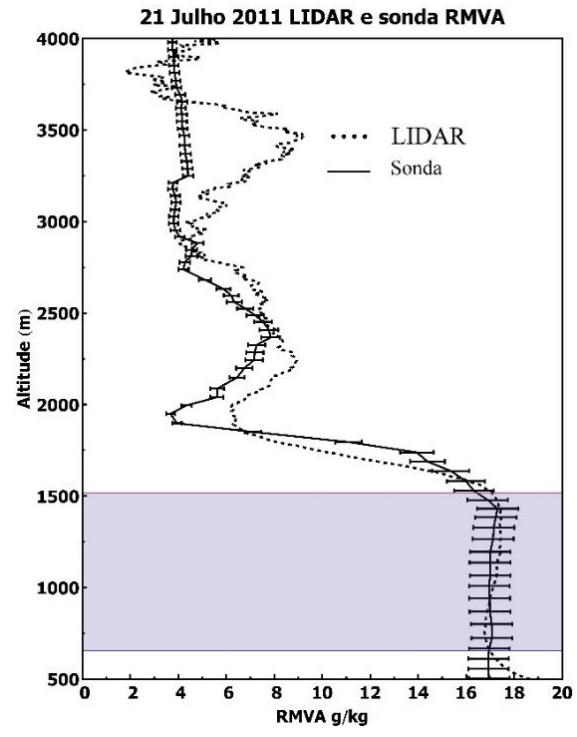

a)

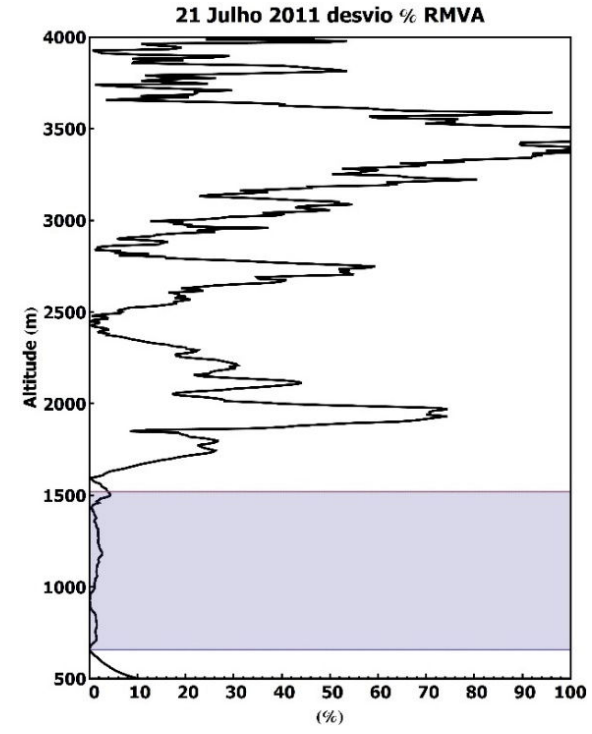

b)

Figura 6.23 - a) Comparação entre a razão de mistura de vapor de água obtida com a LIDAR e com a radiossondagem, após aplicada a constante de calibração. b) Perfil do desvio percentual razão de mistura de vapor de água obtida com o LIDAR e com a radiossonda, mostrando que dentro da região de interesse essa variação é sempre menor que $5 \%$.

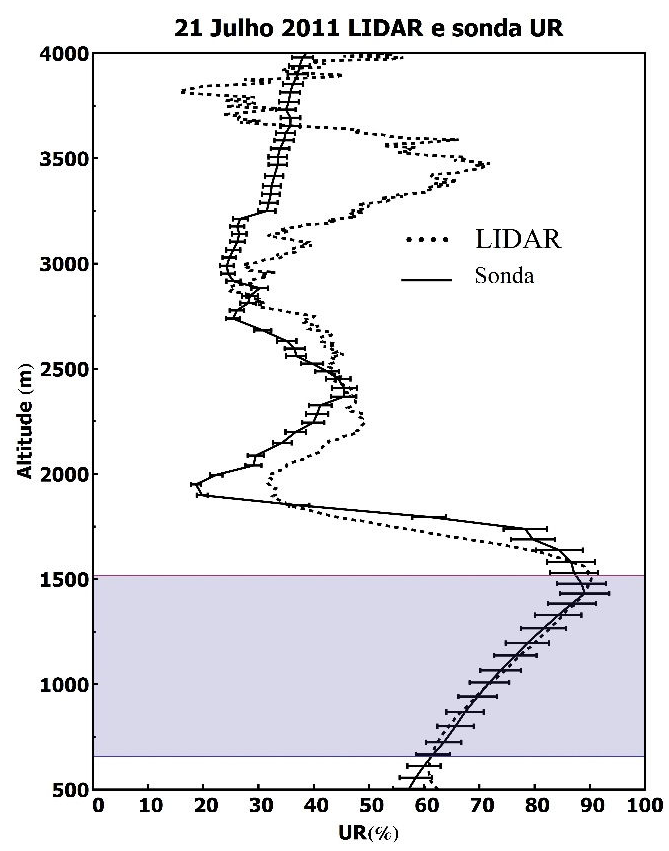

a)

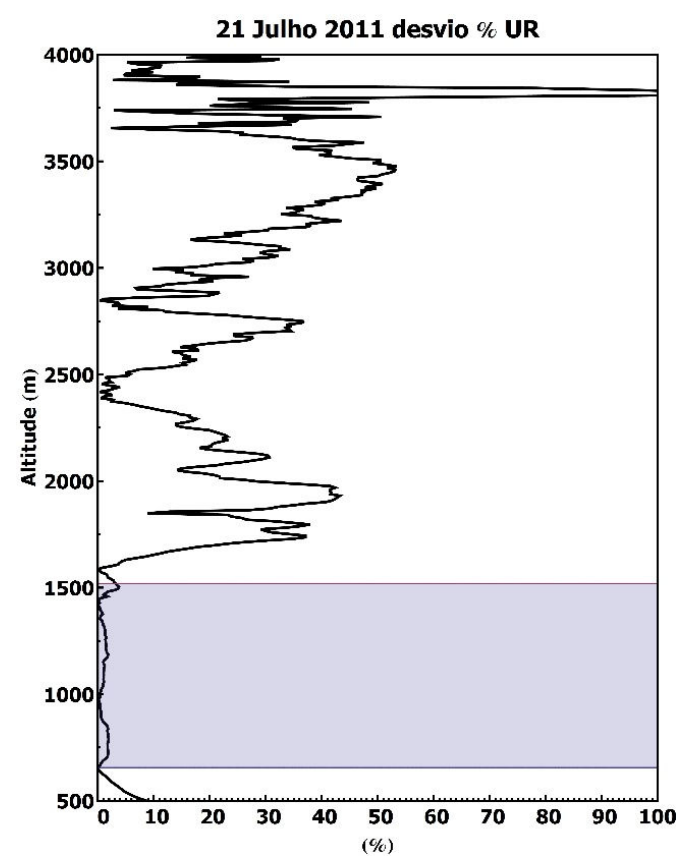

b)

Figura 6.24 - a) Comparação entre a umidade relativa obtida com o LIDAR e com a radiossondagem. Dentro da faixa de interesse para cálculo do crescimento higroscópico, a umidade relativa obtida com o LIDAR variou entre $61 \%$ e $90 \%$ e a obtida com a radiossonda variou entre $61 \%$ e $87 \%$. b) Perfil do desvio percentual umidade relativa obtida com o LIDAR e com a radiossonda, mostrando que dentro da região de interesse essa variação é sempre menor que $5 \%$. 
O umidograma não parametrizado e o parametrizado estão apresentados na Figura 6.25. É possível perceber que os valores obtidos pelo LIDAR e pela radiossonda são concordantes, o que já era esperado devido ao bom ajuste na umidade relativa obtida com ambos instrumentos.

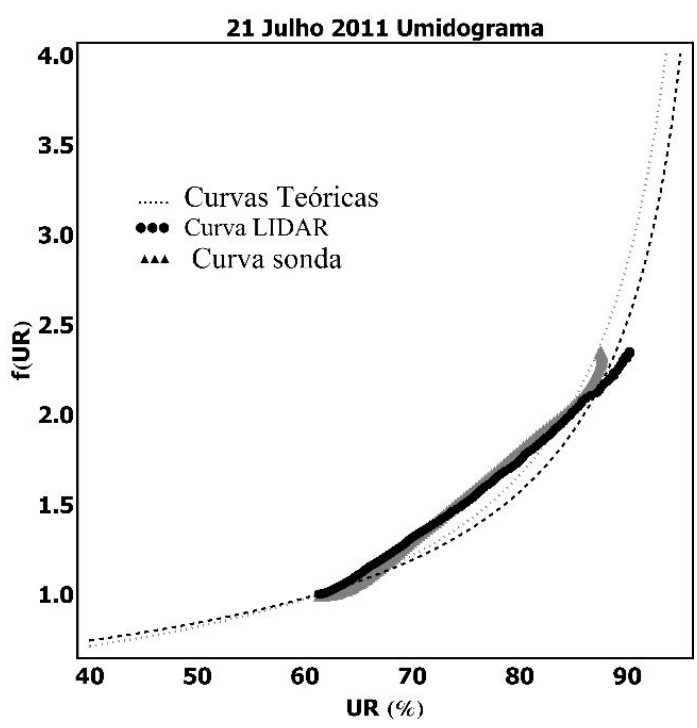

a) $\gamma_{\text {LIDAR }}=0.41 \pm 0.12, \gamma_{\text {radiossonda }}=0.45 \pm 0.04$

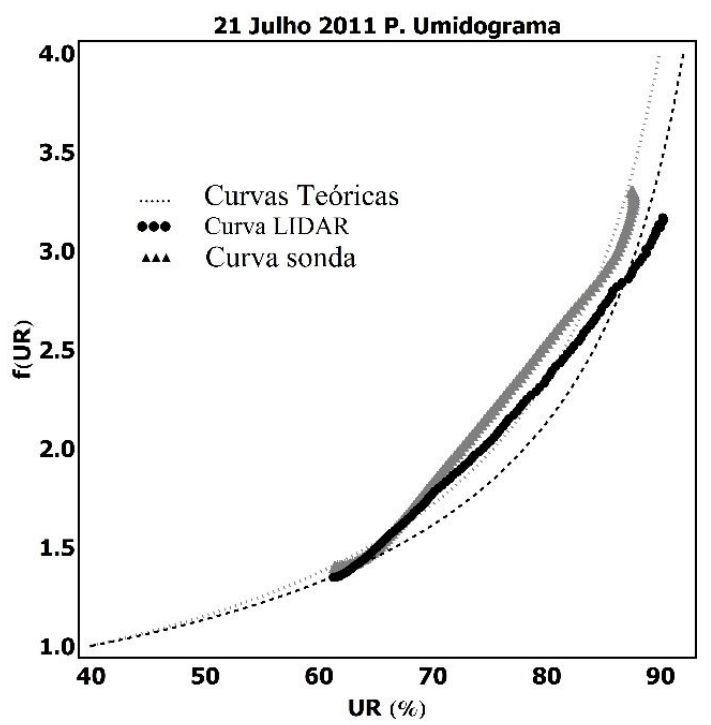

b) $\gamma_{\mathrm{p} \text { LIDAR }}=0.43 \pm 0.12, \gamma_{\mathrm{p} \text { radiossonda }}=0.47 \pm 0.04$

$$
\begin{aligned}
& f_{\beta} \operatorname{LIDAR}(85 \%)=1.78 \pm 0.30 \\
& f_{\beta} \operatorname{SONDA}(85 \%)=1.83 \pm 0.09
\end{aligned}
$$

Figura 6.35 - a) Umidograma não parametrizado mostrando o ajuste dos dados à curva teórica, e os valores ajustados de $\gamma$ para o LIDAR e para a radiossonda. b) Ajuste após parametrização, onde $f_{\beta}(40 \%)$ é igual a 1, e os valores de $\gamma$ parametrizado $\left(\gamma_{p}\right)$ ajustados para o LIDAR e para a radiossonda

Para os dados obtidos com o HURL, os dados são muito semelhantes para os dois dias. As altitudes de referência se encontram em regiões onde ainda não há overlap total, porém os dados do HURL são corrigidos para efeitos de overlap, de maneira que os valores de retroespalhamento podem ser utilizados para altitudes acima de $500 \mathrm{~m}$. A origem dos aerossóis também é muito semelhante.

\begin{tabular}{|c|c|c|c|c|c|c|c|c|c|}
\hline Dia & $\begin{array}{c}\gamma \\
\text { LIDAR }\end{array}$ & $\begin{array}{c}\gamma \\
\text { radiossond } \\
\text { a }\end{array}$ & $\begin{array}{c}\text { Alt } \\
\text { inicial }\end{array}$ & $\begin{array}{c}\text { Alt } \\
\text { final }\end{array}$ & $\begin{array}{c}\text { UR } \\
\text { inicia } \\
\text { I (\%) }\end{array}$ & $\begin{array}{c}\text { UR } \\
\text { fina } \\
1 \\
(\%)\end{array}$ & $\begin{array}{c}\boldsymbol{f}_{\boldsymbol{\beta}}(\mathbf{8 5} \%) \\
\text { LIDAR }\end{array}$ & $\begin{array}{c}f_{\beta}(85 \%) \\
\text { radiossond } \\
a\end{array}$ & Origem \\
\hline $\begin{array}{c}05 / 07 / 201 \\
1\end{array}$ & $\begin{array}{l}0.36 \pm 0.1 \\
4\end{array}$ & 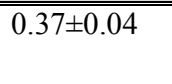 & $\begin{array}{c}843.7 \\
5\end{array}$ & $\begin{array}{c}1503.7 \\
5\end{array}$ & 67 & 85 & $\begin{array}{l}1.64 \pm 0.2 \\
8\end{array}$ & $\overline{c 1.67 \pm 0.09}$ & $\begin{array}{c}\text { Continenta } \\
1\end{array}$ \\
\hline $\begin{array}{c}21 / 07 / 201 \\
1\end{array}$ & $\begin{array}{l}0.43 \pm 0.1 \\
2\end{array}$ & $0.47 \pm 0.04$ & 656.2 & $\begin{array}{c}1518.7 \\
5\end{array}$ & 61 & 87 & $\begin{array}{l}1.78 \pm 0.3 \\
0\end{array}$ & $1.83 \pm 0.09$ & $\begin{array}{c}\text { Continenta } \\
1\end{array}$ \\
\hline
\end{tabular}

Tabela 05 - Sumário de resultados para os dias de medida do HURL 
Os dados em Washington DC foram tomados durante o período de verão, tipicamente encontrando altos valores de umidade relativa. Isso reduz os erros nas medidas de vapor de água pelo LIDAR, mesmo no período diurno.

\section{3 - Discussões gerais e comparação com outros trabalhos encontrados na literatura}

De acordo com a tabela é possível ver que comparar os trabalhos é bastante difícil, na medida que existem muitos deles usando nefelometria, utilizando o comprimento de onda de 532nm, e os poucos trabalhos existentes com o LIDAR usam parâmetros ópticos ou comprimentos de onda diferentes. Para os dados em São Paulo não existem comparativos, mas para os dados de DC, Ziemba (2013) utilizou o nefelômetro a bordo do avião e os resultados obtidos estão de acordo com os obtidos pelo HURL.

Como dados da composição química dos aerossóis estão presentes em poucos trabalhos, a identificação da origem das massas de ar por meio do HYSPLIT, apesar de ser indicativo de uma possível composição química, não é capaz de fornecer informações a respeito do grau de mistura e de processos de transformações atmosféricas do material particulado.

Tabela 6 - Sumário de resultados encontrados neste trabalho e comparação com outros trabalhos encontrados na literatura

\begin{tabular}{|c|c|c|c|c|c|c|c|}
\hline Autor e ano & Local & $\begin{array}{c}\text { Natureza do } \\
\text { Aerossol }\end{array}$ & Instrumento & $\begin{array}{c}\lambda \\
(\mathrm{nm})\end{array}$ & $\begin{array}{l}\text { Parâm } \\
\text { óptico }\end{array}$ & $f(85 \%)$ & $\gamma$ \\
\hline Zieger (2013) & $\begin{array}{c}\text { Jungfraujoch } \\
\text { (Suiça) }\end{array}$ & $\begin{array}{c}\text { Marítimo } \\
\text { poluído }\end{array}$ & Nefelômetro & $\mathbf{5 5 0}$ & $\sigma$ & $1.95 \pm 0.14$ & - \\
\hline Gasso (2000) & $\begin{array}{c}\text { Sagres } \\
\text { (Portugal) }\end{array}$ & $\begin{array}{c}\text { Marítimo } \\
\text { poluído }\end{array}$ & Nefelômetro & $\mathbf{5 5 0}$ & $\sigma$ & 1.4 & 0.27 \\
\hline Zieger (2013) & $\begin{array}{c}\text { Jungfraujoch } \\
\text { (Suiça) }\end{array}$ & $\begin{array}{c}\text { Marítimo } \\
\text { pouco poluído }\end{array}$ & Nefelômetro & $\mathbf{5 5 0}$ & $\sigma$ & $2.97 \pm 0.20$ & - \\
\hline Zieger (2013) & $\begin{array}{c}\text { Jungfraujoch } \\
\text { (Suiça) }\end{array}$ & $\begin{array}{l}\text { Marítimo } \\
\text { limpo }\end{array}$ & Nefelômetro & $\mathbf{5 5 0}$ & $\boldsymbol{\sigma}$ & $3.38 \pm 0.31$ & - \\
\hline Gasso (2000) & $\begin{array}{c}\text { Sagres } \\
\text { (Portugal) }\end{array}$ & $\begin{array}{l}\text { Marítimo } \\
\text { limpo }\end{array}$ & Nefelômetro & 550 & $\sigma$ & 1.8 & 0.60 \\
\hline $\begin{array}{c}\text { Granados- } \\
\text { Munhoz (2014) }\end{array}$ & $\begin{array}{l}\text { Granada } \\
\text { (Espanha) }\end{array}$ & $\begin{array}{c}\text { Continental } \\
\text { Poluido }\end{array}$ & LIDAR & 532 & $\beta$ & 2.1 & $0.56 \pm 0.01$ \\
\hline
\end{tabular}


Tabela 6 - Sumário de resultados encontrados neste trabalho e comparação com outros trabalhos encontrados na literatura (continuação)

\begin{tabular}{|c|c|c|c|c|c|c|c|}
\hline $\begin{array}{c}\text { Granados- } \\
\text { Munhoz (2014) }\end{array}$ & $\begin{array}{l}\text { Granada } \\
\text { (Espanha) }\end{array}$ & $\begin{array}{l}\text { Continental } \\
\text { Poluido }\end{array}$ & LIDAR & 532 & $\boldsymbol{\beta}$ & 3.5 & $1.07 \pm 0.01$ \\
\hline $\begin{array}{c}\text { Este trabalho } \\
12 \text { Set } 2013\end{array}$ & São Paulo & $\begin{array}{l}\text { Urbano } \\
\text { poluido }\end{array}$ & LIDAR & 355 & $\boldsymbol{\beta}$ & $1.95 \pm 0.30$ & $0.48 \pm 0.12$ \\
\hline $\begin{array}{l}\text { Este trabalho } \\
30 \text { Jan } 2014\end{array}$ & São Paulo & $\begin{array}{l}\text { Urbano } \\
\text { Poluido }\end{array}$ & LIDAR & 355 & $\boldsymbol{\beta}$ & $2.58 \pm 0.14$ & $0.78 \pm 0.16$ \\
\hline $\begin{array}{l}\text { Randriamiarisoa } \\
\qquad(2006)\end{array}$ & Paris & $\begin{array}{l}\text { Urbano } \\
\text { poluído }\end{array}$ & Nefelômetro & 550 & $\sigma$ & $1.2-4.5$ & $0.47-1.35$ \\
\hline $\begin{array}{l}\text { Este trabalho } \\
\text { 03 Mai } 2013\end{array}$ & São Paulo & $\begin{array}{l}\text { Urbano } \\
\text { Poluido }\end{array}$ & LIDAR & 355 & $\boldsymbol{\beta}$ & $1.16 \pm 0.04$ & $0.11 \pm 0.03$ \\
\hline $\begin{array}{l}\text { Veselovski } \\
\text { (2009) }\end{array}$ & D.C. & $\begin{array}{l}\text { Marinho com } \\
\text { influências } \\
\text { antropogênicas }\end{array}$ & LIDAR & 355 & $\alpha$ & 2.1 & 0.9 \\
\hline $\begin{array}{l}\text { Este trabalho } \\
05 \text { de Jul } 2011\end{array}$ & DC & Continental & LIDAR & 355 & $\boldsymbol{\beta}$ & $1.64 \pm 0.28$ & $0.36 \pm 0.14$ \\
\hline $\begin{array}{c}\text { Ziemba (2013) } \\
\text { 05 Jul } 2011\end{array}$ & D.C & Continental & Nefelômetro & 550 & $\sigma$ & $1.45 \pm 0.07$ & - \\
\hline $\begin{array}{l}\text { Este trabalho } \\
21 \text { Jul } 2011\end{array}$ & DC & Continental & LIDAR & 355 & $\boldsymbol{\beta}$ & $1.78 \pm 0.30$ & $0.43 \pm 0.12$ \\
\hline $\begin{array}{c}\text { Ziemba (2013) } \\
21 \text { Jul } 2011\end{array}$ & D.C & Continental & Nefelômetro & 550 & $\sigma$ & $1.70 \pm 0.06$ & - \\
\hline Zieger (2013) & $\begin{array}{c}\text { Jungfraujoch } \\
\text { (Suiça) }\end{array}$ & $\begin{array}{l}\text { Poeira do } \\
\text { Saara }\end{array}$ & Nefelômetro & 550 & $\boldsymbol{\sigma}$ & $1.28 \pm 0.10$ & - \\
\hline
\end{tabular}




\section{7 - Conclusões}

O estudo da higroscopicidade com o LIDAR se mostrou uma ferramenta poderosa no entendimento desta propriedade dos aerossóis, apesar das condições necessárias a este estudo estarem raramente presentes na atmosfera. Assim, em três anos de medida foram encontrados apenas três casos em São Paulo e dois casos em Washington D.C, dentre oitenta possíveis casos.

Em São Paulo, no primeiro caso estudado, 03 de maio de 2013, a região de referência para estudo da higroscopicidade estava entre $862.5 \mathrm{~m}$ e $1627.5 \mathrm{~m}$, região onde houve um aumento de 1.15 vezes no valor do retroespalhamento obtido com o LIDAR. A constante de calibração para este dia foi de $1.68 \pm 0.05$, e a razão de mistura de vapor de água em torno de $10 \mathrm{~g} / \mathrm{kg}$ dentro da camada limite. A atmosfera estava estável dentro dos critérios estabelecidos e as massas de ar que adentraram a região metropolitana de São Paulo mostraram ter mesma origem. Um aumento da umidade relativa entre $58 \%$ e $84 \%$ foi verificada nas altitudes de interesse e o fator de crescimento por higroscopicidade em $85 \%$ obtido com o LIDAR foi 1.16 \pm 0.04 . O valor de $\gamma$ obtido com o LIDAR foi de $0.11 \pm 0.03$ e o obtido com a sonda foi de $0.13 \pm 0.01$, após a parametrização, evidenciando o baixo crescimento higroscópico para este dia.

No segundo caso, 12 de setembro de 2013, a região de referência para estudo da higroscopicidade estava entre $1721.25 \mathrm{~m}$ e $2036.25 \mathrm{~m}$, região onde houve um aumento de 1.22 vezes no valor do retroespalhamento obtido com o LIDAR. A constante de calibração para este dia foi de $1.93 \pm 0.03$, e a razão de mistura de vapor de água em torno de $5 \mathrm{~g} / \mathrm{kg}$ dentro da camada limite, já que o mês de setembro é caracteristicamente seco na região metropolitana de São Paulo. A atmosfera estava estável dentro dos critérios estabelecidos e as massas de ar que adentraram a região mostraram ter mesma origem. Um aumento da umidade relativa entre $59 \%$ e $69 \%$ foi verificada nas altitudes de interesse e o fator de crescimento por higroscopicidade em $85 \%$ obtido com o LIDAR foi $1.95 \pm 0.30$. O valor de $\gamma$ obtido com o LIDAR foi de $0.48 \pm 0.12$ e o obtido com a sonda foi de $0.76 \pm 0.05$, após a parametrização, diferenças estas que podem ser explicadas tanto pela distância do LIDAR em relação à sonda quanto ao maior erro associado às medidas de v apor de água de ambos os instrumentos em condições muito secas. 
No terceiro caso, 30 de janeiro de 2014, a região de referência para estudo da higroscopicidade estava entre $828.75 \mathrm{~m}$ e $1743.75 \mathrm{~m}$, região onde houve um aumento de 1.45 vezes no valor do retroespalhamento obtido com o LIDAR. A constante de calibração para este dia foi de $2.00 \pm 0.05$, e a razão de mistura de vapor de água em torno de $9 \mathrm{~g} / \mathrm{kg}$ dentro da camada limite. A atmosfera estava estável dentro dos critérios estabelecidos e as massas de ar que adentraram a região metropolitana de São Paulo mostraram ter mesma origem. Um aumento da umidade relativa entre $46 \%$ e $68 \%$ foi verificada nas altitudes de interesse e o fator de crescimento por higroscopicidade em $85 \%$ obtido com o LIDAR foi $2.96 \pm 0.58$. O valor de $\gamma$ obtido com o LIDAR foi de $0.78 \pm 0.16$ e o obtido com a sonda foi de $0.68 \pm 0.04$, após a parametrização, mostrando que este dia foi o de maior crescimento verificável.

Para os resultados obtidos em São Paulo não existem comparação disponível, já que é a primeira vez que um estudo versando sobre higroscopicidade é feito na cidade.

Para os resultados obtidos em Washington D.C, no dia 05 de Julho de 2011, a região de referência para estudo da higroscopicidade estava entre $843.75 \mathrm{~m}$ e $1503.75 \mathrm{~m}$, região onde houve um aumento de 1.26 vezes no valor do retroespalhamento obtido com o LIDAR. A razão de mistura de vapor de água ficou em torno de $11 \mathrm{~g} / \mathrm{kg}$ dentro da camada limite. A atmosfera estava estável dentro dos critérios estabelecidos e as massas de ar que adentraram a região metropolitana de D.C mostraram ter mesma origem. Um aumento da umidade relativa entre $67 \%$ e $85 \%$ foi verificada nas altitudes de interesse e o fator de crescimento por higroscopicidade em $85 \%$ obtido com o LIDAR foi $1.64 \pm 0.28$. O valor de $\gamma$ obtido com o LIDAR foi de $0.36 \pm 0.14$ e o obtido com a sonda foi de $0.37 \pm 0.04$, após a parametrização.

Para o dia 21 de Julho de 2011, a região de referência para estudo da higroscopicidade estava entre $656.25 \mathrm{~m}$ e $1518.75 \mathrm{~m}$, região onde houve um aumento de 2.33 vezes no valor do retroespalhamento obtido com o LIDAR. A razão de mistura de vapor de água ficou em torno de $17 \mathrm{~g} / \mathrm{kg}$ dentro da camada limite. A atmosfera estava estável dentro dos critérios estabelecidos e as massas de ar que adentraram a região metropolitana de D.C mostraram ter mesma origem. Um aumento da umidade relativa entre $61 \%$ e $87 \%$ foi verificada nas altitudes de interesse e o fator de crescimento por higroscopicidade em $85 \%$ obtido com o LIDAR foi $1.78 \pm 0.30$. O valor de $\gamma$ obtido com o LIDAR foi de $0.43 \pm 0.12$ e o obtido com a sonda foi de $0.47 \pm 0.04$, após a parametrização. 
Para os dados obtidos em D.C existem dados estudados com o uso de nefelômetro a bordo de avião no trabalho de Ziemba, 2013. Estes estudos mostram uma boa concordância com os resultados encontrados neste trabalho.

Quanto ao uso do LIDAR como ferramenta de avaliação da higroscopicidade de aerossóis, verificou-se algumas características que um sistema LIDAR deve possuir para que seja possível realizar este estudo. Em primeiro lugar, um sistema Raman apresenta vantagens sobre um sistema elástico pela possibilidade de determinar os coeficientes de retroespalhamento e extinção sem nenhuma hipótese a priori e de maneira independente, sem a necessidade de um instrumento como o fotômetro solar. Além disso, diferentemente do LIDAR elástico, o LIDAR Raman pode realizar medidas de vapor de água. Ainda assim, a calibração, o perfil de temperatura e de pressão são obtidos por instrumento externo ou derivados por considerações termodinâmicas em condições muito específicas, mostrando que o uso de radiossondagem é bastante importante. Assim, quando as radiossondas se encontram localizadas no mesmo lugar onde está o LIDAR, espera-se que os resultados sejam melhores.

A limitação da radiossondagem é sua resolução temporal. Um instrumento que permitisse monitoramento contínuo de temperatura, como o radiômetro de micro-ondas poderia ser bastante útil no estudo da higroscopicidade com o LIDAR.

Devido ao uso necessário do canal de aerossóis e dos canais Raman do LIDAR para este estudo, é necessário que o LIDAR esteja corretamente alinhado e que sejam aplicadas correções de overlap. Por exemplo, para os dados de D.C, 19 radiossondagem apontavam condições para o estudo, mas os dados do LIDAR estavam fora de alinhamento principalmente no canal elástico, pois o HURL é projetado para estudo de vapor de água.

Quanto as condições para estudar higroscopicidade, elas estão mais presentes durante o dia devido a mistura da camada limite, porém existe uma limitação técnica do LIDAR Raman que é a dificuldade de realização de medidas diurnas. O sistema MSP-LIDAR I precisaria passar por modificações para que fosse capaz de realizar medidas durante o dia, como o HURL. É por isso que durante o inverno é mais possível encontrar as condições em São Paulo, pois a camada limite é menos desenvolvida, porém a umidade também é mais baixa, tornado mais difícil encontrar casos nos quais a umidade relativa suba o suficiente para estudar os efeitos higroscópicos mais pronunciados. Lembrando que a vantagem do 
LIDAR em relação às câmaras é exatamente poder estudar os efeitos higroscópicos acima de $85 \%$ UR, é bem interessante que se garanta a existência dessa condição para que o LIDAR se torne um instrumento interessante no estudo da higroscopicidade.

\section{1 - Futuros trabalhos}

Uma informação de interesse para o estudo da higroscopicidade é poder avaliar distribuição de tamanho do aerossol estudado, o que seria possível com dados de fotômetro solar, uso de modelos ou com a adição do canal de detecção em 1064nm no sistema LIDAR. Também seria de interesse fazer uma correlação entre os valores aqui encontrados e as propriedades químicas dos aerossóis.

Outros desdobramentos incluem estudos relacionados à forçante radiativa dos aerossóis higroscópicos, bem como a avaliação de outros instrumentos colocados de monitoramento contínuo, como o radiômetro de micro-ondas. 
1. ANSMANN, A. Independent measurements of extinction backscatter profiles in cirrus clouds by using a combined Raman elastic-backscatter LIDAR. Applied Optics, v. 31, n.33, p. 7113-7131, 1992.

2. ANSMANN, A.; RIEBESELL, M.; WEITKAMP, C. Measurements of Atmospheric aerosol extinction profiles with a Raman LIDAR. Applied Optics, v.15, n. 13, p. 746-748, 1990.

3. ARGALL, P. S.; SIGA, R. J. The Encyclopedia of Optics - Basic Foundations and Practical Applications. 1st. ed. Germain: Wiley-VHC, 2004

4. BATES, D.R. Rayleigh scaattering by air. Planetary Space Science, v. 32, p. 785-790, 1984.

5. BODHAINE, B.A. On Rayleigh Optical Deph Calculations. Journal of Atmospheric and Oceanic Technology. v.16, p. 1854-1861, 1999.

6. CARRICO, C.M. Water uptake and chemical composition of fresh aerosols generated in open burning of biomass. Atmosferic Chemistry and Physics, p. 3627-3658, 2010.

7. CHARLSON, R.J. Climate Forcing by Anthropogenic Aerosols. Science, 24 de Janeiro, p. 423-430, 1992.

8. DRAXLER, R. R; ROLPH, G. D. HYSPLIT (HYbrid Single-Particle Lagrangian Integrated Trajectory). Disponível em: <http://www. arl. noaa. gov/ready/hysplit4. html >. NOAA Air Resources Laboratory, Silver Spring, Md. (2003). Acesso em 10 de novembro de 2014

9. DUBOVIK, O.; HOLBEN,B.; AND ECK, T.F. Variability of absorption and optical properties of key aerosol types observed in worldwide locations. Journal of Atmosferic Science. v. 59, p. 590-608, 2002.

10. EICHINGER, W.E.; KOVALEV, V.A. Elastic LIDAR: Theory, Practice and Analysis Methods. Nova Jersey: Whiley Publishers, 2004.

11. FEINGOLD, G; GRUND, C. Feasibility of using multiwavelength LIDAR Measurements to Measure Cloud Condensation Nuclei. Journal of Atmospheric and Oceanic Technology. v.2, p. 1543-1558, 1994.

12. FEINGOLD, G.; MORLEY, B. Aerosol hygroscopic properties as measured by LIDAR and comparison with in situ measurements. Journal of Geophysical Research. v.108, p. 1-11, 2003.

13. FERRARE, R.A. et al. A comparison of water vapor measurements made by Raman LIDAR and radiosondes. Journal of Atmospheric and Oceanic Technology. v.12, p. 1177-1195, 1995.

14. GASSO, S. et al. Influence of humidity on the aerosol scattering coefficient and its effect on the upwelling radiance during ACE-2. Tellus B. v. 52(2), 546-567, 2000.

15. GRANADOS-MUNOZZ, M.J. Characterizing the atmospheric aerosol by active and passive remote sensing: microphysical properties and hygroscopic growth effects. Tese (Doutorado), Granada, Espanha. Universidad de Granada, 2014. 
16. GUERRERO-RASCADO, J.L. et al. Towards an instrumental harmonization in the framework of LALINET: dataset of technical specifications. In: Proceedings of SPIE. Amsterdã: SPIE Digital Library, 2014. v. 9246

17. HÄNEL, G. The properties of atmospheric aerosol particles as functions of relative humidity at thermodynamic equilibrium with surrounding moist air. Geophysics. v.19, p. 73-188, 1976.

18. HAYWOOD, J.; BOUCHER, O. Estimates of direct and indirect radiative forcing due to tropospheric aerosols: a review. Reviews of Geophysics. v.38. p.513-543, 2000.

19. HOLBEN, B.N. AERONET: a federal instrument network anda data archive for aerosol characterization. Remote Sensing of Environment. v.66, p.1-16, 1998.

20. HOUGHTON, J.T. ET AL. Climate Change 2001: The Scientific Basis, Contribution of Working Group I to the Third Assessment Report of the Intergovernmental Panel on Climate Change. United Kingdom:Cambridge University Press, 2001.

21. IM, J.S.; SAXENA, V.K. An assessment of hygroscopic growth factors for aerosols in the surface boundary layers for computing direct radiative forcing. Journal of Geophysical Research. v. 106, p. 20213-20224, 2001.

22. INABA, H.; KOBAYASHI, T. Laser Raman radar. Opto-eletronics. v.4, p. 101-123, 1972.

23. JUNGE, C.E. Air Chemistry and Radioactivity. New York: Academic Press, 1963.

24. KLETT, J.D. Stable analytical inversion solution for processing LIDAR returns. Applied Optics. v.20, p. 211-220, 1981.

25. KLETT, J.D. LIDAR calibration and extinction coeficients. Applied Optics. v.22, p. 514, 1983.

26. KLETT, J.D. Extinction boundary value algorithms for LIDAR inversion. Applied Optics. v.25, p.2462, 1986.

27. KOCH, D; DEL GENIO, A.D. Black carbon semi-direct effects on cloud cover: review and synthesis. Atmos. Chem. Phys, v.10 p. 7685-7696, 2010

28. KOTCHENRUTHER, R.A.; HOBBS, P.V. Humidification factors of aerosols from biomass burning in Brazil. Journal of Geophysical Research: Atmospheres. v. 103, 32081-32089, 1998

29. KOTCHENRUTHER, R.A.; HOBBS, P.V.; HEGG, D. A. Humidification factors for atmospheric aerosols off the mid-Atlantic coast of the United States. Journal of Geophysical Research: Atmospheres. v. 104, 2239-2251. 1999.

30. KREIDENWEIS, S.M. et al. Aerosol hygroscopicity: Particle Water Content and its role in atmospheric processes. In: Holland, H.D. (ed). Treatise on Geochemistry. 2 ed. Oxford: Elsevier, 2014. cap.5.13, p.331-361.

31. LANDULFO, E. et al. Synergic measurements of aerosols over São Paulo, Brazil, using LIDAR, sunphotometer an satelite data during dry season. Atmospheric Chemistry and Physics. v.3, p. 1523-1539, 2003. 
32. LEBLANC, T.; MCDERMID, I. S.; ASPEY, R. A. First-year operation of a new water vapor Raman LIDAR at the JPL Table Mountain Facility, California, J. Atmos. Ocean. Tech., v. 25, p. 1454-1462, 2008.

33. LIOU, K.N. An Introduction to Atmosferica Radiation. 2 ed. California: Academica Press, 2002.

34. LIST, R.J. Smithsonian Meteorological Tables. Washington, D.C.: Smithsonian Institution, 1951.

35. LOPES, F.J. Validação dos dados do satélite CALIPSO usando um sistema LIDAR de retroespalhamento elástico e o fotômetro solar da rede AERONET. Tese (Doutorado), São Paulo, Brasil: Instituto de Pesquisas Energéticas e Nucleares, 2011.

36. MACKINNON, D.J. The Effect of Hygroscopic Particles on the Backscattered Power from a Laser Beam. Journal of The Atmospheric Sciences. v.26, p. 500-510, 1969.

37. MATTIS, I.; ANSMANN, A. Relative-humidity profiling in the troposphere with a Raman LIDAR. Applied Optics. v. 41, n.30, p. 6451-6462, 2002.

38. MEASURES, R.M. Laser Remote Sensing Fundamentals and Applications. 1 ed. Florida: Krieger Publishing Company, 1984.

39. MENON, S. et al. Currente Uncertanties Assessing Aerosol Effects on Climate. Annu. Rev. Environmental Researches. p. 1-30, 2004.

40. MOSS, A. ET AL. Calibration and Validation of water vapour LIDAR measurements from Eureka, Nunavut, using radiosondes and the Atmospheric Chemistry Experiment fourier transform spectrometer. Atmos. Meas. Tech. Discuss, v.5, p. 5665-5689, 2012.

41. MÜLLER ET AL. Aerosol-type-dependent LIDAR ratios observed with Raman LIDAR. Journal of Geophysical Research, v.112, p. 1-11. 2007

42. NAVAS-GUZMÁN, F. et al. Tropospheric water vapour and relative humidity profiles from lidar and microwave radiometry. Atmos. Meas. Tech., v.7, p.1201-1211, 2014.

43. RANDRIAMIARISOA, $\mathrm{H}$. et al., Relative humidity impact on aerosol parameters in a Paris suburban area. Atmospheric Chemistry and Physics, v. 6(5), p. 1389-1407, 2006.

44. RISSLER, J. Hygroscopic Properties of biomass burning and combustion aerossols. Thesis (Licenciate), Lund, 2003.

45. ROGERS, R.R.; YAU, M.K. A short course in Cloud Physics. New York: Pergamon, 1988.

46. SANTARPIA, J.L.; LI, R,; COLLINS, D.R. Direct measurement of the hydration state of ambient aerosol populations. Journal of Geophysical Research. v.109, p. 1-16, 2004.

47. SEINFELD, J.H.; PANDIS, S.N. Atmospheric Chemistry and Physics: from Air Pollution to Climate Change. New Jersey: Wiley-Interscience, 2006.

48. SOLOMON, S.; QIN, D; MANNING, M; Contribution of Working Group I to the Fourth Assessment Report of the Intergovernmental Panel on Climate Change. United Kingdom:Cambridge University Press, 2007. 
49. STOKER, T. Climate Change 2013: The Scientific Basis, Contribution of Working Group I to the Third Assessment Report of the Intergovernmental Panel on Climate Change. United Kingdom:Cambridge University Press, 2013.

50. SVENINGSON, B., RISSLER, J.; SWUIETLICKI, E. Hygroscopic growth and critical supersaturations for mixed aerosol particles of inorganic and organic compounds of atmospheric relevance. Atmospheric Cheminstry and Physics. v.6, p. 1937-1952, 2006.

51. TARDIF, R. Boundary layer aerosol backscattering and its relatioship to relative humidity from a combined raman-elastic backscattering LIDAR. Boulder: University of Colorado, 2002.

52. TORRES, A.S. Desenvolvimento de uma metodologia de calibração independente para um LIDAR Raman na obtenção e estudo de perfis de vapor de água atmosféricos. Tese (Doutorado), São Paulo: Instituto de Pesquisas Energéticas e Nucleares, 2008.

53. Van Dorland et al. Radiative Forcing due to tropospheric ozone and sulfate aerosols. Journal of Geophysical Research. v.102, p.148-227, 1997

54. VAUGHAN, G.; WAREING, D.; THOMAS, L.; MITEV, V. Humidity measurements in the free troposphere using Raman backscatter, Q. J. Roy. Meteorol. Soc., v. 114, p. 1471-1484, 1988.

55. VENABLE, D. Lamp Mapping technique for independent determination of the water vapor mixing ratio calibration factor for a Raman LIDAR system. Applied Optics. v. 50, p. $4622-$ 4632, 2011.

56. VESELOVSKI, I; WHITEMAN, D.N. Demonstration of Aerosol Property Profile by Multiwavelength LIDAR under Varying Relative Humidity Conditions. Journal of Atmosferic and Oceanic Technology. v. 6, p. 1543-1557, 2009.

57. WAllaCe, J.M.; HOBBS, P.V. Atmspheric Science - An introductory Survey. 2 ed. California: Academic Press, 2006.

58. WEITKAMP, C. Lidar Range-Resolved Optical Remote Sensing of the Atmosphere. Springer, 2005.

59. WHITEMAN, D.N; MELFI, S.H.; FERRARE, R.A. Raman LIDAR sytem for the measurement of water vapor and aerosol in the earth atmosphere. Applied Optics, v.31, n.16. p. 3068-3082, 1992.

60. WHITEMAN, D.N. et al. Examination of the tradicional Raman LIDAR Technic II. Evaluating the ratios for water vapor and aerosols. Applied Optics. v.42, n. 15, p. 25932608, 2003.

61. WHITEMAN, D.N. et al. Raman LIDAR Measurements during the International $\mathrm{H}_{2} 0$ Project. Part I: Instrumentation and Analysis Techniques. Journal of Atmospheric and Oceanic Technology. v.23, p. 157-169, 2006.

62. WHITEMAN, D.N. LIDAR - a computacional approach Lectures. Washington, D.C.: Howard University, 2006.

63. ZIEGER, P. et al. Effects of relative humidity on aerosol light scattering: results from different European sites. Atmospheric Chemistry and Physics Discussions, v. 13(4), p. 8939-8984, 2013. 
64. ZIEMBA, LUKE D. Airborne observations of aerosol extinction by in situ and remotesensing techniques: Evaluation of particle hygroscopicity. Geophysical Research Letters. V.40, p. 417-422, 2013. 